ALBERTO MESSIAS DA COSTA SOUZA

UMA NOVA ARQUITETURA PARA INTERNET DAS COISAS COM ANÁLISE E RECONHECIMENTO DE PADRÕES E PROCESSAMENTO COM BIG DATA 
ALBERTO MESSIAS DA COSTA SOUZA

\title{
UMA NOVA ARQUITETURA PARA INTERNET DAS COISAS COM ANÁLISE E RECONHECIMENTO DE PADRÕES E PROCESSAMENTO COM BIG DATA
}

\author{
Tese de Doutorado \\ Orientador: Prof. Dr. José Roberto de Almeida Amazonas
}

\section{UNIVERSIDADE DE SÃO PAULO \\ ESCOLA POLITÉCNICA}

São Paulo 
ALBERTO MESSIAS DA COSTA SOUZA

\title{
UMA NOVA ARQUITETURA PARA INTERNET DAS COISAS COM ANÁLISE E RECONHECIMENTO DE PADRÕES E PROCESSAMENTO COM BIG DATA
}

\author{
Tese apresentada à Escola \\ Politécnica da Universidade de São \\ Paulo para obtenção do título de \\ Doutor em Ciências.
}

Área de concentração:

Sistemas Eletrônicos

Orientador:

Prof. Dr. José Roberto de Almeida Amazonas

São Paulo 


\section{Catalogação-na-publicação}

Souza, Alberto

Uma nova arquitetura para Internet das Coisas com análise e reconhecimento de padrões e processamento com Big Data / Souza, A. M. C. -- São Paulo, 2015.

$118 \mathrm{p}$.

Tese (Doutorado) - Escola Politécnica da Universidade de São Paulo. Departamento de Engenharia de Sistemas Eletrônicos.

1. Internet das Coisas 2. Redes de Comunicação 3.

Reconhecimento de Padrões 4. Modelo de Referência 5. Big

Data I. Universidade de São Paulo. Escola Politécnica.

Departamento de Engenharia de Sistemas Eletrônicos II. t. 
Dedico ao Arthur, à Alice, à Evelyn, à minha mãe Salete e ao meu pai Geraldo. 


\section{AGRADECIMENTOS}

Agradeço primeiramente a Deus pela força de vontade, oportunidade e motivação nesta longa caminhada. Gostaria de agradecer em especial aos meus filhos, Arthur e Alice e à esposa Evelyn, aos meus pais Salete e Geraldo, meu irmão Sandro e sua família Marcia, Vitória e Davi, que por vezes, ao me ausentar e souberam me compreender e respeitar.

Agradeço ao professor Dr. Clovis Torres Fernandes por acreditar em mim, ao professor Dr. Ivan Carlos Alcântara de Oliveira que me auxiliou no início desta pesquisa e, sobretudo, ao meu orientador professor Dr. José Roberto de Almeida Amazonas, que foi fundamental nesta pesquisa, que soube me conduzir e cobrar.

Agradeço ainda, aos amigos que me motivaram e me acompanharam neste período. 
Não podem haver barreiras para o empenho humano. Não importa o quão ruim a vida pareça estar, sempre existe algo que você pode fazer e triunfar, onde há vida, há esperança. 


\section{RESUMO}

A Internet das Coisas é um novo paradigma de comunicação que estende o mundo virtual (Internet) para o mundo real com a interface e interação entre objetos. Ela possuirá um grande número de dispositivos heteregôneos interconectados, que deverá gerar um grande volume de dados. Um dos importantes desafios para seu desenvolvimento é se guardar e processar esse grande volume de dados em aceitáveis intervalos de tempo. Esta pesquisa endereça esse desafio, com a introdução de serviços de análise e reconhecimento de padrões nas camadas inferiores do modelo de para Internet das Coisas, que procura reduzir o processamento nas camadas superiores. Na pesquisa foram analisados os modelos de referência para Internet das Coisas e plataformas para desenvolvimento de aplicações nesse contexto. A nova arquitetura de implementada estende o LinkSmart Middeware pela introdução de um módulo para reconhecimento de padrões, implementa algoritmos para estimação de valores, detecção de outliers e descoberta de grupos nos dados brutos, oriundos de origens de dados. O novo módulo foi integrado à plataforma para Big Data Hadoop e usa as implementações algorítmicas do framework Mahout. Este trabalho destaca a importância da comunicação cross layer integrada à essa nova arquitetura. Nos experimentos desenvolvidos na pesquisa foram utilizadas bases de dados reais, provenientes do projeto Smart Santander, de modo a validar da nova arquitetura de IoT integrada aos serviços de análise e reconhecimento de padrões e a comunicação cross-layer.

Palavras-chave: Internet das Coisas. Redes de Comunicação. Reconhecimento de Padrões. Modelo de Referência. Big Data. 


\begin{abstract}
The Internet of Things is a new communication paradigm in which the Internet is extended from the virtual world to interface and interact with objects of the physical world. The IoT has high number of heterogeneous interconnected devices, that generate huge volume data. The most important IoT challenges is store and proccess this large volume data. This research addresses this issue by introducing pattern recognition services into the lower layers of the Internet of Things reference model stack and reduces the processing at the higher layers. The research analyzes the Internet of Things reference model and Middleware platforms to develop applications in this context. The new architecture implementation extends the LinkSmart by introducing a pattern recognition manager that includes algorithms to estimate parameters, detect outliers, and to perform clustering of raw data from IoT resources. The new module is integrated with the Big Data Haddop platform and uses Mahout algorithms implementation. This work highlights the cross-layer communication intregated in the new IoT architecture. The experiments made in this research using the real database from Smart Santander Framework to validate the new IoT architecture with pattern recognition services and cross-layer communication.
\end{abstract}

Keywords: Internet of Things. Communications Network. Pattern Recognition. Reference Model. Big Data 


\section{LISTA DE ILUSTRAÇÕES}

Figura $1 \quad$ Mapa conceitual que destaca os conceitos pertinentes à pesquisa. . $\quad 20$

Figura 2 Interação entre as redes de comunicação, o mundo físico e o virtual. 26

Figura 3 Modelo Inclusivo para a IoT. . . . . . . . . . . . . . . 27

Figura $4 \quad$ Modelo de Referência para IoT proposto pelo ITU-T. . . . . . . . . 28

Figura $5 \quad$ Modelo de Ecossitema para IoT, proposto pelo ITU-T. . . . . . . . 32

Figura $6 \quad$ Alto nível de taxonomia, influências e dependências entre o modelo

\begin{tabular}{|c|c|}
\hline & de rofôn \\
\hline
\end{tabular}

Figura $7 \quad$ Interações entre os sub-modelos do modelo de referência para IoT. $\quad 34$

Figura 8 Interações entre o modelo funcional e requisitos uificados e a visão funcional. . . . . . . . . . . . . . . 35

Figura $9 \quad$ Grupos de funcionais do Modelo Funcional para IoT. . . . . . . . . 36

Figura $10 \quad$ Categorias que impactam no desenvolvimento para IoT. . . . . . . 38

Figura $11 \quad$ Estrutura em camadas do LinkSmart middleware. . . . . . . . . . . . 44

Figura $12 \quad$ Arquitetura ilustrativa para o desenvolvimento de serviços e aplicações baseadas no LinkSmart. . . . . . . . . . . . . . . . . . 45

Figura $13 \quad$ Fluxo de dados com a plataforma Ubidots (UBIDOTS, 2014). . . . 46

Figura $14 \quad$ Widget criado na plataforma Ubidots. . . . . . . . . . . . 47

Figura $15 \quad$ Pseudo-código do algoritmo k-means. . . . . . . . . . 52

Figura $16 \quad$ Modelo em camadas para a mineração de dados para a IoT. . . . . 55

Figura $17 \quad$ Aplicação de teste com a plataforma Ubidots. . . . . . . . . . . . . 61

Figura $18 \quad$ Aplicação de teste com o LinkSmart middleware. . . . . . . . . . . 62

Figura $19 \quad$ Proposta de nova estrutura em camadas do LinkSmart middleware com os mecanismos de análise e reconhecimento de padrões. 64

Figura 20 Representação gráfica do fluxo de dados e informações na arquitetura proposta. . . . . . . . . . . . . . . 65

Figura $21 \quad$ Diagrama de classes do Pattern Manager incluindo os pacotes, a Interface e a classe que a implementa. . . . . . . . . . . 68

Figura 22 Diagrama de Classes com a implementação do serviço de clustering no módulo Pattern Manager. . . . . . . . . . . . . . . . . . . . 69

Figura 23 Diagrama de classes do serviço de estimação de valores no módulo Pattern Manager. . . . . . . . . . . . . . . . . . . . 71

Figura 24 Diagrama de Classes do serviço de detecção de outlier implementado no módulo Pattern Manager. . . . . . . . . . . . . . . . . 
Figura 25 Detecção de Outlier: são observados três clusters e respectivamente seus raios e dois pontos considerados outlier. . . . . . . . 76

Figura $26 \quad$ Diagrama de classes com os parâmetros da comunicação cross layer no módulo de Pattern Manager. . . . . . . . . . . . . . 78

Figura $27 \quad$ Exemplo de aplicação do processamento de eventos complexos e criação de sensores virtuais em IoT. . . . . . . . . . . . . 79

Figura $28 \quad$ Aplicação disponível com realidade aumentada e as informações na cidade de Santander. . . . . . . . . . . . . . 83

Figura $29 \quad$ Página com o status do LinkSmart. . . . . . . . . . . . . . . 85

Figura $30 \quad$ Página de status gerada pelo Servlet do gerenciador de padrões. . . 85

Figura $31 \quad$ Aplicação que simula o Resource Manager que representa a camada física na validação da comunicação cross layer. . . . . . . . . . 86

Figura 32 Execução da aplicação cliente desenvolvida para o experimento da comunicação cross layer. . . . . . . . . . . . . . . . . . 87

Figura $33 \quad$ Trecho do arquivo de $L O G$ de execução dos serviços do ClassificationManager. . . . . . . . . . . . . 88

Figura $34 \quad$ Execução da classe Resource Manager para experimentação do serviço de clustering na camada de middleware. . . . . . . . . . . 89

Figura 35 A aplicação cliente para experimentação do serviço de clustering na camada de middleware. . . . . . . . . . . . . . . . . 90

Figura $36 \quad$ Todas as instâncias mostradas em um gráfico 3D e todos os clusters identificados por números e diferentes cores. . . . . . . . . 91

Figura $37 \quad$ Decaimento do SSE pela quantidade de clusters. . . . . . . . . 92

Figura $38 \quad$ Valores do Silhouette coefficient pela quantidade de clusters. . . . . 93

Figura 39 Execução da aplicação de teste do serviço de detecção de outlier desenvolvido. . . . . . . . . . . . . . . . 95

Figura $40 \quad$ Curva $R O C$ gereda a partir os resultados do classificador gerado com o modelo criado pelo algoritmo de detecção de outlier desenvolvido. . . . . . . . . . . . . . . . . . . . 96

Figura $41 \quad$ Execução da aplicação de teste do serviço de estimação de valores desenvolvido. . . . . . . . . . . . . . . . . 97

Figura $42 \quad$ Gráfico com as instâncias reais e seus respectivos valores estimados. 98 Figura $43 \quad$ Caso de uso do aplicativo para a criação de rotas com base nas prioridades definidas pelo usuário. . . . . . . . . . . . . . . . 99 

de Santander . . . . . . . . . . . . . . . . . . . . . . 102

Figura 45 Mapa das cidade de Santander exibindo pontos de temperatura e ocupação com o serviço de detecção de outlier desativado. . . . . 102

Figura $46 \quad$ Primeira rota mais exibida pelo aplicativo. . . . . . . . . . . 103

Figura $47 \quad$ Segunda rota mais exibida pelo aplicativo. . . . . . . . . . . . 104

Figura $48 \quad$ Terceira rota mais exibida pelo aplicativo. . . . . . . . . . . . . 104

Figura $49 \quad$ Quarta rota mais exibida pelo aplicativo. . . . . . . . . 105 


\section{LISTA DE TABELAS}

Tabela 1 Tabela com exemplos de valores de temperatura de entrada e metros cúbicos de água poluída. . . . . . . . . . . . . . . . 49

Tabela 2 Tabela comparativa entre o LinkSmart Middleware e a plataforma Ubidots. . . . . . . . . . . . . . . . . 60

Tabela 3 Tabela com a descrição dos dados de temperatura obtidos no projeto Smart Santander. . . . . . . . . . . . . . . . . . 83

Tabela 4 Tabela com a descrição dos dados de tráfego obtidos no projeto Smart Santander. . . . . . . . . . . . . . . . . . 84

Tabela 5 Tabela com o resumo das publicações. . . . . . . . . . . . . . 108 


\section{LISTA DE ABREVIATURAS E SIGLAS}

$2 \mathrm{G}$

$3 \mathrm{G}$

AAAA

API

ASPIRE

AUC

BAN

CAN

CEP

DCA

DSL

EPA

EPC

EPN

FCAPS

FG

FP6

GPS

GSN

HDFS

HTTPs

HYDRA

IoT-A

IPv6

IoT

ITU

LTE

MAE

$\mathrm{MB}$

MIT

MPP

NFC

OSGI
Segunda Geração

Terceira Geração

Authentication, Authorization, Accounting, and Auditing

Application Program Interface

Advanced Sensors and lightweight Programmable middleware for Innovative Rfid Enterprise applications Area Under Curve

Body Area Networks

Controler Area Network

Processamento de Eventos Complexos

Coleta e Análise de Dados

Digital Subscriber Line

Agente de Processamento de Evento

Código Eletrônico de Produto

Rede de Processamento de Eventos

Fault, Configuration, Accounting, Performance, Security

Grupos Funcionais

Sixth Research Framework Programme

Sistema de Posicionamento Global

Global Sensor Network

Hadoop Distributed File System

Protocolo de Transferência de Hypertexto Seguro

Heterogeneous Physical Devices in a Distribued Architecture

Internet of Things Architecture

Protocolo de Internet Versão 6

Internet das Coisas

International Telecommunication Union

Long-Term Evolution Networks

Mean Absolute Error

Mega Bytes

Massachusetts Institute of Technology

Massive Parallel Processing Databases

Near Field Communication

Open Services Gateway Initiative 


$\begin{array}{ll}\text { OSI } & \text { Open Systems Interconnection } \\ \text { PHID } & \text { Pattern Hardware Identification } \\ \text { PSTN } & \text { Public Switched Telephone Network } \\ \text { QR } & \text { Quick Response } \\ \text { RFID } & \text { Radio Frequency Identification } \\ \text { RFID } & \text { Identificação por Radiofrequência } \\ \text { RMSE } & \text { Root Mean Squared Error } \\ \text { ROC } & \text { Receiver Operation Characteristics } \\ \text { SDK } & \text { Software Development Kit } \\ \text { SIRENA } & \text { Service Infrastructure for Real-time Embedded Networked Devices } \\ \text { SMEPP } & \text { Secure Middleware For Embedded P2P } \\ \text { SMS } & \text { Short Message Service } \\ \text { SOA } & \text { Service-oriented Architecture } \\ \text { SSE } & \text { Sum of the Square Errors } \\ \text { TB } & \text { Tera Bytes } \\ \text { UBIWARE } & \text { Smart Semantic Middleware for Ubiquitous Computing } \\ \text { Wi-Fi } & \text { Wireless Fidelity }\end{array}$


1 INTRODUÇÃO . . . . . . . . . . . . . . . . . . . . . . . . . 17

1.1 CONCEITOS INTRODUTÓRIOS $\ldots \ldots \ldots \ldots$

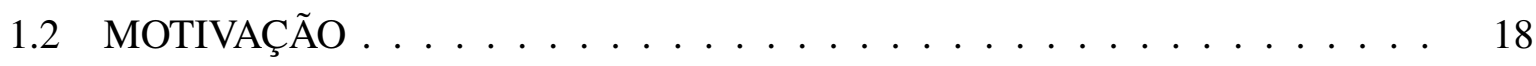

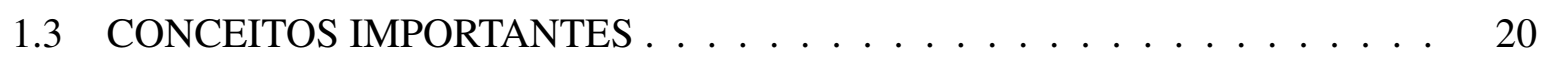

1.4 ESCOPO E OBJETIVOS DE PESQUISA $\ldots \ldots \ldots \ldots \ldots \ldots \ldots \ldots$

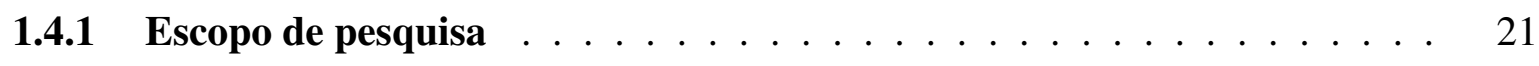

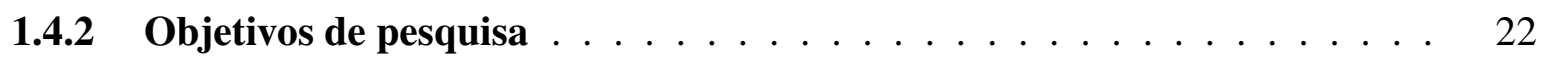

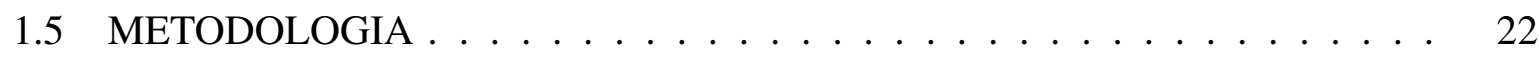

1.6 ORGANIZAÇÃO DO TRABALHO $\ldots \ldots \ldots \ldots \ldots \ldots$

2 INTERNET DAS COISAS, RECONHECIMENTO DE PADRÕES

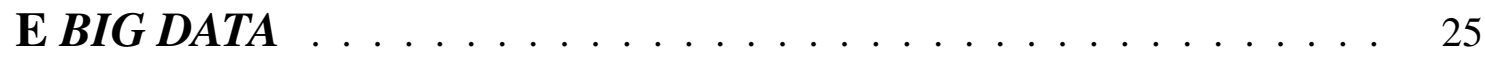

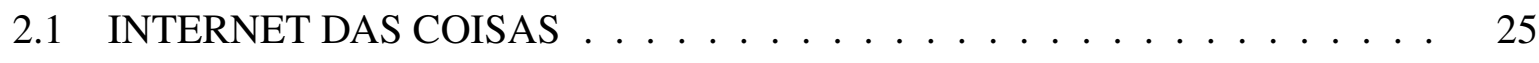

2.2 MODELOS DE REFERÊNCIA PARA IOT _ . . . . . . . . . . . . . . 27

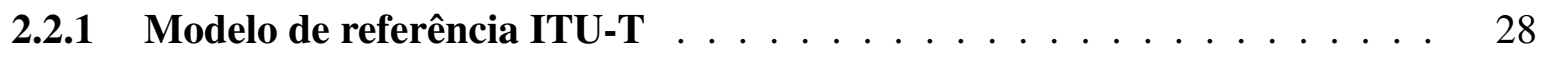

$2.2 .1 .1 \quad$ Funcionalidades de gerenciamento $\ldots \ldots \ldots \ldots \ldots$

$2.2 .1 .2 \quad$ Funcionalidades de segurança . . . . . . . . . . . . . . . 31

2.2 .1 .3 Ecossitema da IoT . . . . . . . . . . . . . . . . . . . 31

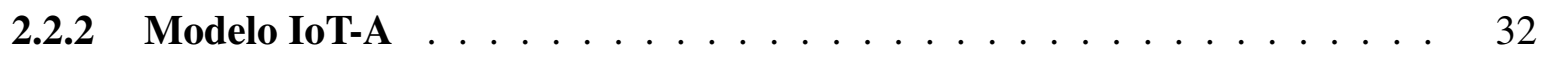

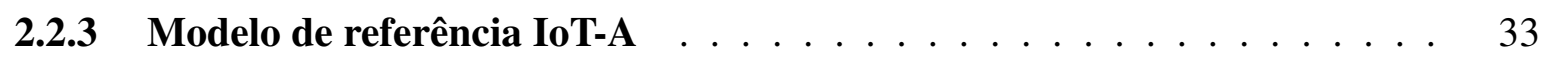

2.2 .4 Arquitetura de referência IoT-A $\ldots \ldots \ldots \ldots \ldots \ldots \ldots$

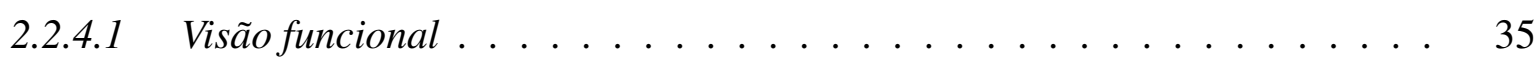

2.2 .4 .2 Visão de informação $\ldots \ldots \ldots \ldots \ldots \ldots \ldots . \ldots \ldots \ldots$

$2.2 .4 .3 \quad$ Visão de desenvolvimento e operação . . . . . . . . . . . . . 37

2.3 MIDDLEWARE DE INTERNET DAS COISAS . . . . . . . . . . . . 41

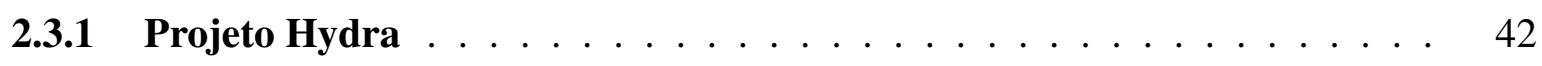

2.3 .2 Projeto Ubidots $\ldots \ldots \ldots \ldots \ldots \ldots$

2.4 ANÁLISE E RECONHECIMENTO DE PADRÕES . . . . . . . . . . . . . . 47

$2.4 .1 \quad$ Técnica de regressão linear $\ldots \ldots \ldots \ldots \ldots \ldots$

$2.4 .2 \quad$ Técnicas de clustering $\ldots \ldots \ldots \ldots \ldots \ldots$

$2.4 .2 .1 \quad$ Algoritmo de clustering k-means . . . . . . . . . . . . . 51

2.4 .2 .2 Algoritmo de clustering canopy $\ldots \ldots \ldots \ldots \ldots \ldots \ldots$

2.4 .3 Deteç̧ão de Outlier . . . . . . . . . . . . . . . . . . 52

2.5 TECNOLOGIA BIG DATA $\ldots \ldots \ldots \ldots \ldots \ldots \ldots$ 
$2.5 .1 \quad$ Framework Hadoop . . . . . . . . . . . . . . . . . . . 53

2.6 TRATAMENTO DOS DADOS NO MODELO DE INTERNET DAS COISAS 54

2.6 .1 Volume de dados gerados com a IoT $\ldots \ldots \ldots \ldots \ldots \ldots$

2.6 .2 Gerenciamento de dados em IoT $\ldots \ldots \ldots \ldots \ldots$

2.6.2.1 Coleta e análise de dados $(D C A) \ldots \ldots \ldots \ldots \ldots \ldots$

2.6 .2 .2 Sensores virtuais _ . . . . . . . . . . . . . . . . . . . . 57

$2.6 .2 .3 \quad$ Processamento de eventos complexos (CEP) . . . . . . . . . . . 57

2.6 .3 Tipos de dados em IoT $\ldots \ldots \ldots \ldots \ldots \ldots$

2.7 CONSIDERAÇÕES FINAIS $\ldots \ldots \ldots \ldots \ldots \ldots \ldots$

3 NOVA ARQUITETURA PARA INTERNET DAS COISAS COM RECONHECIMENTO DE PADRÕES E BIG DATA . . . . . . . . 59

$3.1 \quad$ ANÁLISE DE MODELOS DE REFERÊNCIA EM IOT . . . . . . . . . . . . 59

3.2 ANÁLISE CRíTICA E COMPARATIVA ENTRE O LINKSMART MIDDLEWARE E PLATAFORMA UBIDOTS $\ldots \ldots \ldots$. . . . . . . . . . . 60

3.3 ANÁLISE E RECONHECIMENTO DE PADRÕES NAS CAMADAS DE $M I$ DDLEWARE/SERVIÇO E DE DISPOSITIVO/GATEWAY NO MODELO DE

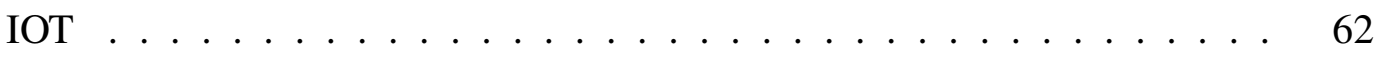

3.4 ASPECTOS DE IMPLEMENTAÇÃO DO MÓDULO DE RECONHECIMENTO DE PADRÕES E O PROCESSAMENTO COM BIG DATA . . . . . . . . . 67

3.4.1 Implementação do serviço de clustering . . . . . . . . . . . . . . . 68

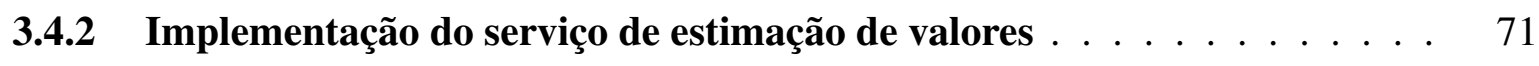

3.4.3 Implementação do serviço de deteç̧ão de outlier . . . . . . . . . . . . . 73

3.4.3.1 Algoritmo de detecção de outlier usando Big Data $e$ o algoritmo de cluste-

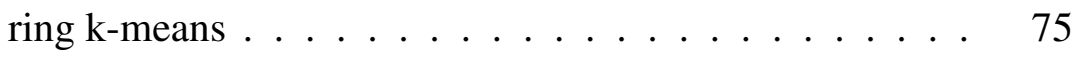

3.4.4 Implementação da comunicação cross layer no modelo de IoT $\ldots \ldots$ 3.5 UTILIZAÇÃO DE TÉCNICAS DE SENSORES VIRTUAIS E PROCESSAMENTO DE EVENTOS COMPLEXOS NO MODELO DE IOT . . . . . . 77

3.6 CONSIDERAÇÕES FINAIS $\ldots \ldots \ldots \ldots \ldots \ldots$

4 VALIDAÇÃO E EXPERIMENTOS COM A NOVA ARQUITETURA PARA INTERNET DAS COISAS $\ldots \ldots \ldots \ldots \ldots$. . . . . 81

4.1 CENÁRIO DA VALIDAÇÃO EXPERIMENTAL . . . . . . . . . . . . 81

4.1.1 Descrição do Cenário: Cidade Inteligente $\ldots \ldots \ldots \ldots \ldots$. . . . . . 81

4.1 .2 Dados obtidos $\ldots \ldots \ldots \ldots$

4.2 MÓDULO DE RECONHECIMENTO DE PADRÕES EM EXECUÇÃO. . . . . 84

4.3 APLICAÇÃO DE TESTE DA COMUNICAÇÃO CROSS LAYER . . . . . . . . 84 
4.3.1 Conclusões da experimentação da comunicação cross layer . . . . . . . . 88

$4.4 \quad$ APLICAÇÃO DE TESTE DO SERVIÇO DE CLUSTERING . . . . . . . . . 89

4.4 .1 Conclusões da experimentação do serviço de clustering $\ldots \ldots \ldots$

4.5 APLICAÇÃO DE TESTE DO SERVIÇO DE DETECÇÃO DE OUTLIER . . . 94

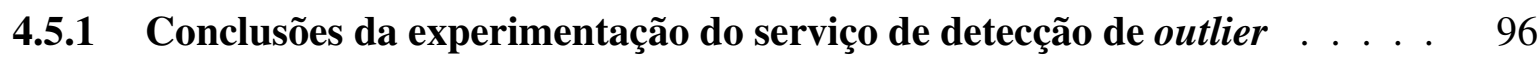

4.6 APLICAÇÃO DE TESTE DO SERVIÇO DE ESTIMAÇÃO DE VALORES . . 97

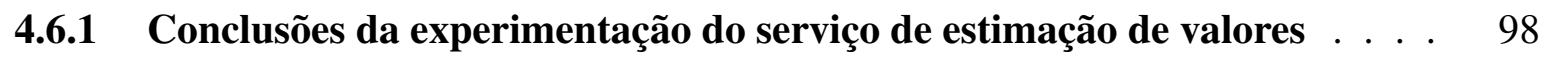

4.7 APLICAÇÃO ABRANGENTE NO CENÁRIO DE CIDADE INTELIGENTE. 99

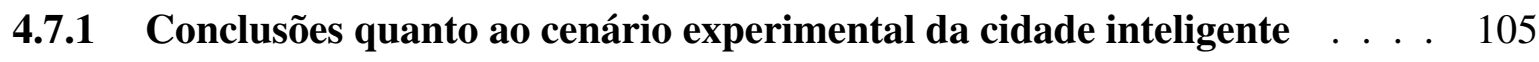

5 CONCLUSÕES E TRABALHOS FUTUROS . . . . . . . . . . . . 106

$5.1 \quad$ CONCLUSÕES . . . . . . . . . . . . . . . . . . . . . . . . 106

$5.2 \quad$ DIVULGAÇÃO DA PESQUISA $\ldots \ldots \ldots \ldots \ldots \ldots \ldots$

5.3 TRABALHOS FUTUROS $\ldots \ldots \ldots \ldots \ldots \ldots$

Referências . . . . . . . . . . . . . . . . . . . . . . . 111 


\section{INTRODUÇÃO}

Este capítulo tem por objetivo introduzir os principais conceitos relacionados com a pesquisa, além de sua motivação, escopo e objetivos. São apresentadas também a metodologia empregada e a estrutura da tese.

\subsection{CONCEITOS INTRODUTÓRIOS}

Weiser (1999) menciona que as tecnologias mais profundas são aquelas que desaparecem. Lyytinen e Yoo (2002) discutem que o próximo passo da computação é tornar o computador embutido nas ações naturais e interações humanas. A essência da computação pervasiva reside na criação de ambientes saturados de computação e capacidade de comunicação que se integrem com a vida humana (SATYANARAYANAN, 2001).

Essas novas tecnologias desenham um novo paradigma, a chamada era pós- $P C$, caracterizado por milhões de dispositivos inteligentes interconectados, que deverão mudar a vida das pessoas e especialmente os negócios, usando nanotecnologia, microsistemas, redes de sensores e identificação única, além das possíveis Body Area Networks (BAN), que são redes de comunicação com pequenos dispositivos inseridos ou implantados dentro do corpo e que se comunicam (MATTERN; ZURICH, 2005).

Em abordagens preliminares, observa-se que deverão existir centenas de dispositivos por pessoa, por ambientes, de todas as escalas, conectados às redes sem fio, tornando a computação onipresente, além da evolução das interfaces com os seres humanos que deverão ser mais transparentes e simples (WEISER, 1999).

Essa revolução não influenciará somente na quantidade de informações, mas na qualidade dela. Inúmeros e pequenos processadores embutidos em diversos objetos estarão integrados no dia-a-dia. Weiser (1999) dizia que a tecnologia é somente um meio para o propósito, ou seja, a tecnologia é uma ferramenta. Nesse momento se definia o termo computação ubíqua, numa forma mais acadêmica e idealista. O termo computação pervasiva aparece como uma tecnologia para o processamento onipresente e foi definido pela indústria (MATTERN; ZURICH, 2005).

O conceito de Internet das Coisas foi proposto inicialmente pelo Auto-ID center do Massachusetts Institute of Technology (MIT) (MIT, 2011) e no relatório de pesquisa escrito pelo International Telecommunication Union (ITU) (ITU, 2005) (ITU, 2009).

Al-Qutayri (2010) menciona que os termos computação pervasiva e computação ubíqua podem ser empregados como sinônimos, nesta tese utiliza-se o termo Internet das Coisas (IoT) também como sinônimo e deste ponto em diante será mencionada como IoT. 


\subsection{MOTIVAÇÃO}

Hurlburt, Voas e Miller (2012) mencionam que a Internet se iniciou como um meio de comunicação num grupo restrito de pessoas. Seu desenvolvimento a tornou um meio de comunicação entre pessoas e organizações e posteriormente entre organizações. Surge um novo e importante paradigma, no qual coisas, que são inanimadas, poderão ser programadas para se comunicar, sentir e interagir com outras coisas.

Gluhak et al. (2009) discutem que este mecanismo de comunicação com o mundo físico possuirá um grande número de dispositivos físicos e que esse número tende a crescer em escala (CLARK, 2005), em razão do desenvolvimento de novos dispositivos ubíquos, que deverão permitir diferentes modalidades de interação, que terão como tráfego principal interações centradas nos seres humanos, mas predominantemente comunicação de máquina para máquina.

A heterogeneidade dos dispositivos deve crescer significativamente, incluindo-se pequenos sensores e atuadores, que conforme citado em Clark (2005), agrega-se a necessidade de interoperabilidade. $\mathrm{O}$ volume de informação diversificada gerada crescerá exponencialmente, conforme o discutido em Kitsuregawa (2008), fato este que demandará segurança e privacidade no acesso às informações contextualizadas e aos serviços de atuação no ambiente (GLUHAK et al., 2009).

As informações geradas pelos diferentes dispositivos deverão ser processadas ou guardadas para um posterior processamento. Conforme informam Botts et al. (2007), serão necessários metadados dessas informações que possibilitem sua futura análise, como por exemplo, metadados que incluam localização geográfica e temporal. Conforme afirmado em Gluhak et al. (2009) serão necessários novos mecanismos eficientes e políticas inerentes à própria infraestrutura da rede para o gerenciamento e armazenamento desses dados.

O fluxo de informação trafegado pela Internet é fim-a-fim, ou seja, uma comunicação entre duas ou mais entidades ou aplicações que compartilham algo. Nesse novo modelo de rede, a IoT, o fluxo de informações deverá tornar-se mais complexo. Esse fluxo de informação possuirá vários atores, como, nós de origem de dados, coletores de informações e pontos intermediários de processamento. Os fluxos de informações poderão ser alterados nos nós finais ou intermediários ao longo do caminho (GLUHAK et al., 2009).

A comunicação com o mundo real dos objetos na IoT deverá criar um tráfego de rede diferente dos padrões da Internet atual. Esperam-se diferentes padrões de tráfegos de rede, nos quais deverão existir pequenos trechos de carga útil e padrões irregulares conduzidos por essa interação com o mundo real (SALTZER; REED; CLARK, 1981)

(KRNIC; KRCO, 2008). 
A IoT preenche um espaço entre as necessidades decorrentes da evolução do mercado, das informações, dos usuários e coisas pelo movimento em direção a um Framework comum e que possibilite novos desafios, como a quantidade adicional de informação que pode ser gerada e utilizada. Esse desafio de análise de grandes quantidades de dados terá grandes impactos no uso da IoT em novas áreas como cidades inteligentes, transporte e muitas outras que afetarão o futuro ecosistema global da Internet (SKARMETA, 2013).

Smith (2012), menciona que o gerenciamento de dados em IoT é um aspecto crucial. Considerando um mundo com objetos interconectados e constantemente trocando informações de todos os tipos, o volume de dados gerado e os processos envolvidos em gerenciar esses dados é crítico. Há muitas tecnologias e fatores envolvidos no gerenciamento de dados no contexto de IoT, dentre eles, os mais relevantes são: coleta e análise de dados, Big Data, redes de sensores semânticos, sensores virtuais ou processamento de eventos complexos.

No escopo da coleta e análise de dados, há a área de estrutura Multitenant, que destaca a descentralização, que necessita de diferentes componentes, distribuição geográfica em diferentes localizações de modo a cooperar e trocar dados, funcionalidades de mineração de dados, integrando capacidades para processamento de dados guardados, extraindo informações úteis a partir do enorme conjunto de conteúdos armazenados (SMITH, 2012).

Bin, Yuan e Xiaoyi (2010) afirmam que a estratégia de enviar todos os dados capturados a um nó central em uma rede não otimiza o uso de energia elétrica e tráfego de rede. As características da IoT, como o grande volume de dados, informações distribuídas, relação de tempo e localização, a heterogeneidade entre os dispositivos e, em alguns casos, a limitação de recursos nos dispositivos, destacam alguns problemas em uma arquitetura centralizada de mineração de dados: (1) o grande volume de dados distribuídos em diferentes localidades ou sites, torna-se uma dificuldade na centralização para processamento; (2) essa massa de dados gerados na IoT necessita de processamento em tempo real, que em caso de processamento centralizado requer alto desempenho do hardware; (3) considerações de segurança e privacidade, tolerância a falhas, necessidades das empresas, ou atendimento às legislações locais, inviabilizam a arquitetura centralizada; (4) a limitação de recursos.

De acordo com Smith (2012) serão necessários criar e prover serviços capazes de processar e analisar o massivo volume de dados gerados pela comunicação entre os diversos dispositivos, usando interfaces abertas que permitam integração simples entre várias aplicações.

A partir dessas evidências, destacam-se os conceitos pertinentes à pesquisa e a direção de pesquisa neste trabalho, relacionada ao tratamento de dados no modelo atual de IoT. 


\subsection{CONCEITOS IMPORTANTES}

A Figura 1 ilustra o mapa conceitual elaborado para a pequisa. O mapa conceitual elenca os principais conceitos pertinentes à pesquisa, com o objetivo de aprofundar-se no conhecimento deles e estabelecer suas relações.

Figura 1 - Mapa conceitual que destaca os conceitos pertinentes à pesquisa.

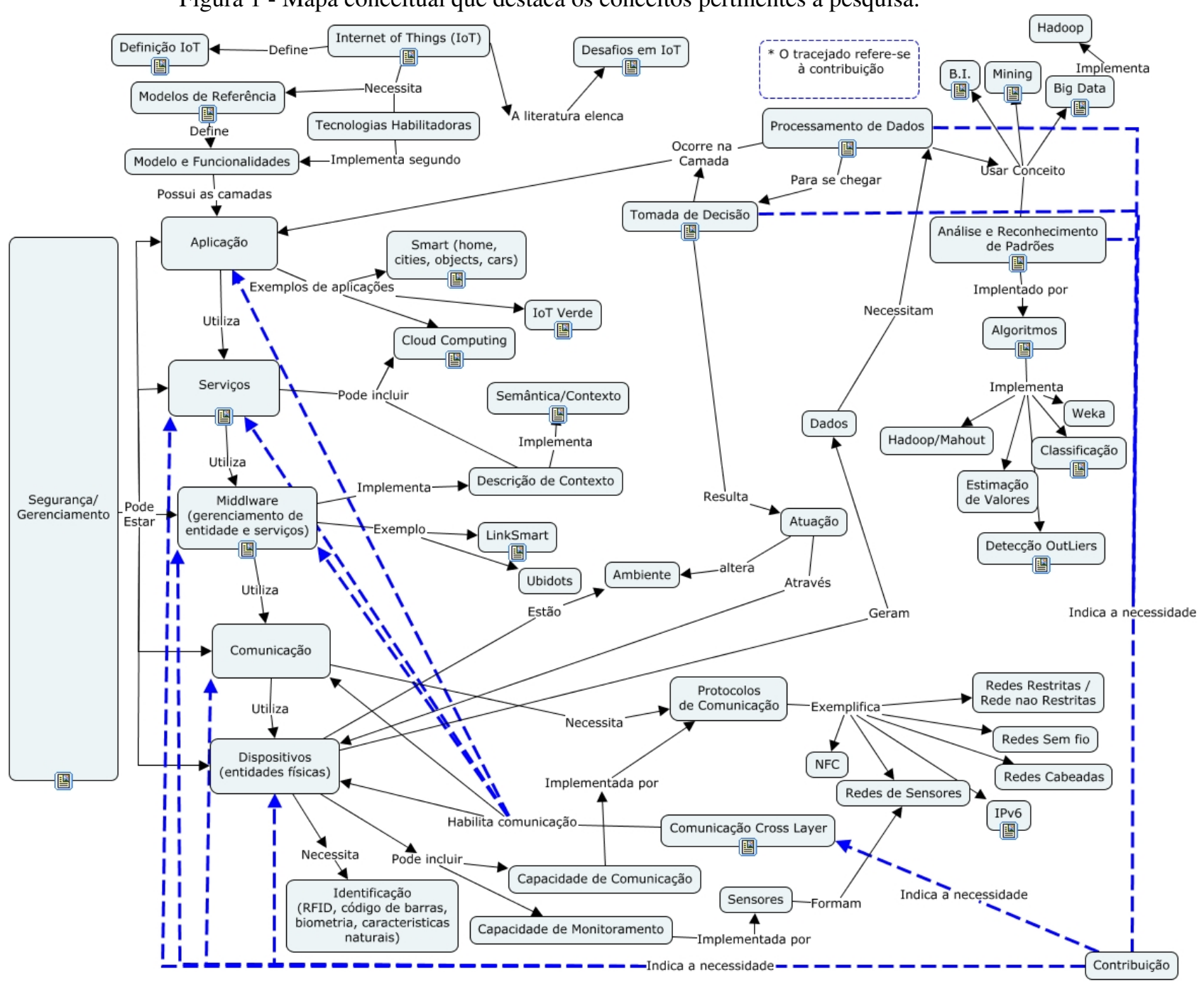

Fonte: Elaborada pelo autor.

O modelo de referência para IoT seguido no mapa conceitual apresenta as seguintes camadas: aplicação, serviços, middleware, comunicação e dispositivos; cada uma das camadas possui um conjunto de tecnologias habilitadoras, foram citadas algumas e em paralelo a cada camada, observa-se, com um papel fundamental, a segurança e o gerenciamento.

As camadas presentes no modelo utilizado desempenham funções específicas:

- Camada de Dispositivos (entidades físicas): que implementa a coleta de dados, atuação no ambiente, comunicação e identificação das entidades físicas. 
- Camada de Comunicação: que tem por função habilitar a comunicação entre as entidades físicas e camadas superiores, requer protocolos de comunicação, como por exemplo, o Protocolo de Internet Versão 6 (IPv6), que devem acompanhar a evolução das redes de sensores e redes de sensores sem fio.

- Camada de Middleware: que desempenha funções como gerenciamento, segurança e contextualização de dados, entidades ou serviços, escalabilidade e facilidade de integração entre dispositivos heterogêneos.

- Camada de Serviços: desempenha funções de gerenciamento de serviços, segurança e contextualazação dos serviços, e podem ser implementadas sob um middleware.

- Camada de Aplicação: é representada por aplicações pervasivas como, por exemplo, aplicações inteligentes em casas, automóveis, cidades, transportes e objetos. Nessa camada reside a inteligência e tomada de decisão no contexto de IoT no modelo atual.

Os dados gerados na camada de entidades físicas devem ser encaminhados à uma aplicação, de acordo com o modelo em camadas proposto. Por sua vez, na aplicação, os dados deverão ser agregados a outros, processados e analisados, para que a aplicação possa tomar uma decisão e executar ações no ambiente.

\subsection{ESCOPO E OBJETIVOS DE PESQUISA}

Esta seção tem por objetivo elencar o escopo e objetivos de pesquisa.

\subsubsection{Escopo de pesquisa}

No escopo da pesquisa, estão tópicos relacionados ao modelo de referência em IoT e à arquitetura de referência de IoT, a análise e reconhecimento de padrões, o processamento de eventos complexos, sensores virtuais e tecnologia de big data.

Não estão no escopo da tese, a identificação única de objetos, protocolos de comunicação, descrição de serviços em IoT, segurança no modelo de IoT, redes de sensores, tecnologias habilitadoras como: Radio Frequency Identification (RFID), código de barras, Near Field Communication (NFC), protocolo IPv6, cloud computing ou web semântica. 


\subsubsection{Objetivos de pesquisa}

O principal objetivo de pesquisa é: introduzir mecanismos de análise e reconhecimento de padrões no modelo de IoT, com a abstração e implementação de algoritmos para reconhecimento de padrões como: algoritmos de agrupamento, que deste ponto em diante optou-se por usar o termo em inglês clustering, estimação de valores e detecção de anomalias, que deste ponto em diante optou-se por usar o termo em inglês outliers (SOUZA; AMAZONAS, 2013). Assim, pode-se identificar os dados relevantes para análises, prever ou inferir sobre comportamentos humanos, sociais, animais, redes de comunicação, trânsito, consumo, segurança, assistência, automação, dentre inúmeras outras funcionalidades mencionadas por Roussos (2011), Esses mecanismos de análise e reconhecimento de padrões serão implementados em camadas inferiores do modelo, nas camadas de entidade física e middleware/serviços (SOUZA; AMAZONAS, 2013), conforme ilustrado na Figura11. A implementação na camada de entidade física irá especificar capacidades de detecção de outliers e estimação de valores e na camada de middleware as capacidades da camada de entidade física e mais o serviço de clustering.

Como objetivos secundários se tem:

1. Analisar os modelos de referência em IoT, de modo a definir qual modelo será utilizado para o desenvolvimento de futuras aplicações e experimentos na pesquisa.

2. Propor uma arquitetura para mineração e processamento distribuído de dados para a IoT. E,

3. Propor e implementar a comunicação cross-layer, acrescentando ao modelo de arquitetura uma sub-camada para filtragem, mineração de dados ou estimação e introduzindo flags que informem às camadas superiores ou aos próximos dispositivos, que ocorreram pré-processamentos nos dados (mineração ou estimação de valores que por ventura não tenham sido lidos). Dada a criticidade do domínio, essa pode ser uma informação importante para a aplicação.

Na Figura 1 as linhas tracejadas ilustram as novas relações entre os conceitos elencados na pesquisa.

\subsection{METODOLOGIA}

A metodologia de pesquisa utilizada foi a exploratória, na qual deve-se fazer uma análise aprofundada do referencial teórico e o posterior estudo experimental. 
O seguinte conjunto de atividades foi desenvolvido no decorrer da pesquisa:

1. Especificação detalhada, modelagem e desenvolvimento do tema e solução proposta.

2. Identificação e adequação do ambiente de testes e experimentações.

3. Experimentação e análise dos resultados.

Optou-se por fazer a análise do referencial teórico sobre IoT entre os anos de 2008 e 2015. Como temas secundários à pesquisa foi feita a análise de referencial teórico das áreas de análise e reconhecimento de padrões e big data compreendendo essencialmente o período entre os anos de 2001 e 2015.

A etapa seguinte consistiu em avaliar e estudar o material identificado, com o intuito de criar uma base de conhecimento que possibilitasse o desenvolvimento dos objetivos propostos. O desenvolvimento dos objetivos da pesquisa envolve atividades como, organização das informações pesquisadas, especificação detalhada, modelagem e desenvolvimento do tema proposto, testes e análise dos resultados.

As etapas de especificação detalhada, modelagem e desenvolvimento do tema e solução proposta ocorreram entre Dezembro de 2013 e Junho de 2014. Foi desenvolvida a nova arquitetura para IoT, com os serviços de análise e reconhecimento de padrões nas camadas física e de middleware do modelo de IoT, bem como sua modelagem orientada a objetos e a comunicação cross-layer proposta.

Como cenário experimental optou-se por utilizar o cenário Smart Santander (KRČO et al., 2012), que será melhor descrito na Seção 4.1.1, esse projeto propõe um cenário experimental em larga escala, para o desenvolvimento e experimentação de aplicações para IoT. Os dados coletados foram inseridos em uma base de dados para posterior recuperação nos experimentos desenvolvidos.

Para o desenvolvimento e experimentações utilizou-se: sistema operacional Linux, linguagem de programação Java, banco de dados Mysql e a plataforma para Big data Hadoop.

A etapa de experimentação e análise dos resultados obtidos teve por objetivo avaliar se os resultados e as conclusões obtidos são consistentes ou de acordo com o esperado. Nessa análise, avaliou-se a necessidade de revisão dos conceitos utilizados, das hipóteses assumidas e dos desenvolvimentos propostos. Essa etapa ocorreu no período entre Julho e Setembro de 2014. Foram desenvolvidas aplicações para experimentar a comunicação cross-layer, os servios de reconhecimento de padrões e a integração com a arquitetura desenvolvida.

A elaboração de artigos para publicação em eventos internacionais consistiu em consolidar os conceitos, resultados e contribuições obtidas com a pesquisa, em textos originais para 
publicação em eventos e revistas internacionais. Essa atividade ocorreu no período entre Outubro de 2014 e Abril de 2015.

A etapa final consistiu na elaboração do texto da tese, organizando todas as informações acumuladas nas etapas anteriores, além das conclusões e resultados obtidos. Essa etapa ocorreu entre Abril e Agosto de 2015.

\subsection{ORGANIZAÇÃO DO TRABALHO}

Este trabalho é organizado da seguinte maneira:

A Introdução apresentada neste capítulo.

O Capítulo 2 apresenta a fundamentação teórica relacionada à pesquisa, na qual são definidos conceitos como IoT, os modelos de referência do ITU-T e Internet of Things Architecture (IoT-A), bem como a arquitetura de referência proposta pelo IoT-A, middlewares para IoT, técnicas e algoritmos de análise e reconhecimento de padrões, como ocorre o tratamento de dados no modelo de IoT, quais tipos de dados e as tecnologias que permeiam seu processamento.

O Capítulo 3 apresenta a solução proposta, mais especificamente, o detalhamento da implementação da proposta de solução e aspectos técnicos.

O Capítulo 4 traz as aplicaçẽs desenvolvidas para experimentação e validação da arquitetura e algoritmos propostos.

Por fim, o Capítulo 5 elenca as conclusões de pesquisa e trabalhos futuros. 


\section{INTERNET DAS COISAS, RECONHECIMENTO DE PADRÕES E BIG DATA}

Este capítulo está dividido da seguinte maneira: a Seção 2.1 tem por objetivo introduzir conceitos relacionados à Internet das Coisas; a Seção 2.2 descreve os modelos de referência e a arquitetura de refêrencia para Internet das Coisas; a Seção 2.3 descreve a função dos middlewares de Internet das Coisas e mostra alguns mais relevantes para esta pesquisa; na Seção 2.4 são mencionadas as técnicas de análise e reconhecimento de padrões, como técnica de regressão, técnicas de classificação e clustering e detecção de outliers; a Seção 2.5 é mencionada a tecnologia de Big Data; a Seção 2.6 que ilustra o volume de dados gerados no contexto de IoT e algumas técnicas para seu gerenciamento; e, por fim, a Seção 2.7 com as considerações sobre o capítulo.

\subsection{INTERNET DAS COISAS}

A IoT é definida como uma infraestrutura de rede global, que interconecta fisicamente e virtualmente objetos, com o objetivo de explorar dados capturados e suas capacidades de comunicação. Essa infraestrutura inclui e envolve a Internet e as redes de comunicação, ela necessita de identificação única de objetos, sensores e capacidade de conexão, como base para o desenvolvimento independente de serviços e aplicações. Ela é caracterizada pelo alto grau de captura autônoma de dados, transferência de eventos de rede, conectividade e interoperabilidade (CASAGRAS, 2009).

A Figura 2 ilustra a interação existente em qualquer implementação para IoT, que inclui a interação entre as redes de comunicação, o mundo físico e virtual, representado pela Internet (CASAGRAS, 2009).

A IoT refere-se à próxima geração de Internet (BAHGA; MADISETTI, 2014), que possuirá trilhões de nós, representados por pequenos dispositivos ubíquos ou embutidos nos diversos ambientes, dotados de sensores, interconectados a servidores web, supercomputadores ou clusters. Tecnologias como as redes de sensores, a identificação única de objetos, a comunicação móvel, a localização em tempo real, a computação ubíqua, o protocolo IPv6 integram essa nova infraestrutura de computação e comunicação.

Em (GREENGARD, 2015), o termo IoT refere-se não somente à interconexão entre objetos do mundo real, mas, à contextualização de informações referentes às coisas do mundo real. A aplicação do termo Coisas, inclui objetos do mundo real que existem em grandes quantidades e de diferentes tipos que possuirão uma identificação única na Internet. 
Figura 2 - Interação entre as redes de comunicação, o mundo físico e o virtual.

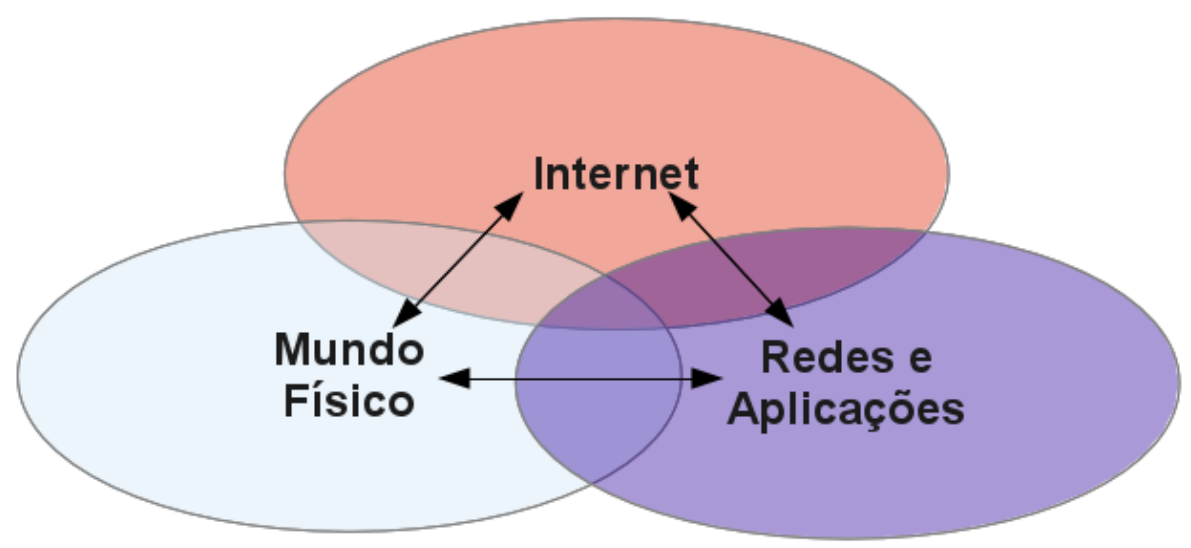

Fonte: Adaptado de (CASAGRAS, 2009).

A Figura 3 ilustra o Modelo Inclusivo para a IoT, adaptado de (AMAZONAS, 2011) 1 .

A Figura 3 representa o processo de captura e processamento de dados em IoT, que ocorre da seguinte maneira: os dados gerados pelos objetos físicos são lidos pelo dispositivo interrogador, também designado como gateway. Esses dados são enviados ao sistema de gerenciamento de informação, a partir desse, usando a Internet ou outras tecnologias de rede, são obtidos outros dados associados aos objetos ou aos próprios dados iniciais. O resultado do processamento por uma aplicação ou serviço é uma atuação no ambiente em que estão presentes os objetos e/ou uma atuação sobre eles (CASAGRAS, 2009).

Conforme se observa em CASAGRAS (2009), são propostas três classes de dispositivos para IoT:

1. Objetos puramente passivos com identificação e dados fixos, são objetos presentes na Physical Interface Zone, na parte superior da Figura 3.

2. Objetos dotados de moderado poder computacional e percepção de contexto, que por meio de sensores podem gerar mensagens e variar a informação associadas a eles de acordo com o tempo e lugar, representados pelos objetos presentes na Physical Interface Zone, mais ao centro da Figura 3 .

3. Objetos que possuem conectividade em rede, sem a intervenção humana, possibilitando a emergência de inteligência nos sistemas de rede, representados pelos objetos presentes na Physical Interface Zone, na parte inferior da Figura 3 .

\footnotetext{
${ }^{1}$ Optou-se por manter as imagens com textos e nomenclaturas em inglês, tendo em vista serem reproduções de artigos publicados em eventos internacionais.
} 
Figura 3 - Modelo Inclusivo para a IoT.

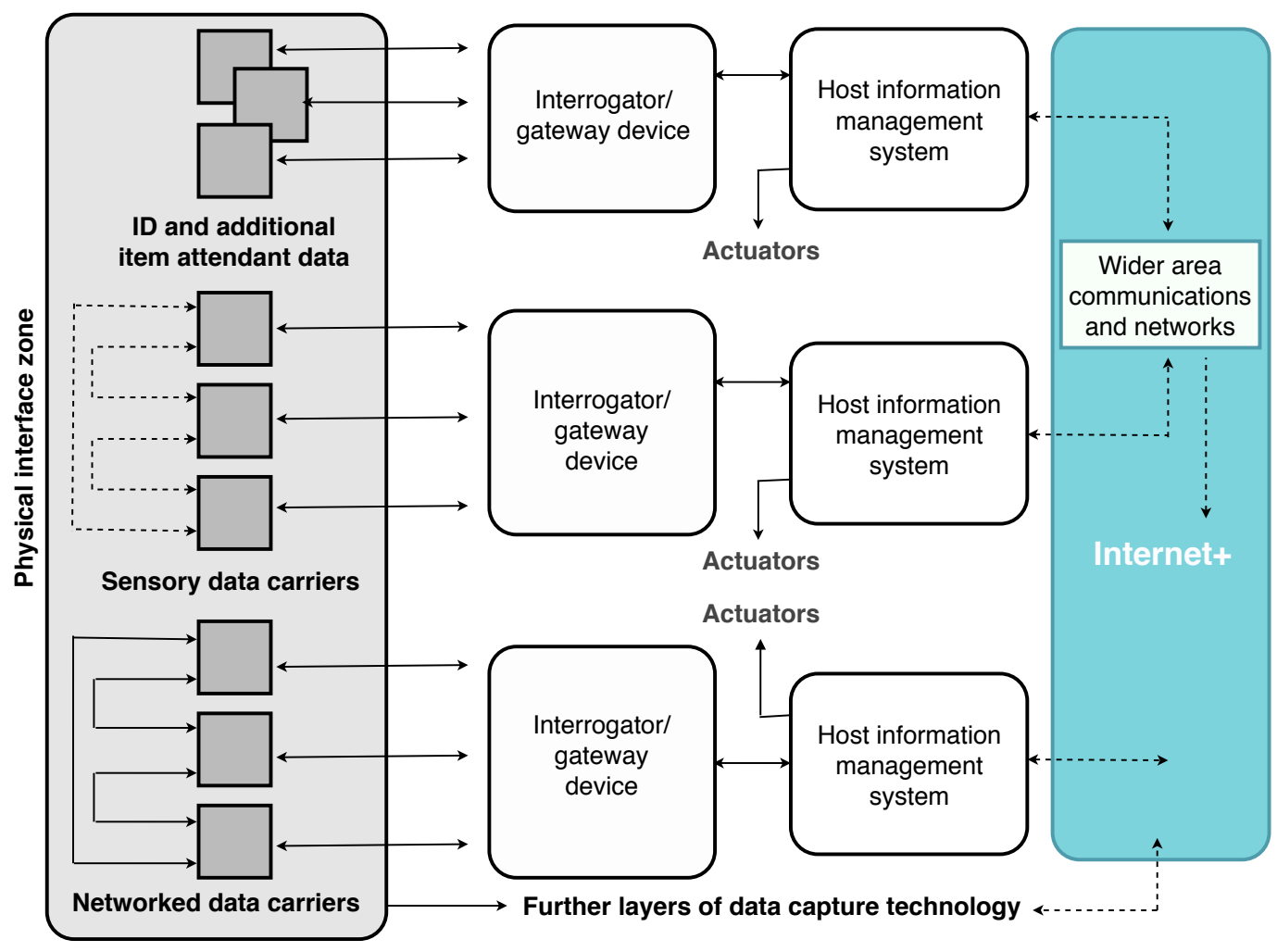

Fonte: Adaptado de (AMAZONAS, 2011).

O modelo ilustrado pela Figura 3 pode ser exemplificado através de um processo baseado em IoT (HUANG; LI, 2010). No dado processo um objeto do mundo real possui uma informação, por exemplo, dentro de uma tarja eletrônica. A informação é resgatada por meio de um interrogador, que pode estar conectado a um serviço ou aplicação, na qual usuários ou aplicações, que estão no mundo real, poderão ler ou compartilhar a informação do objeto em tempo real. Por fim, esta aplicação pode atuar no ambiente, por meio dos atuadores presentes em objetos (AMAZONAS, 2011). Cabe ressaltar que a tarja eletrônica pode ser substituída por outras tecnologias de identificação única, ou seja, não se restringe à tecnologia de RFID.

\subsection{MODELOS DE REFERÊNCIA PARA IOT}

Um modelo de referência é uma estrutura para entendimento de relacionamentos entre entidades em um dado domínio, para se desenvolver padrões ou especificações consistentes de suporte. Um modelo de referência é baseado no conjunto dos principais conceitos, abstrações, suas interações, suas interfaces com ambientes externos que podem ser usados como base para entendimento do dado domínio (COMER, 2015).

Uma arquitetura de referência serve como base para a construção e projeto de arquiteturas 
coerentes com o domínio de aplicação e é baseada num modelo de referência. Esta seção descreve dois modelos de referência para arquiteturas de IoT.

\subsubsection{Modelo de referência ITU-T}

Esta seção descreve o modelo de referência proposto pelo ITU-T em ITU-T (2012), as funções propostas para as camadas e uma breve descrição do ecosistema de IoT proposto.

De acordo com a ITU-T (2012), a IoT refere-se a uma infraestrutura global de informação. Ela envolve serviços avançados pela interconexão física e virtual de coisas, baseando-se na interoperabilidade das informações e protocolos de comunicação. As coisas podem ser quaisquer objetos do mundo físico ou informação do mundo virtual, que possam ser identificados e integrados às redes de comunicação.

A Figura 4ilustra o modelo de referência ITU-T para IoT. Ele é composto por 4 camadas, que possuem capacidades de gerenciamento de funcionalidades e segurança, para se acessar suas funcionalidades.

Figura 4 - Modelo de Referência para IoT proposto pelo ITU-T.

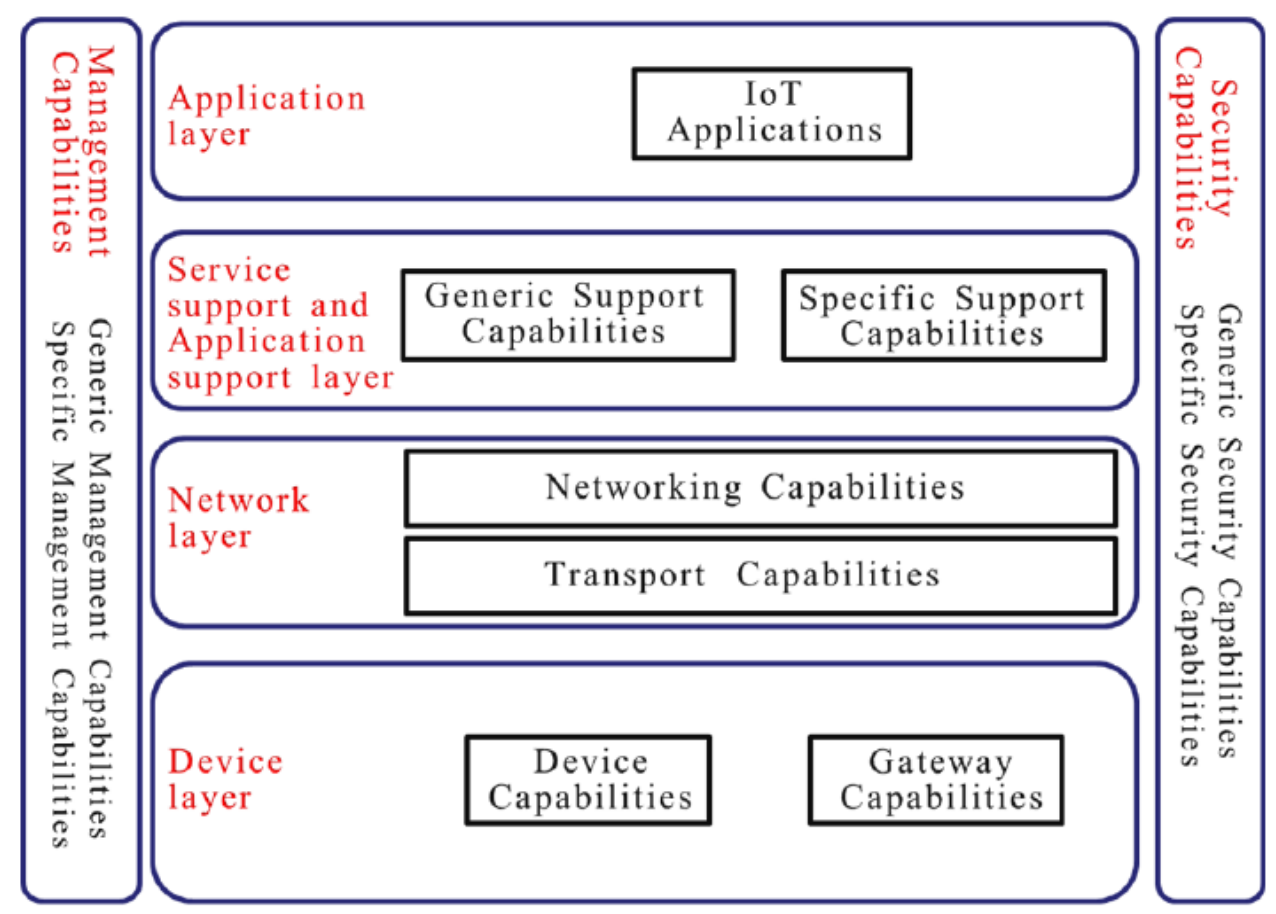

Fonte: (ITU-T, 2012).

Segue a descrição detalhada de cada uma das 4 camadas:

- Application Layer: contém as aplicações para IoT.

- Service Support and Application Support layer: consiste em dois grupos de funcionalidades: 
- Generic Support Capabilities: são as funcionalidades comuns que podem ser usadas por diferentes aplicações de IoT como, por exemplo, processamento e armazenamento de dados. Essas funcionalidades podem ser iniciadas pelas funcionalidades específicas de suporte de modo a as compor.

- Specific Support Capabilities: essas funcionalidades são específicas de cada tipo de aplicação de IoT. Elas consistem em agrupamentos de detalhes de implementação, que proveem diferentes suportes para os diferentes tipos de aplicações de IoT.

- Network Layer: suas funções não são análogas às da camada de rede e transporte presentes no modelo de referência Open Systems Interconnection (OSI). Essa camada provê dois tipos de funcionalidades:

- Networking Capabilities: provê controles de funções de conectividade, como funções de acesso e controle de transporte, gerenciamento móvel de contas, autenticação e autorização (Authentication, Authorization, Accounting, and Auditing (AAAA)).

- Transport Capabilities: provê conectividade para o transporte de serviços de IoT, dados e informações de aplicações específicas, bem como o controle de transporte e o gerenciamento relacionado à IoT.

- Device Layer: a camada de dispositivo pode ser dividida logicamente em dois tipos de funcionalidades:

- Device Capabilities: as funcionalidades de dispositivos incluem, mas não estão limitadas a:

1. Interação direta com comunicação de rede: dispositivos que reúnem e submetem informações diretamente, ou seja, sem usar funcionalidades de gateway para a comunicação de rede. Eles também podem receber informações, ou comandos, a partir dessa comunicação de rede.

2. Interação indireta com comunicação de rede: dispositivos que reúnem e submetem informação indiretamente pela rede, ou seja, usam as funcionalidades dos dispositivos gateway, por outro lado, são dispositivos que podem, indiretamente, receber informações, ou comandos, a partir da comunicação de rede.

3. Redes Ad-hoc: dispositivos que podem construir redes ad-hoc em diversos cenários que necessitam de escalabilidade e rápido desenvolvimento. 
4. Hibernados: dispositivos que possuem mecanismos de hibernação e acionamento para economia de energia. O suporte às funcionalidades desse dispositivo pode ser direto ou indireto e a comunicação por rede não é obrigatória.

- Gateway Capabilities: as funcionalidades de gateway incluem, mas não se limitam a:

1. Suporte a múltiplas interfaces: na camada de dispositivo as funcionalidades de gateway suportam dispositivos conectados a partir de diferentes tecnologias com cabos ou sem fio, como redes Controler Area Network (CAN) bus, ZigBee, Bluetooth ou Wireless Fidelity (Wi-Fi). Assim como na camada de rede, as funcionalidades de gateway poderão permitir comunicação entre várias tecnologias, como redes de telefonia Public Switched Telephone Network (PSTN), redes de Segunda Geração (2G) ou de Terceira Geração (3G), Long-Term Evolution Networks (LTE), redes Ethernet ou redes Digital Subscriber Line (DSL).

2. Conversão de protocolos: há duas situações onde essas funcionalidades são necessárias, quando ocorrem comunicações na camada de dispositivo, que usam diferentes protocolos, por exemplo, protocolo ZigBee e Bluetooth e quando ocorrem comunicações envolvendo ambas as camadas de dispositivo e de rede, usando diferentes protocolos, como por exemplo, protocolo ZigBee na camada de dispositivo e tecnologia $3 G$ como camada de rede.

\subsubsection{Funcionalidades de gerenciamento}

As funcionalidades de gerenciamento em IoT incluem gerenciamento baseado nas categorias Fault, Configuration, Accounting, Performance, Security (FCAPS) (ITU-T, 2012).

As funcionalidades de gerenciamento podem ser categorizadas em funcionalidades de gerenciamento genéricas e específicas.

As funcionalidades de gerenciamento genéricas em IoT incluem:

- Gerenciamento remoto de dispositivos, como ativação ou desativação, diagnósticos, atualização de firmware ou software ou gerencimento de status de dispositivos.

- Gerenciamento de topologia local.

- Gerenciamento de tráfego e congestionamento, como detecção de perda de pacotes e a 
implementação de reserva de recursos para fluxos de informação sensíveis ao tempo ou ao ciclo de vida.

As funcionalidades de gerenciamento específicas são acopladas aos requisitos específicos da aplicação, como requisitos de monitoramento de linhas de transmissão em smart grid.

\subsubsection{Funcionalidades de segurança}

Há dois tipos de funcionalidades de segurança: funcionalidades genéricas e específicas. As funcionalidades de segurança genéricas são independentes de aplicação e incluem:

- Na camada de aplicação: autorização, autenticação, proteção de confidencialidade e integridade da aplicação, proteção de privacidade, auditoria e antivirus.

- Na camada de rede: autorização, autenticação, uso dos dados e sinalização de confidencialidade e sinalização de proteção de integridade.

- Na camada de dispositivo: autenticação, autorização, validação de integridade de dispositivo, controle de acesso, confidencialidade de dados e proteção de integridade.

As funcionalidades de segurança específicas são acopladas aos requisitos específicos da aplicação, por exemplo, tarifações móveis ou necessidades de controle de acesso.

\subsubsection{Ecossitema da IoT}

De acordo com ITU-T (2012), o ecossitema de IoT é composto por uma variedade de atores de negócio. Cada um desses atores possui um papel, os papéis são ilustrados pela Figura 5 .

A Figura 5 ilustra os papéis de negócios presentes no ecossitema de IoT e o relacionamento entre eles. Segue uma pequena descrição de cada um dos papéis.

\section{Device provider}

O provedor de dispositivo é responsável por fornecer os dados brutos ou o conteúdo para o provedor de rede e provedor de aplicação, de acordo com a lógica de negócio.

\section{Network provider}

O provedor de rede possui o papel central no ecossitema de IoT. Ele possui as seguintes funções principais:

- Acesso e integração de recursos providos por outros provedores. 
Figura 5 - Modelo de Ecossitema para IoT, proposto pelo ITU-T.

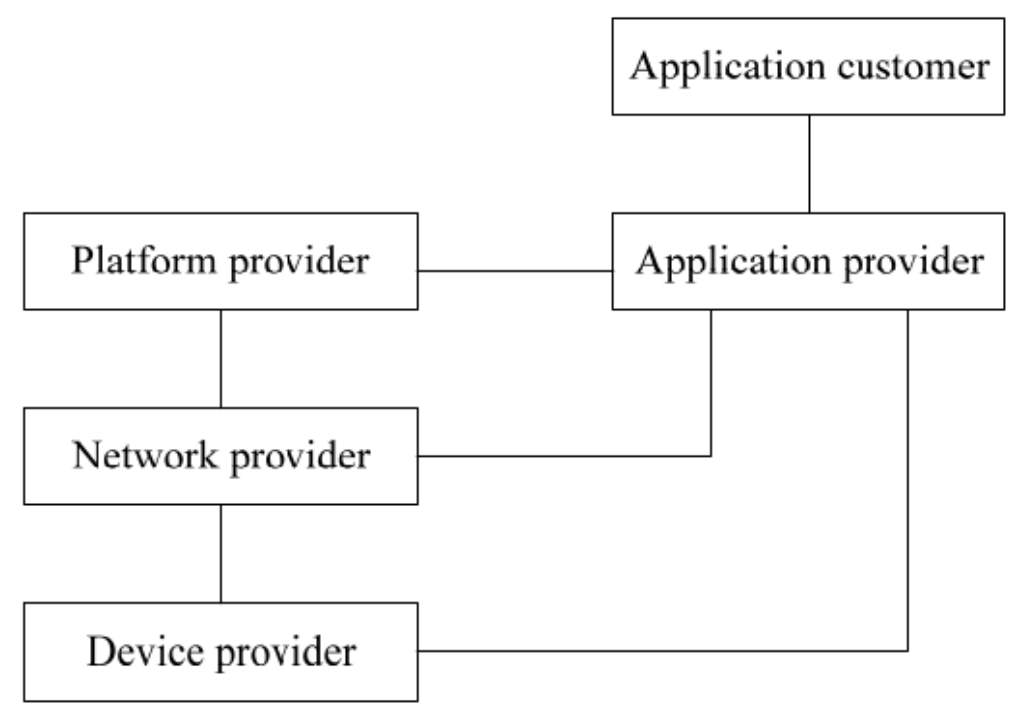

Fonte: (ITU-T, 2012).

- Suporte e controle das capacidades de infraestrutura de IoT.

- Oferecer capacidades de IoT, incluindo capacidades de rede e exposição de recursos para outros provedores.

\section{Platform provider}

O provedor de plataforma fornece capacidades de integração e interfaces abertas. Diferentes plataformas podem oferecer diferentes capacidades para provedores de aplicação. Capacidades de plataforma incluem tipicamente capacidades de integração, como por exemplo, armazenamento de dados, processamento de dados ou gerenciamento de dispositivos e suporte para diferentes tipos de aplicações de IoT.

\section{Application provider}

O provedor de aplicação fornece e utiliza capacidades ou recursos providos por provedores de rede, de dispositivos e de plataformas, de modo a prover aplicações de IoT para aplicações clientes.

\section{Application customer}

A aplicação cliente é o usuário das aplicações de IoT fornecidas pelos provedores de aplicação. Nesse caso, uma aplicação cliente pode representar múltiplas aplicações de usuário.

\subsubsection{Modelo IoT-A}

Confome se observa em Joachim e Walewski (2012), o Modelo de Referência para IoT provê um alto nível de abstração para a definição da Arquitetura de Referência. Ele promove 
um entendimento comum do domínio de IoT. A descrição do modelo de referência inclui um discurso geral sobre o domínio de IoT, um modelo de domínio como um alto nível de descrição, um modelo de informação que mostra como o conhecimento de IoT é modelado e um modelo de comunicação, de modo a descrever a interação entre objetos inteligentes.

A arquitetura de referência para IoT é utilizada para construção de arquiteturas para IoT. Ela provê visões e perspectivas sobre diferentes aspectos de arquitetura respeitando definições, implementações e padrões já existentes.

A Figura 6, ilustra as entradas e dependências entre o modelo de referência para IoT e a arquitetura de referência para a IoT.

Figura 6 - Alto nível de taxonomia, influências e dependências entre o modelo de referência para IoT e a arquitetura de referência para IoT.

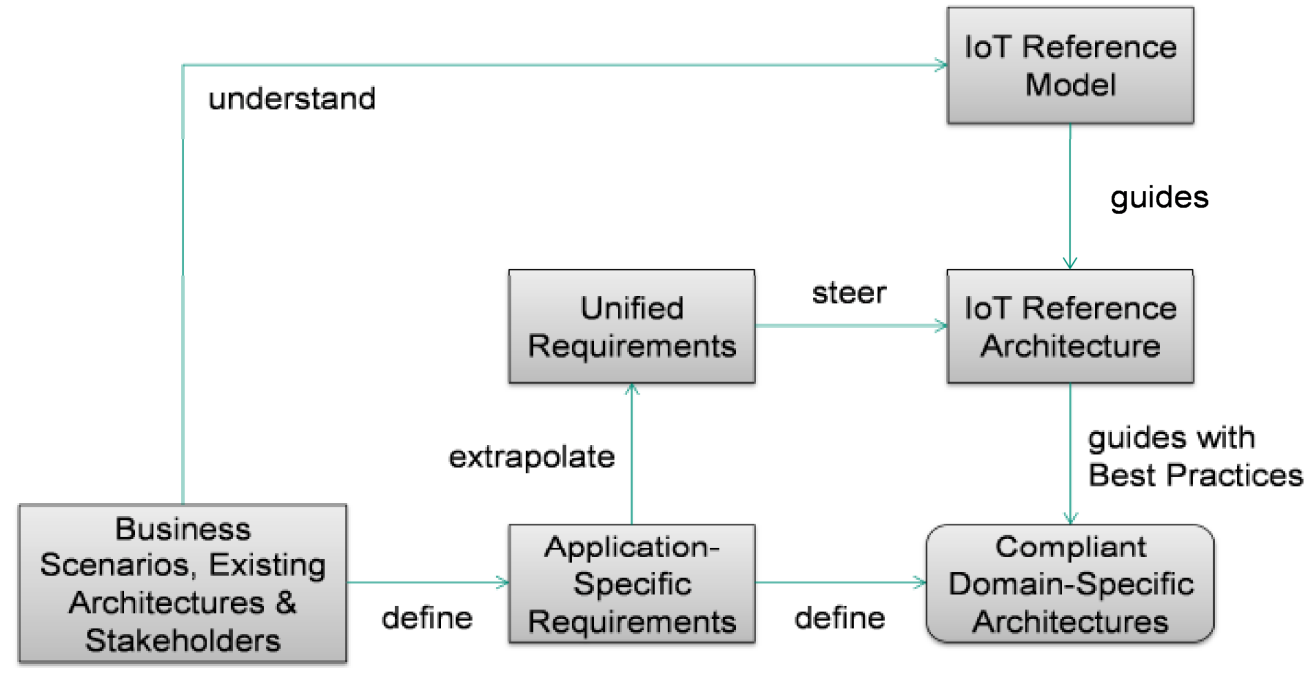

Fonte: (JOACHIM; WALEWSKI, 2012).

De acordo com a Figura 6, o modelo de referência para IoT provê um guia para a descrição da arquitetura de referência para a IoT. Observa-se que o modelo de referência deve ser cunhado a partir das expectativas das partes interessadas, de cenários de negócio e arquiteturas existentes, de modo a criar um entendimento comum sobre o domínio de IoT. A partir desse entendimento, são definidos os principais requisitos de aplicação, que posteriormente definirão a arquitetura de referência para IoT.

Joachim e Walewski (2012) mencionam que o modelo do IoT-A é composto por um modelo de referência para IoT e uma arquitetura de referência, melhores descritos em 2.2.3 e 2.2.4, respectivamente.

\subsubsection{Modelo de referência IoT-A}

O modelo de referência consiste em uma série de submodelos, que compõem um conjunto com importantes aspectos de projeto para IoT. O mais importante é o Modelo de Domínio, 
que descreve todos os conceitos relevantes para a IoT. Os outros modelos e Arquitetura de Referência são baseados nos conceitos introduzidos no Modelo de Domínio. O modelo de referência tem o objetivo de definir uma base e linguagem comum para arquiteturas e sistemas de IoT. A Figura 7 ilustra as interações e os submodelos propostos.

Figura 7 - Interações entre os sub-modelos do modelo de referência para IoT.

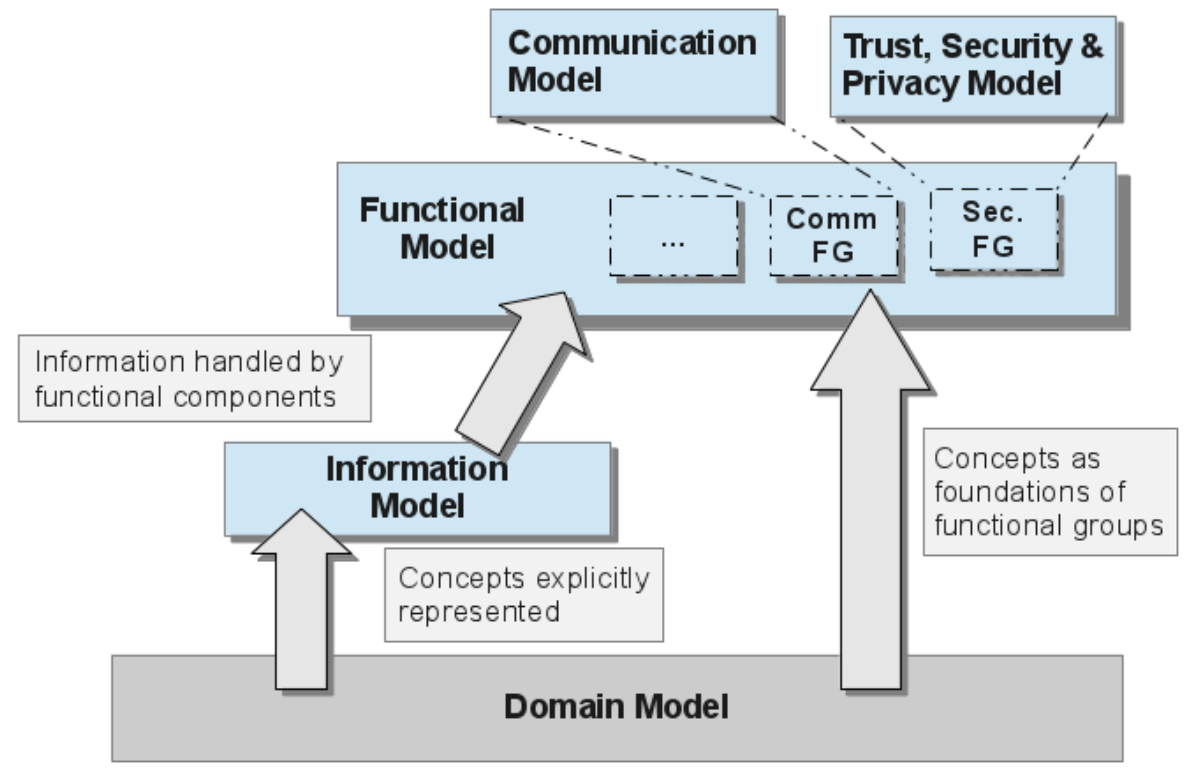

Fonte: Adaptada de (JOACHIM; WALEWSKI, 2012).

O Modelo de Domínio introduz os principais conceitos da IoT, como dispositivos, serviços e entidades virtuais e as relações entre eles. Esse nível de abstração é independente de tecnologia e são casos de uso e requisitos invariantes no tempo.

O Modelo de Informação foi desenvolvido baseado no modelo de domínio. Ele possui uma estrutura (por exemplo, relacionamentos e atributos) que contém todas as informações (dados) que são manipuladas em um sistema de IoT, em um nível conceitual, sem discutir como ele deverá ser representado. Sendo assim, as informações pertinentes aos conceitos do Modelo de Domínio são modeladas. As informações sobre os dispositivos, serviços ou entidades virtuais são explicitamente resgatadas, armazenadas e processadas em um sistema de IoT.

O Modelo Funcional identifica grupos de funcionalidades que dizem respeito, em muitos casos, aos principais conceitos do Modelo de Domínio. Esses Grupos Funcionais (FG) são construídos de forma hierárquica. Um grupo funcional provê as funcionalidades para interação com as instâncias desses conceitos ou gerencia as informações relacionadas aos conceitos. As funcionalidades de gerenciamento de informação usam o modelo de Informação de IoT como a base para estruturar suas informações.

A funcionalidade principal em qualquer sistema computacional distribuído é a comunicação entre os diferentes componentes, especificamente para um sistema de IoT é a hetero- 
geneidade de tecnologias de comunicação necessárias. O modelo de comunicação introduz conceitos para a complexa manipulação da comunicação em ambientes de IoT heterogêneos. A comunicação constitui um grupo funcional no Modelo Funcional.

A segurança e privacidade são de suma importância em ambientes típicos de IoT, as funcionalidades relevantes e suas interdependências e interações são introduzidas no Modelo de Segurança. Como no caso da comunicação, a segurança constitui um grupo funcional no modelo funcional.

\subsubsection{Arquitetura de referência IoT-A}

A arquitetura de referência é utilizada para a construção de arquiteturas de IoT, que possuem necessidades específicas. Essa arquitetura segue uma abordagem de visões e perspectivas e aborda os seguintes questionamentos: (1) elementos funcionais; (2) interação entre os elementos; (3) gerenciamento de informação; (4) características operacionais; e (5) desenvolvimento do sistema.

A Arquitetura de Referência IoT-A propõe as seguintes visões: Visão Funcional, Visão de Informação e Visão de Desenvolvimento e Operação.

\subsubsection{Visão funcional}

A visão funcional é definida pela aplicação da decomposição funcional, conforme o ilustrado pela Figura 8

Figura 8 - Interações entre o modelo funcional e requisitos uificados e a visão funcional.

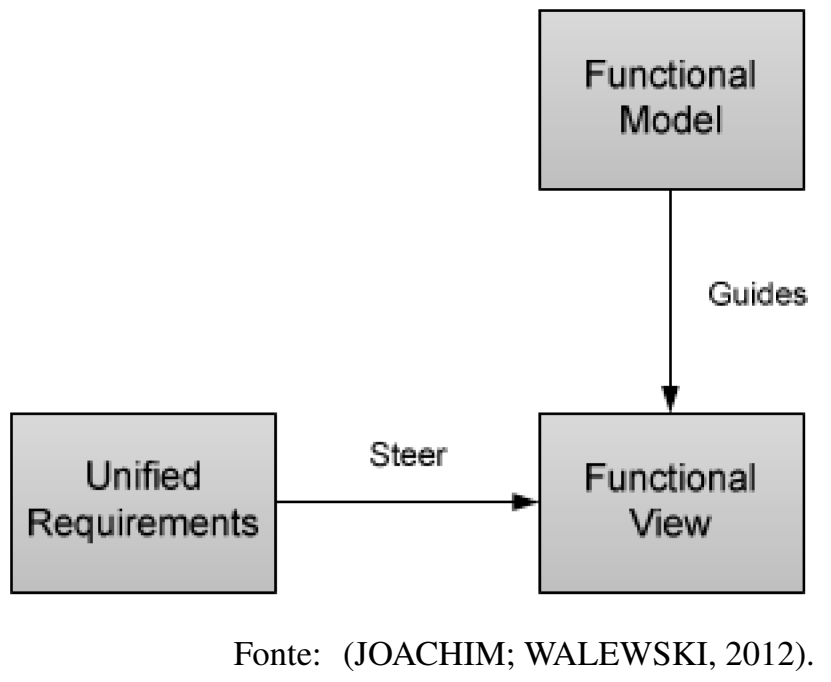

No primeiro passo, os requisitos são mapeados para diferentes grupos de funcionalidades do modelo funcional. No próximo passo, os requisitos com funcionalidades semelhantes são 
agrupados e os componentes funcionais são definidos para esses requisitos. Por fim, após discussões técnicas, os componentes funcionais são refinados.

Os pontos de vista usados para a construção funcional são: (1) Requisitos Unificados e (2) Modelo Funcional.

Todos os componentes funcionais são definidos através de diagramas de casos de uso, de sequência e definição de interfaces. O diagrama com os grupos funcionais estão ilustrados na Figura 9 .

Figura 9 - Grupos de funcionais do Modelo Funcional para IoT.

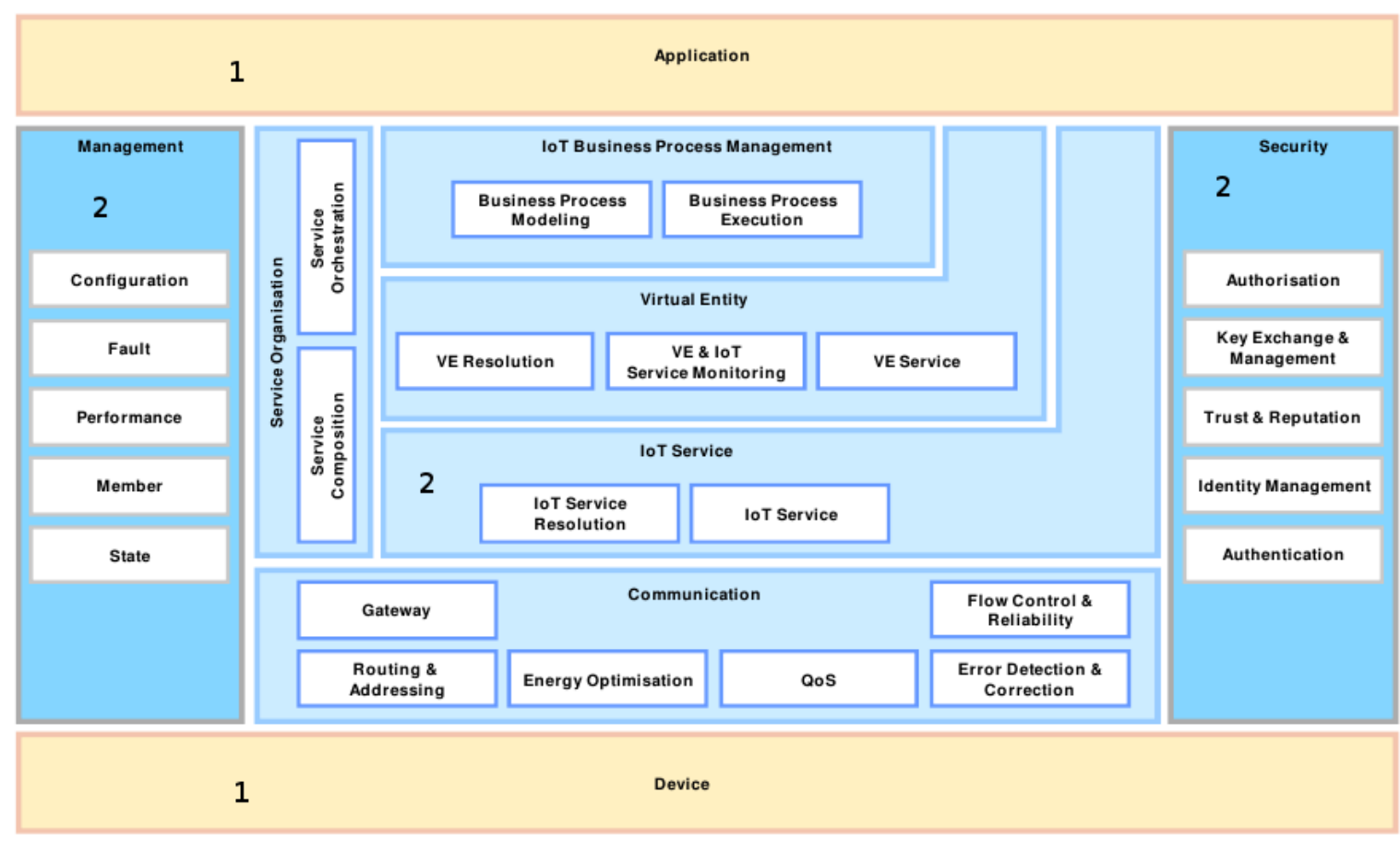

Fonte: Adaptada de (JOACHIM; WALEWSKI, 2012).

Conforme se observa na Figura 9, o diagrama funcional exibe 9 grupos funcionais do Modelo Funcional:

- Grupos funcionais de Aplicação e de Dispositivos: que estão fora do escopo da Arquitetura de Referência de IoT e estão coloridos em laranja e marcados com o número 1.

- Grupos funcionais de Gerenciamento e de Segurança: são grupos de funcionalidades transversais e estão coloridos em azul e marcados com o número 2.

Observa-se que, para cada grupo funcional há componentes funcionais especificados. 


\subsubsection{Visão de informação}

Uma das principais propostas de conexões e objetos inteligentes em IoT é a troca de informações entre cada objeto com os sistemas externos. Sendo assim, a maneira como definir, estruturar, armazenar, processar, gerenciar e trocar as informações é de extrema importância. A visão de informação provê uma visão geral sobre estruturas de informações estáticas e fluxos de informações dinâmicos.

Baseado no Modelo de Informação de IoT, essa visão deve detalhar como as informações relevantes devem ser representadas em um sistema de IoT. A descrição da arquitetura proposta em Joachim e Walewski (2012), se opõe às arquiteturas de sistemas específicos, várias alternativas são discutidas dentro do modelo de informação. O modelo descreve componentes que manipulam informações, fluxos e o seu ciclo de vida nos sistemas de IoT.

O foco da Visão de Informação são as descrições, a manipulação e o ciclo de vida das informações, mas ela fornece também detalhes sobre o fluxo de informação entre os sistemas e componentes envolvidos.

\subsubsection{Visão de desenvolvimento e operação}

A visão de desenvolvimento e operação tem por objetivo prover, aos usuários do modelo de referência IoT-A, um conjunto de manuais, de modo a guiá-los entre os diferentes projetos e escolhas. Para isso, essa visão discute, a partir de descrições de serviços e identificações de diferentes elementos funcionais, a seleção de inúmeras tecnologias disponíveis em IoT para a construção e desenvolvimento de aplicações (JOACHIM; WALEWSKI, 2012).

A Figura 10 ilustra as categorias criadas sob a perspectiva de desenvolvimento para IoT.

Foram identificadas as categorias que têm impacto no desenvolvimento e realização de sistemas de IoT. Iniciando pelo modelo de domínio, são definidos três grupos principais de elementos: dispositivos, recursos e serviços, destacados respectivamente com os números 1 , 2 e 3. Cada um dos grupos aborda diferentes problemas de desenvolvimento e se reflete em capacidades operacionais do sistema.

Os pontos de vista usados no desenvolvimento e operação são:

1. O diagrama do modelo de domínio é usado como um guia para descrever domínios de aplicação específicos. A extensão de diagramas UML pode ser usada para detalhar a interação entre os vários elementos que irão compor a aplicação.

2. O Modelo Funcional é usado como uma referência para a definição do sistema. Ele define grupos funcionais como serviços de IoT e conectividade, que são fundamentais 
Figura 10 - Categorias que impactam no desenvolvimento para IoT.

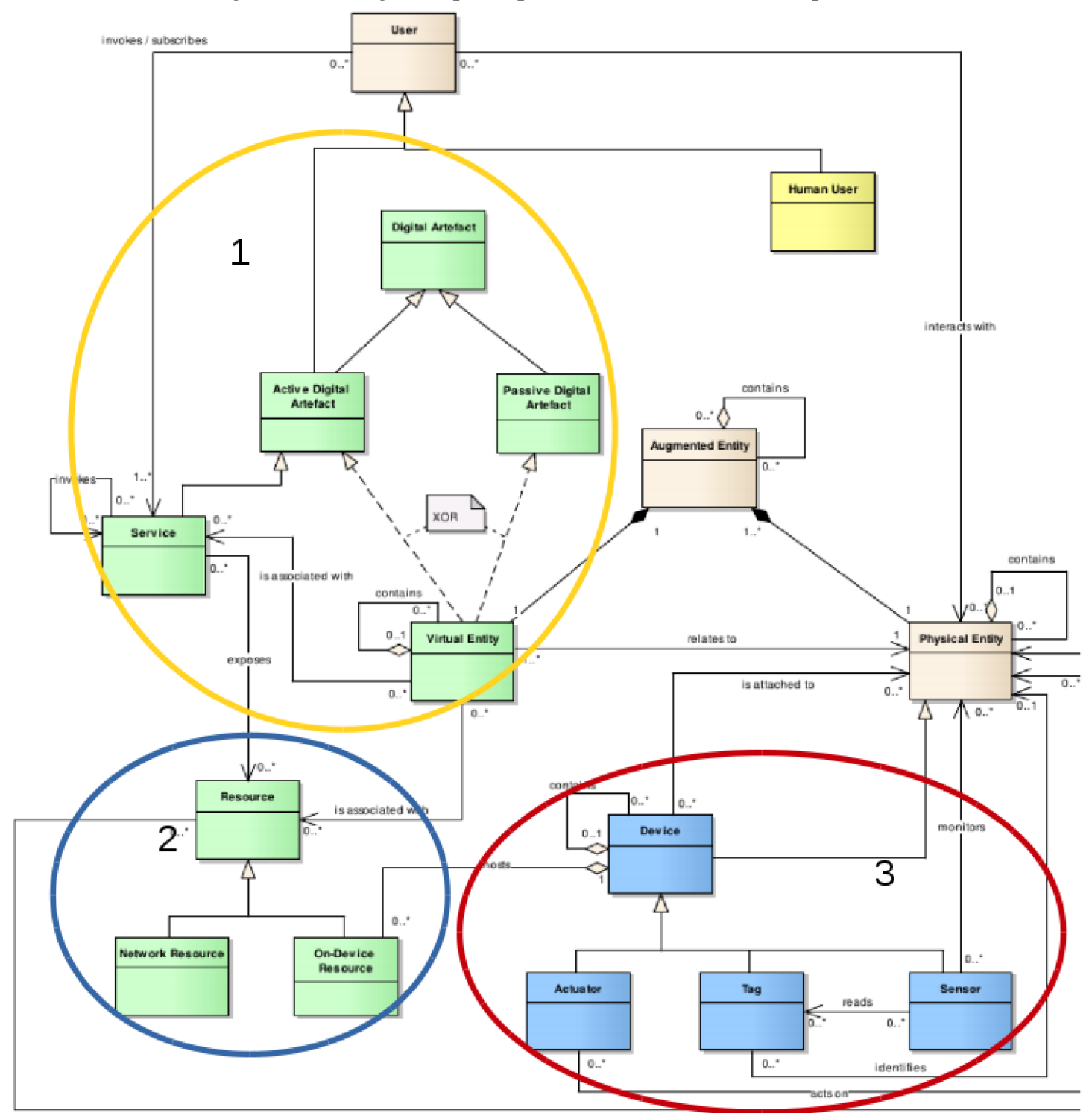

Fonte: (JOACHIM; WALEWSKI, 2012).

para a correta definição do sistema.

3. Os diagramas de conectividade de rede podem ser usados para planejar a topologia de conectividade, de modo a implementar as capacidades de redes desejadas pelo objetivo de aplicação. No nível de desenvolvimento, o diagrama de conectividade pode ser usado para definir hierarquias e os tipos de sub-redes que comporão o sistema completo de rede de comunicação.

4. Descrições dos dispositivos, como especificações técnicas e manuais de usuário, podem ser usados como um mapeamento de hardware, serviços e recursos sobre os requisitos de sistema. Os dispositivos em requisitos de sistemas de IoT incluem todo espectro de tecnologias, que vão desde simples tarjas de radiofrequência até especificações de 
servidores. Essas unificações de características principais são duas: (i) cada dispositivo é conectado com um outro formando uma parte da IoT; e, (ii) cada dispositivo é "inteligente", cada um possui um grau de complexidade, e isso é provido por capacidades computacionais. Essas duas características são as primeiras escolhas que o projetista deve fazer. Um dado dispositivo será completamente interoperável em um sistema de IoT se ele respeitar as definições do Modelo Funcional. Sendo assim, para sistemas legados que não são completamente suportados pelo modelo funcional, poderão ser implementados pacotes ou adaptações de software para a compatibilidade com modelo. A seleção da complexidade computacional para um dado dispositivo é intrinseca ao objetivo de aplicação. Desse modo, escolher entre diferentes tipos de conectividade não é escolher comparando apenas vantagens, mas também em diferentes áreas. É possível criar diferentes sistemas implementando as mesmas aplicações ou similares a partir da visão funcional e que sejam extremamente diferentes a partir da visão de desenvolvimento e operação.

Sob o ponto de vista de escolhas de implementação é importante discutir os seguintes aspectos de conectividade:

1. Redes de sensores e atuadores.

2. RFIDs e tarjas inteligentes.

3. Wi-Fi ou outras tecnologias.

4. Redes de equipamentos móveis.

Como uma consequência da coexistência de diferentes tecnologias de comunicação em um mesmo sistema, a segunda escolha de um projetista de sistema está relacionada a protocolos de comunicação. As funcionalidades de conectividade nos sistemas de IoT são definidas no documento de Grupos de Funcionalidades de Comunicação no Modelo Funcional. São identificadas as seguintes possibilidades:

1. Suíte de protocolos de IoT: essa é a principal alternativa suportada por um projeto e provê a melhor solução para interoperabilidade.

2. Soluções proprietárias $A d$-hoc: sempre que requisitos de desempenho sejam mais importantes que a versatilidade do sistema, soluções $A d$-hoc são um bom caminho.

3. Outros padrões: dependendo do objetivo do domínio de aplicação ou regulamentações, o projetista deverá adotar soluções a partir de sugestões da suite de protocolos de IoT ou soluções adotadas em projetos anteriores. 
Depois de selecionar os dispositivos e os métodos de comunicação, o projetista deve definir os recursos e serviços. Essas são as peças de software que vão desde uma simples aplicação binária aumentando sua complexidade até se chegar, por exemplo, em um complexo software de controle. O ponto principal é escolher onde implantar o software relacionado a um determinado dispositivo. As opções são:

1. Nos objetos inteligentes: essa escolha se aplica à definição de recursos e serviços simples, como um web-service que pode ser realizado com poucas dezenas ou centenas de bytes.

2. Nos gateways: sempre que um dispositivo não puder executar funções necessárias, os gateways ou outros dispositivos com maior capacidade poderão suprir essa necessidade.

3. Na nuvem: os softwares poderão ser implantados na nuvem. Essa solução provê maior disponibilidade para os serviços, mas poderá reduzir o desempenho, em termos de latência e fluxo de dados.

Essas escolhas podem ser feitas dependendo do tipo de dispositivo e serviço.

É importante também selecionar o tipo de tecnologia para coleta de informação pelo sistema, se as informações são unicamente providas por sensores, ou também por usuários. Nesse caso, o projetista deverá levar em consideração se são dados ou informações sensíveis (por exemplo, se a segurança é provida pelo dispositivo ou por um Framework), qual é o grau de disponibilidade, redundância e resiliência. Algumas das opções são:

1. Somente local: os dados são armazenados somente em dispositivos que provêm serviços. Nesse caso o sistema não necessita da complexidade de bases distribuídas, mas dependendo da localização de uma requisição a resposta poderá demorar e em alguns casos até se perder.

2. Somente na Web: não são mantidas cópias nos dispositivos locais. Os dados são enviados para um agregador e esses são despachados para bancos de dados.

3. Armazenamento local e em caches na Web: uma estrutura hierárquica para o armazenamento dos dados é mantida a partir de dispositivos e de servidores.

Uma das características principais de sistemas para IoT é a resolução de serviços e entidades, que são providas por capacidades funcionais. Essa é uma considerável carga de requisições semânticas de recursos e serviços, descoberta de novos elementos, ligações entre usuários e dados e recursos e serviços. Em particular, isso pode ser implementado a partir da utilização de definições de entidades virtuais. Há duas escolhas para o projetista: 
1. Desenvolvimento interno: a parte principal é instalada em servidores ao longo do sistema e esses são dedicados à aplicação ou compartilhados entre diferentes aplicações do mesmo provedor.

2. Desenvolvimento externo: a parte principal é provida por uma terceira parte, o projetista tem um conjunto de Application Program Interface (API) para o desenvolvimento.

Diferentemente de outras escolhas, essa está associada ao custo de manutenção da parte principal do software. De fato, isto pode ser um componente crítico do sistema, como requisitos de segurança, disponibilidade e robustez, mas para empresas menores as soluções externas podem ser mais viáveis.

\subsection{MIDDLEWARE DE INTERNET DAS COISAS}

Segundo Kjaer (2005), existem diversos Middlewares de software, cuja definição é um sistema de software que provê uma camada de abstração entre o sistema operacional e as aplicações em execução, para o desenvolvimento de aplicações no contexto de computação pervasiva, cujo foco é prover uma suite abstraída e usual para a heterogeneidade de dispositivos e contextos de informação.

Em Kjaer (2005), Bandyopadhyay et al. (2011)b e Bandyopadhyay et al. (2011)a é sugerida uma taxonomia que classifica os diversos contextware middlewares de acordo com suas características. Alguns middlewares, representativos do estado da arte, que suportam computação pervasiva e móvel baseada em contexto de informação são:

1. ISMB (SIMONOV, 2010).

2. Advanced Sensors and lightweight Programmable middleware for Innovative Rfid Enterprise applications (ASPIRE) (GRANELLI et al., 2009).

3. Smart Semantic Middleware for Ubiquitous Computing (UBIWARE) (KATASONOV et al., 2008).

4. UBISOAP (CAPORUSCIO; RAVERDY; ISSARNY, 2012).

5. UBIROAD (TERZIYAN; KAYKOVA; ZHOVTOBRYUKH, 2010).

6. Global Sensor Network (GSN) (SALEHI, 2010).

7. Secure Middleware For Embedded P2P (SMEPP) (ALBANO et al., 2007).

8. SOCRADES (CANNATA; GEROSA; TAISCH, 2008). 
9. Service Infrastructure for Real-time Embedded Networked Devices (SIRENA) (BOHN; BOBEK; GOLATOWSKI, 2006).

10. WHEREX (PULIAFITO et al., 2010).

\section{Ubidots (UBIDOTS, 2014).}

Os middlewares proveem diferentes métodos de adaptação, coleta e mudanças de contexto, embora possuam diferentes objetivos.

Além dos middlwares citados, destaca-se o projeto Network Embeded System Middleware Heterogeneous Physical Devices in a Distribued Architecture (HYDRA) desenvolvido no âmbito do Sixth Research Framework Programme (FP6) (PEREIRA; EISENHAUER, 2011) e que será descrito na Seção 2.3.1.

\subsubsection{Projeto Hydra}

O primeiro objetivo do projeto Hydra foi desenvolver um middleware de software baseado em Service-oriented Architecture (SOA), no qual a comunicação entre as camadas inferiores ocorre de forma transparente (PEREIRA; EISENHAUER, 2011).

O framework suporta arquiteturas distribuídas ou centralizadas, segurança e confiança e modelos de desenvolvimento de aplicações baseados em model-driven. O desenvolvimento do framework teve como premissa a aplicabilidade nas redes atuais e também nos novos modelos de rede, com dispositivos interconectados, que dispõem recursos computacionais, energia e capacidade de memória reduzidos.

Os sistemas embarcados e a arquitetura orientada a serviço móvel permitem a interoperabilidade de acesso a dados, informações ou conhecimento entre plataformas heterogêneas, incluindo serviços web e suporte a ambientes inteligentes para redes de dispositivos ubíquos.

O segundo objetivo do projeto Hydra foi desenvolver um Software Development Kit (SDK) que é usado para o desenvolvimento de novas aplicações e de códigos que possam ser executados em novos dispositivos.

Em Sarnovsky et al. (2008), são elencados dois tipos diferentes de usuários, desenvolvedores e usuários finais. Uma das primeiras tarefas do projeto HYDRA foi criar cenários que permitissem observar o comportamento de usuários finais e interação com as funcionalidades da plataforma em três diferentes domínios: automação, aplicação médica e agricultura. Esses cenários provêm coerência, compreensão e descrições consistentes e plausíveis sobre as possíveis interações entre as principais funcionalidades imaginadas.

O objeto resultante desse projeto foi o chamado LinkSmart middleware, nome que será utilizado para se referir ao middleware de software desenvolvido deste ponto em diante. 
A estrutura funcional do modelo proposto pelo projeto HYDRA é dividida em duas partes: elementos de aplicação e elementos de dispositivos. Esses elementos diferem nos seguintes aspectos:

1. Poder computacional.

2. Propósito do componente.

3. Usuário desenvolvedor.

Os elementos de aplicação descrevem componentes que serão desenvolvidos para hardware com maior capacidade de processamento e energia. Esses elementos estarão ligados a aplicações específicas que compõem os sistemas de automação.

Os elementos de dispositivos descrevem componentes desenvolvidos baseados no LinkSmart middleware e serão executados em pequenos dispositivos que possuem recursos e energia limitados (SARNOVSKY et al., 2008).

A Figura 11 ilustra a estrutura em camadas do LinkSmart middleware.

Na Figura 11, os elementos do LinkSmart middleware estão entre as camadas sistema operacional e de aplicação, exibidos no diagrama. A camada física está relacionada à comunicação de rede, enquanto a camada de aplicação contém módulos relacionados ao gerenciamento do fluxo de informação, interface com o usuário, lógica da aplicação e detalhes de configuração. Entre as duas camadas, encontra-se o LinkSmart middleware, composto por três sub-camadas, de rede, de serviço e semântica (SARNOVSKY et al., 2008).

O LinkSmart baseia-se na arquitetura Open Services Gateway Initiative (OSGI) (BAKKER; ERTMAN, 2013), ou seja, disponibiliza seus serviços nesta especificação e, todo e qualquer cliente que venha a se conectar deverá implementar um WebSerivce Client na especificação AXIS (JAYASINGHE; AZEEZ, 2011). A Figura 12 ilustra a arquitetura base para o desenvolvimento de aplicações ou serviços baseando-se no LinkSmart.

Na Figura 12 se vê uma camada inferior que representa a camada física, que deve implementar ou ter um Gateway como cliente WebService com a especificação OSGI/AXIS para inserir dados no LinkSmart. Na camada central se encontra o LinkSmart Middeware que provê alguns serviços do modelo e, na camada superior, a aplicação que também deve implementar ou possuir um Gateway como cliente WebSerivce na especificação OSGI/AXIS.

Os serviços implementados pelo LinkSmart (LANG, 2015) mais relevantes para esta pesquisa são:

- NetworkManager: provê maneiras de registro de clientes ou serviços e busca de serviços dentro do LinkSmart. Ele pode ser usado para comunicação entre dois nós de LinkSmart, para o envio de mensagens e abstração dos métodos de comunicação e rede. 
Figura 11 - Estrutura em camadas do LinkSmart middleware.

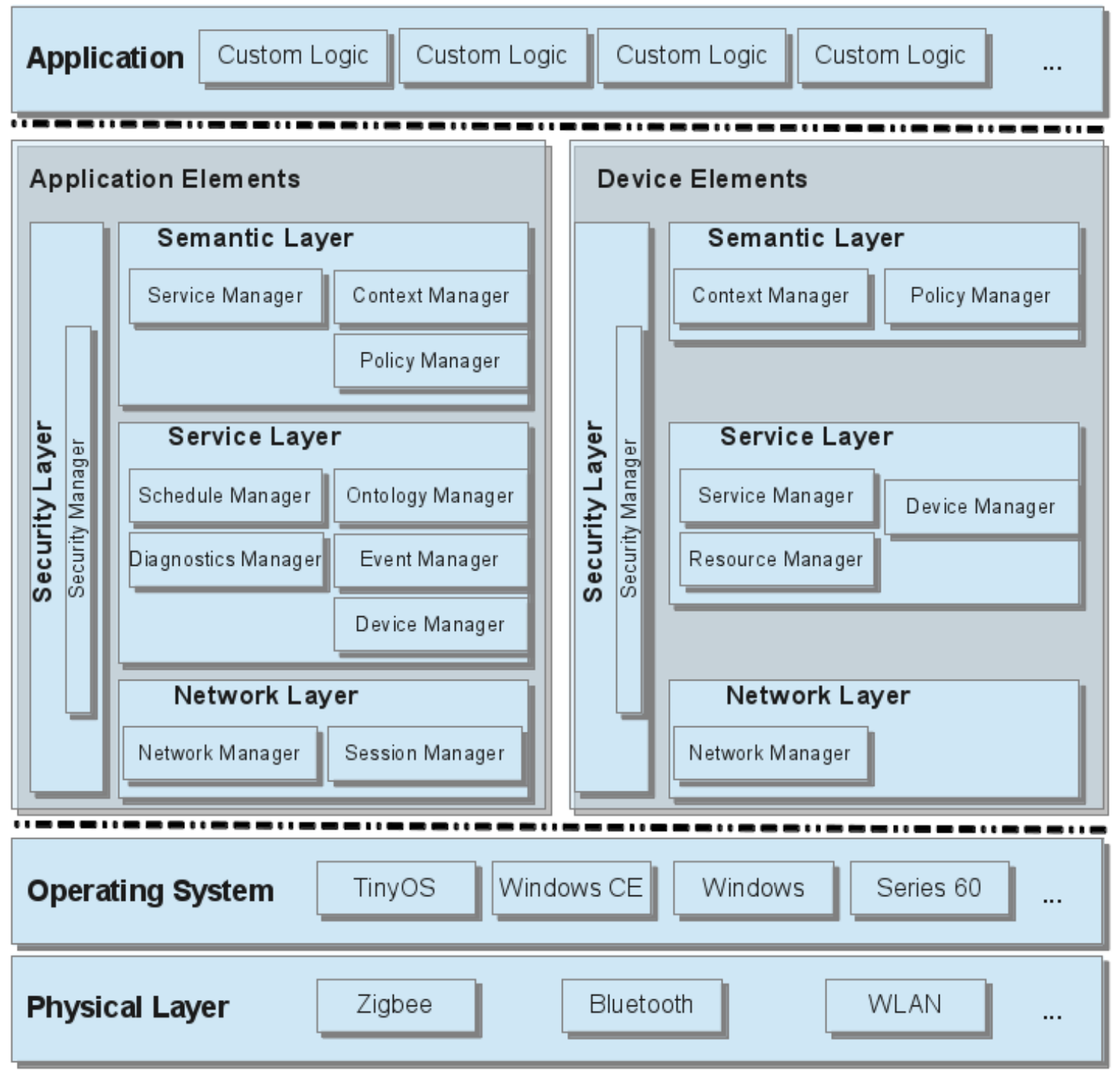

Fonte: Adaptada de (SARNOVSKY et al., 2008).

- SecuritiryManager: provê serviços para operações com criptografia, gerenciamento de chaves e certificados de segurança e conexão confiável ao Middeware.

- EventManager: esse serviço implementa o padrão de projetos Observer (GAMMA et al., 2006), ou seja, implementa uma arquitetura de barramento com publish-subscriber. Esse serviço provê a escalabilidade para um sensor, onde, uma única leitura proveniente de sensor com baixo ou nenhum poder computacional pode ser lida ou requisitada por uma quantidade escalável de clientes, através do barramento implementado por ele.

Cabe destacar a modularização e independência entre os serviços implementados pelo LinkSmart, pois se baseia na arquitetura OSGI. 
Figura 12 - Arquitetura ilustrativa para o desenvolvimento de serviços e aplicações baseadas no LinkSmart.

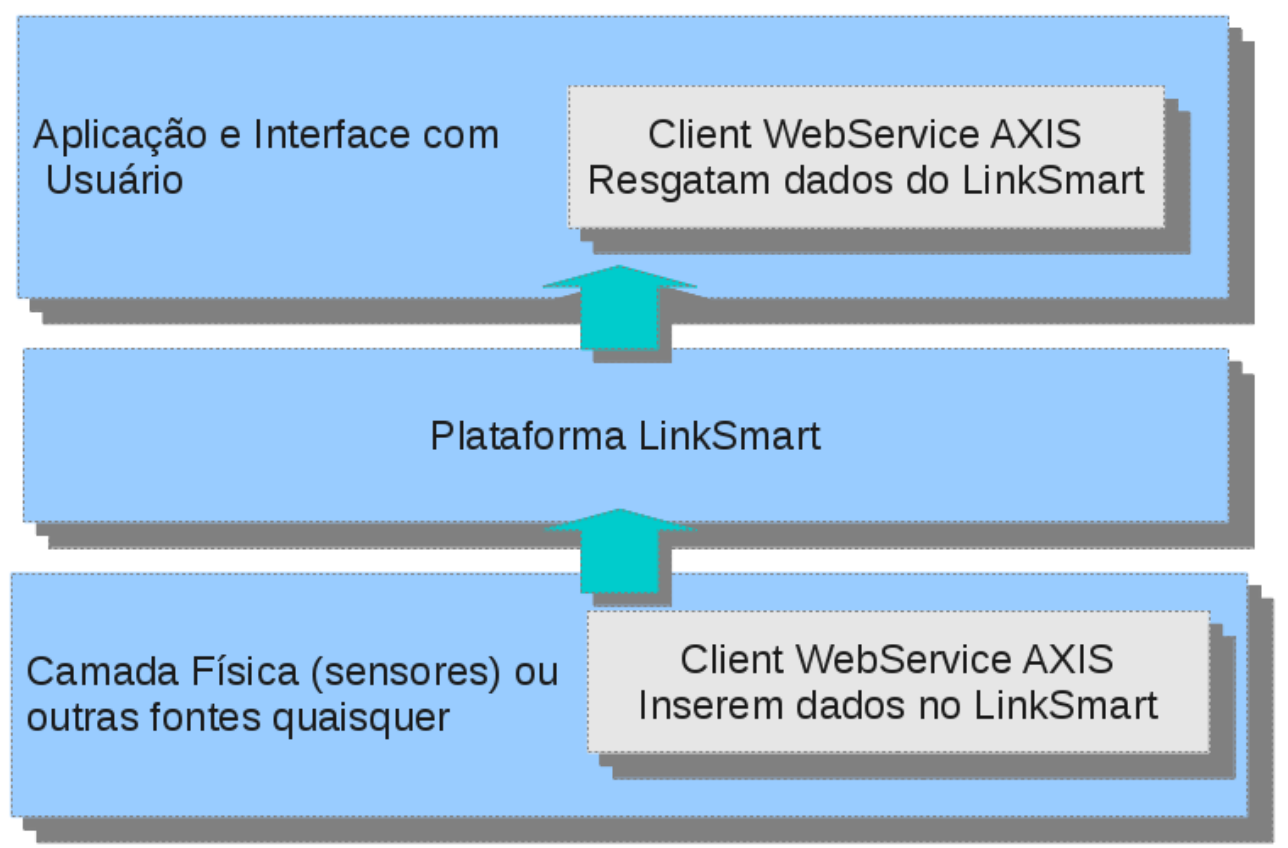

Fonte: Elaborada pelo autor.

\subsubsection{Projeto Ubidots}

O projeto Ubidots é proveniente de uma startup promovida pelo alumni of MassChallenge Accelerator 13 (Boston, MA) (UBIDOTS, 2014). Seu objetivo é prover um Framework para auxílio no desenvolvimento de aplicações para a captura de dados do mundo real e sua disponibilização para aplicações reais.

Desenvolvedores podem utilizar a API Ubidots para conectar dispositivos à plataforma e ter seus dados disponíveis na $W E B$ para visualização em tempo real. Alguns conceitos importantes no contexto de desenvolvimento de aplicativos com Ubidots são (UBIDOTS, 2014):

- Data Source: trata-se de um dispositivo conectado à plataforma. Um Data Source pode conter uma ou mais variáveis, cada uma contendo valores em uma série temporal, por exemplo, uma série temporal com valores de temperatura e luminosidade.

- Variável: é uma série de valores resgatados ao longo do tempo, por exemplo, série temporal da temperatura de uma sala.

- Valor: é uma medida da variável em um dado ponto no tempo, por exemplo, o valor de 25 graus celsius de uma sala às 15:35.

- Evento: é uma condição definida que desencadeará uma ação por parte da plataforma, por exemplo, sempre que a temperatura da sala atingir 30 graus celsius a plataforma 
enviará uma mensagem de Short Message Service (SMS) pelo serviço de telefonia, de modo a alertar dada a medição.

- Widget: são visualizações customizadas dos dados no portal da plataforma Ubidots, por exemplo, um gráfico personalizado com a variação da temperatura da sala nas últimas horas.

A Figura 13 ilustra o fluxo de dados com a plataforma Ubidots.

Figura 13 - Fluxo de dados com a plataforma Ubidots (UBIDOTS, 2014).

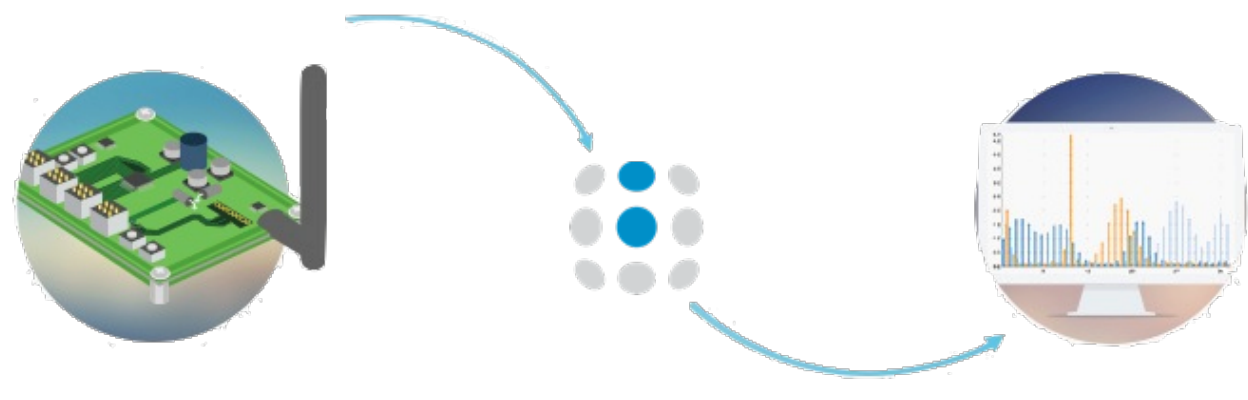

Fonte: (UBIDOTS, 2014).

O sensor ou o gateway envia os dados para a plataforma, que por sua vez, pode disparar uma ação, exibir a série de dados num Widget ou disponibilizar os dados para uma aplicação cliente qualquer.

Através do portal da plataforma pode-se criar eventos ao selecionar uma variável e comparar com um dado valor, com os operadores $>,>=,<,<=,=$, por exemplo, criar um evento sempre que a temperatura for maior ou igual a 30. Os eventos podem disparar um acesso à $U R L$, envio de $S M S$, envio de email ou inserção de valor em outra variável.

Os widgets podem ser criados através do portal escolhendo o tipo de gráfico e selecionando as variáveis que se deseja. Os tipos de widgets que podem ser selecionandos na plataforma são: lista ou tabela de valores, gráfico de linha com uma ou mais variáveis, exibir o último valor da variável, gráfico de dispersão com uma ou mais variáveis, exibição de ponto no mapa, caminho no mapa, indicador ou medição em escala.

Na Figura 14 são ilustrados dois widgets, à esquerda, que exibe a variável de temperatura em um indicador e à direita que exibe um gráfico de linha com duas variáveis, de temperatura e luminosidade ao longo do tempo.

A API permite cálculos de média, variância, valor mínimo, valor máximo, contagem de valores e soma de valores. Ela atende a requisitos de segurança como: autenticação baseada em tokens e tráfego de informações criptografadas através do Protocolo de Transferência de Hypertexto Seguro (HTTPs). 
Figura 14 - Widget criado na plataforma Ubidots.

\section{:?ubidots}

\section{Dashboard}

temperature (degress)

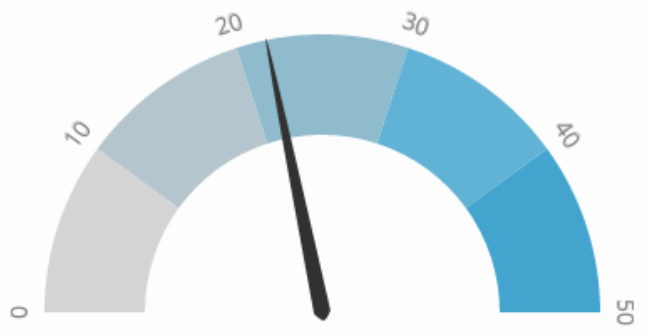

temperature (degress), light (lightnes

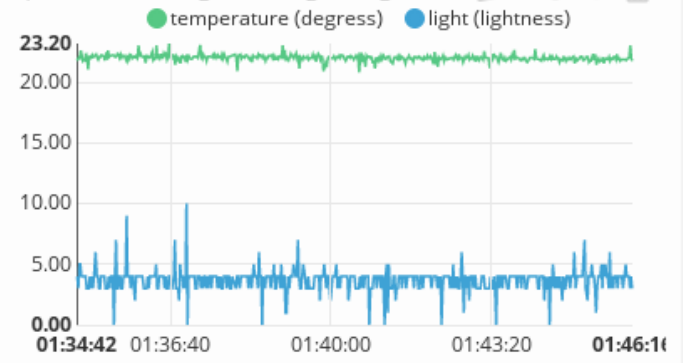

Fonte: Elaborada pelo autor.

\subsection{ANÁLISE E RECONHECIMENTO DE PADRÕES}

Minerar dados é o processo de descobrir informações relevantes como padrões, associações, mudanças, anomalias e estruturas, em grandes quantidades de dados armazenados em bancos de dados, depósitos de dados ou outros depósitos de informação. A mineração de dados fornece percepções dos dados, descobrindo padrões e relacionamentos ocultos em grandes bancos de dados e inferindo regras a partir deles, para prever comportamentos futuros (ZAKI; MEIRA, 2014).

O reconhecimento de padrões é uma disciplina da ciência que tem como objetivo classificar objetos em um número de categorias ou classes, conforme o observado em (THEODORIDIS; KOUTROUMBAS, 2008). Dependendo da aplicação, esses objetos podem ser, por exemplo, imagens, sinais de ondas de rádio, ou qualquer tipo de medida que se deseja classificar. Observa-se ainda que, com as técnicas de reconhecimento de padrões pode-se, por exemplo, estimar valores, selecionar atributos relevantes para classificação, reconhecer pontos fora da curva, chamados de outliers (DOUGHERTY, 2012).

Nas próximas seções serão descritas algumas técnicas de análise e reconhecimento de padrões que são relevantes para a implementação das soluções propostas, são as seguintes categorias: técnicas de regressão, técnicas de classificação (THEODORIDIS; KOUTROUMBAS, 2008) e detecção de outliers. As categorias serão descritas nas Seções 2.4.1, 2.4.2 e 2.4 .3 , respectivamente. 


\subsubsection{Técnica de regressão linear}

A predição numérica ou regressão é definida como uma técnica para se prever valores numéricos a partir de uma dada entrada, por exemplo uma situação industrial, onde se deseja prever a quantidade de metros cúbicos de água poluída por determinado componente na saída de água corrente em um processo químico, dado que esse valor está relacionado à temperatura de entrada da água. Observa-se, nesse caso, que a variável de quantidade é dependente da variável de temperatura. Nesse exemplo, as técnicas de regressão podem ser utilizadas para a predição dos valores (LARSON; FARBER, 2010) (NAVIDI, 2014).

Para se prever uma variável dependente a partir de uma outra independente usando a regressão linear, se faz necessário determinar a equação da reta de regressão que melhor modela os dados. A reta de regressão e sua equação podem ser usadas na predição do valor de $y$, para um dado valor de $x$ (LARSON; FARBER, 2010).

Uma reta de regressão, ou reta de ajuste ótimo, é aquela para a qual a soma dos quadrados dos resíduos é mínimo.

A equação de uma reta de regressão para uma variável independente $x$ e uma variável dependente $y$ é dada pela Eq.(1):

$$
\hat{y}=m x+b,
$$

onde, ý é o valor $y$ previsto para um valor $x$ dado, a inclinação $m$ é dada pela Eq.(2) e o intercepto $b$ é dado pela Eq.(3):

$$
\begin{gathered}
m=\frac{n \sum x y-\left(\sum x\right)\left(\sum y\right)}{n \sum x^{2}-\left(\sum x\right)^{2}} \\
b=\bar{y}-m \bar{x}=\frac{\sum y}{n}-m \frac{\sum x}{n},
\end{gathered}
$$

onde, $\bar{x}$ e $\bar{y}$ são as médias de valores nos conjuntos de dados $x$ e $y$. A reta de regressão passa sempre pelo ponto $(\bar{x}, \bar{y})$ (LARSON; FARBER, 2010).

A Tabela 1 exemplifica valores de temperatura de entrada de água e quantidade de metros cúbicos de água poluídos.

Para o exemplo ilustrado pela Tabela 1 observa-se, $n=8, \sum x=15,8, \sum y=1634$, $\sum x y=3289,9$ e $\sum x^{2}=32,44$. Estes valores podem ser utilizados para se calcular a inclinação $m$, aplicando-se a Eq.(2), e o intercepto $b$ da reta de regressão, aplicando-se a Eq.(3), conforme o ilustrado pelas Eq.(4) e Eq.(5) respectivamente:

$$
m=\frac{8(3289,8)-(15,8)(1634)}{8(32,44)-15,8^{2}}=\frac{501,2}{9,88} \approx 50,7287
$$


Tabela 1 - Tabela com exemplos de valores de temperatura de entrada e metros cúbicos de água poluída.

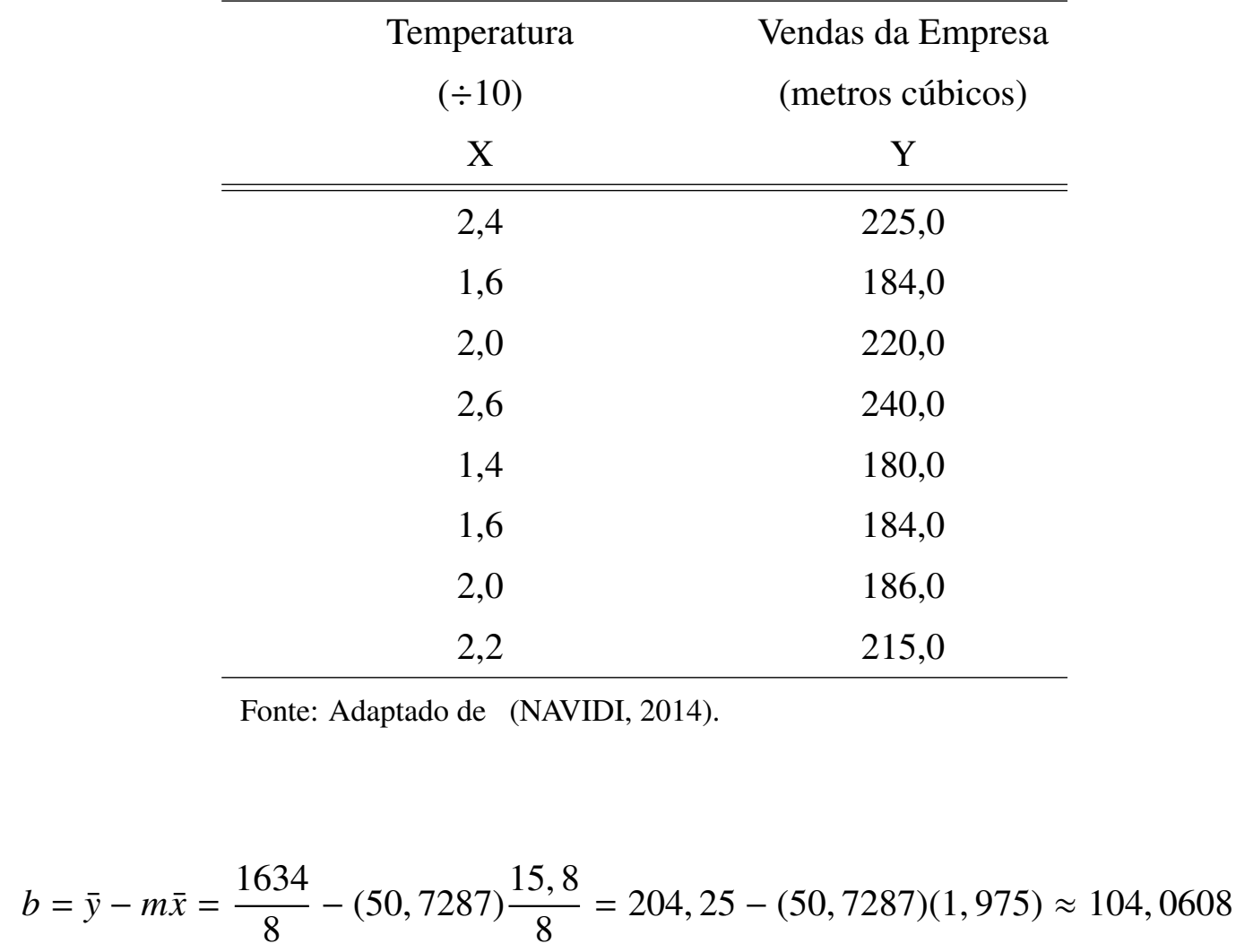

Portanto, a equação da reta de regressão para o exemplo citado é dada pela Eq.(6):

$$
\hat{y}=50,729 x+104,061
$$

Para esse exemplo, discutido em Larson e Farber (2010), se consegue prever qualquer valor de metros cúbicos de água poluídos, dado por $y$, dependente da temperatura de passagem da água, dada por $x$.

Em outros ambientes um melhor modelo de previsão para uma variável dependente pode ser obtido com a ajuda de mais de uma variável independente. Modelos que contêm mais de uma variável independente são modelos de regressão múltipla, dados pela Eq. (7) (TRIOLA, 2014):

$$
\hat{\mathrm{Y}}_{i}=\beta_{0}+\beta_{1} X_{i 1}+\beta_{2} X_{i 2}+\ldots+\beta_{p-1} X_{i, p-1}+\varepsilon_{i},
$$

onde, $\hat{\mathrm{Y}}_{i}$ é a resposta no i-ésimo ensaio, $\beta_{0}, \beta_{1}, \beta_{2}$ até $\beta_{p-1}$ são os parâmetros das variáveis preditoras, $X_{i 1}, X_{i 2}$ até $X_{i, p-1}$ são os valores das variáveis preditoras no i-ésimo ensaio e $\varepsilon_{i}$ é o valor do erro.

Os parâmetros $\beta_{n}$ são resultantes da função de minimização obtida através do método dos mínimos quadrados, de acordo com a definição dada pela Eq. (8) (TRIOLA, 2014):

$$
f=\sum_{i}^{n}\left(y_{i}-\beta_{0} X_{0 i}-\beta_{1} X_{1 i}-\ldots-\beta_{n} X_{n i}\right)^{2}
$$


Os valores de $\beta$ em forma de vetor são dados por:

$$
\vec{\beta}=\left(\beta_{0}, \beta_{1}, \beta_{2}, \beta_{i}\right)
$$

A predição dos valores de $y$ é deduzida pela Eq. (9):

$$
\hat{\mathrm{Y}}_{i}=\sum_{i} \beta_{j} X_{j i}=X_{i} \beta_{i}
$$

Conforme o observado em Larson e Farber (2010), após se ter obtido a equação da reta de regressão múltipla, ela poderá ser utilizada para prever valores de $y$ dentro do intervalo da variação dos dados, utilizando a Eq.(7) ou a Eq.(9).

\subsubsection{Técnicas de clustering}

Segundo Theodoridis e Koutroumbas (2008), as técnicas de classificação estão inseridas na área de reconhecimento de padrões, no qual se deseja classificar objetos em um determinado número de categorias ou classes.

Em Dougherty (2012) é citado que, para se dividir objetos em classes é necessário observar as características dos objetos, verificar quais características discriminam melhor as classes e a partir delas iniciar o processo de classificação.

Em Theodoridis e Koutroumbas (2008) e em Dougherty (2012) são encontradas diversas técnicas de classificação, como por exemplo, classificadores probabilísticos, classificadores baseados na teoria de decisão de Bayes, classificadores lineares baseados em funções de probabilidade, classificadores baseados em rede neurais, métodos estocásticos, classificadores polinomiais, dentre outros.

Para a criação de classificadores se deve incialmente passar por uma etapa de treinamento, na qual é criado um conjunto de treinamento, onde se conhece a quais classes essas instâncias de treinamento pertencem, para que seja possível, posteriormente, o classificador associar novas instâncias a essas classes inicialmente impostas a ele.

Em Theodoridis e Koutroumbas (2008) e em Dougherty (2012), são mencionadas técnicas de criação de classificadores ou de algoritmos de clustering onde não necessariamente existe essa etapa de treinamento.

Existem duas técnicas de implementação de classificadores, uma técnica chamada de aprendizado supervisionado, na qual inicialmente o classificador passa por uma etapa de aprendizado e seus resultados são confrontados diretamente com resultados reais. As diferenças obtidas entre os seus resultados e o resultado real servem para ajustar o classificador para que, em novas iterações desse treinamento os resultados sejam mais próximos do esperado. 
Outra técnica utilizada é o aprendizado não supervisionado, no qual não se faz necessária a pré-definição de classes. Nessa técnica os objetos são agrupados usando suas similaridades, por exemplo, como a medida da distância euclidiana, que mede a distância entre dois pontos.

\subsubsection{Algoritmo de clustering k-means}

O algoritmo de clustering k-means foi proposto incialmente por MacQueen (1967), e utiliza medidas de similaridade entre os objetos.

O algoritmo deve receber como parâmetro a quantidade de grupos ou clusters (desse ponto em diante optou-se por utilizar o termo em inglês) nos quais se deseja agrupar os objetos. $\mathrm{O}$ algoritmo escolhe aleatoriamente $N$ objetos, que tornam-se representantes de cada cluster, $\mathrm{e}$ são designados por centróides. A cada iteração, os outros objetos são alocados nos clusters, ou seja, o objeto é colocado no cluster do centróide mais próximo. A cada iteração, o algoritmo recalcula o centróide, usando a média das distâncias entre todos os integrantes do cluster. Quando não ocorrerem mais variações nos posicionamentos dos centróides, significa que o algoritmo convergiu. A Figura 15 ilustra o pseudo-código do algoritmo (DOUGHERTY, 2012).

\subsubsection{Algoritmo de clustering canopy}

A algoritmo de clustering Canopy é um método rápido para agrupamento de instâncias em clusters. Os objetos são representados como um ponto no espaço multidimensional, o algoritmo utiliza uma medida de distância e dois limiares $T 1>T 2$ para o processamento. Ele inicia com um conjunto de pontos e remove um ponto aleatoriamente, cria um canopy contendo esse ponto e percorre o restante do conjunto de pontos. Em cada ponto, se a distância do primeiro ponto é menor que T1, se adiciona o ponto ao cluster. Se, a distância também for menor que $\mathrm{T} 2$, em seguida, se remove o ponto do conjunto. $\mathrm{O}$ algoritmo continua a iteração até que o conjunto inicial esteja vazio, criando conjuntos com todos os objetos, cada um contendo um ou mais pontos. Um determinado ponto pode estar em mais de um Canopy (MCCALLUM; NIGAM; UNGAR, 2000).

Esse algoritmo é usado frequentemente como um passo inicial para outros algoritmos de clustering, como o K-Means (GIACOMELLI, 2013). 
Figura 15 - Pseudo-código do algoritmo k-means.

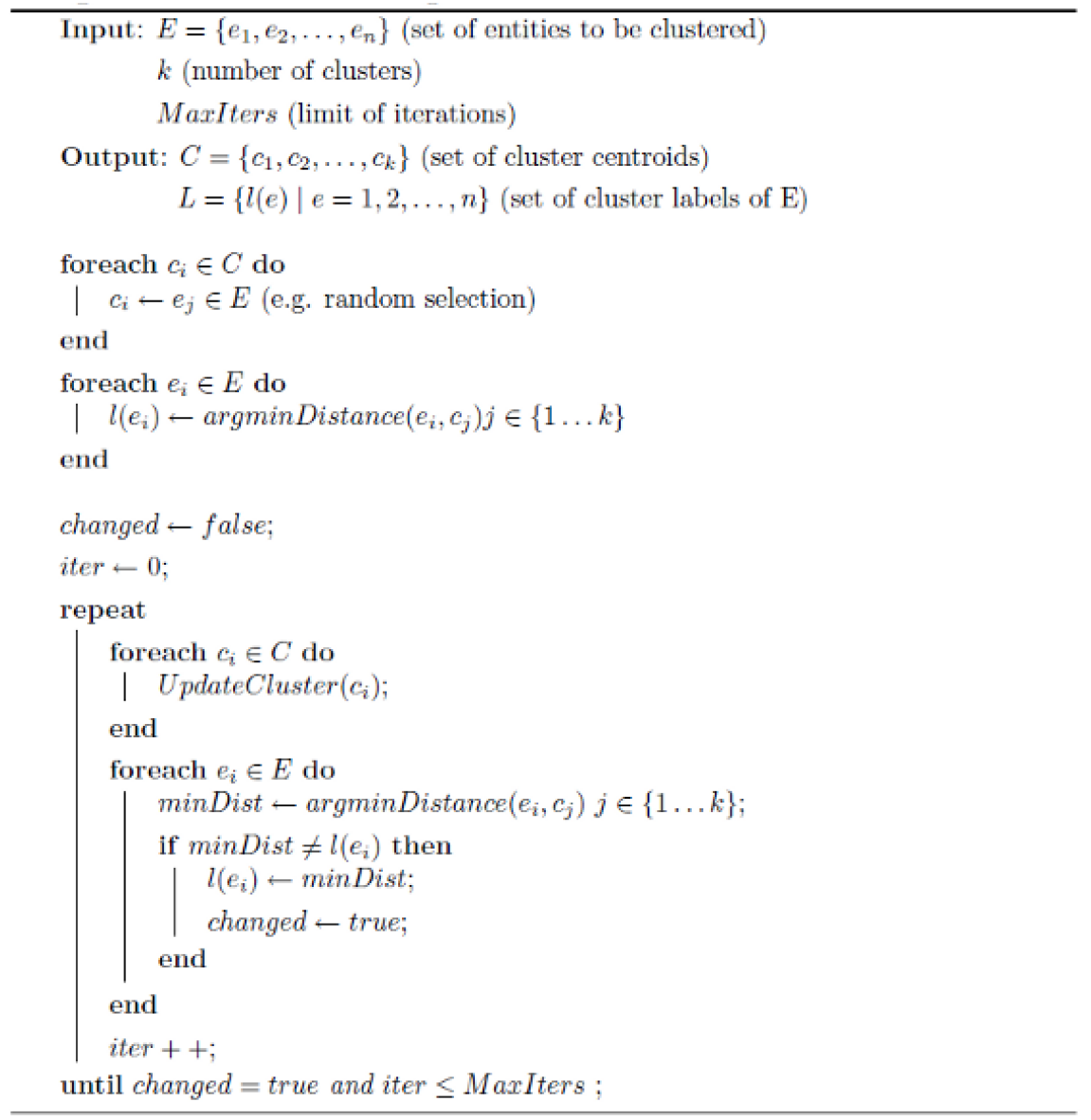

Fonte: (DOUGHERTY, 2012).

\subsubsection{Detecção de Outlier}

Segundo Zaki e Meira (2014) uma anomalia ou um outlier (desse ponto em diante será utilizado o termo outlier) ocorre quando uma instância ou conjunto de instâncias são consideradas diferentes do restante do conjunto de dados. A detecção de outliers tem importantes aplicações para detecção de fraudes em cartões de crédito, fraudes em sistemas de telecomunicações, detecção de falhas, redes de sensores, detecção de intrusos, detecção de spam em emails, diagnósticos médicos ou aplicações em marketing.

Há três tipos de técnicas elencadas na literatura para a detecção de outliers: técnicas baseadas em distância, baseadas em densidade ou baseadas em estatísticas (ZAKI; MEIRA, 2014). Dado o foco desta pesquisa, destaca-se a técnica baseada em distância, no qual uma dada instância é considerada um outlier caso uma fração, onde $p(0<p<1)$, de instâncias em uma base de dados estão fora do raio de uma vizinhança $O$. Caso esse limiar seja muito grande, pontos que deveriam ser considerados outliers não serão, e caso esse limiar seja muito pequeno, grande parte dos pontos serão considerados outlier erroneamente. Esta abordagem é relevante para a implementação e proposta de algoritmo que será descrita na 
Seção 3.4 .3 .

\subsection{TECNOLOGIA BIG DATA}

Mayer-Schonb e Cukier (2014) mencionam que Big Data refere-se a grandes conjuntos de dados que são difíceis de armazenar, pesquisar, visualizar e analisar como, por exemplo, uma empresa aérea que coleta 10 terabytes de dados de sensores durante 30 minutos de vôo do avião. Nathan e Warren (2015) mencionam que Big Data é usado comercialmente para se analisar grandes quantidades de dados para se tomar decisões, baseando-se na análise do comportamento e preferências do consumidor.

Segundo Smith (2012), Big Data refere-se ao processamento e análise de repositórios de dados extremamente grandes e que não seriam possíveis se processar ou analisar com as ferramentas convencionais de análise de dados. Big Data requer grande poder computacional para processar eficientemente grandes quantidades de dados em intervalos de tempos toleráveis. Essa tecnologia envolve Massive Parallel Processing Databases (MPP), grids de mineração de dados, sistemas de arquivos distribuídos, plataformas de computação em nuvem, redes de comunicação e sistemas de armazenamento escaláveis.

\subsubsection{Framework Hadoop}

Hadoop é o termo usado para se referir a uma família de projetos relacionados, que compõe a infraestrutura para computação distribuída e de larga escala de processamento, que usa o conceito de Big Data. De acordo com White (2015), Hadoop é a implementação para MapReduce e sistema de arquivos distribuído mais utilizado e conhecido.

O MapReduce é um modelo de processamento de dados distribuído e um ambiente de execução em clusters de larga escala. Esse modelo divide o processamento em mapas e o divide em fases, cada fase se baseia em um par de chave/valor usado como entrada e saída para o processo. O programador especifica duas funções, o mapa e as funções de redução, para serem usadas na implementação e execução específica (WHITE, 2015).

O projeto Hadoop possui o Hadoop Distributed File System (HDFS) que é um sistema de arquivos projetado para armazenar arquivos extremamente grandes com um padrão de fluxo de acesso, executar sob clusters de máquinas de comodities ou plataformas de hardware comuns (WHITE, 2015). O MapReduce e o HDFS possuem uma API para o desenvolvimento e o uso de suas funcionalidades.

Outro projeto relacionado ao Hadoop e importante para esta pesquisa é o Mahout, que é um projeto de código livre da fundação Apache que possui uma biblioteca de implementação 
de algoritmos para aprendizagem de máquina. De acordo com Giacomelli (2013), o objetivo do projeto Mahout é ser uma escolha de ferramenta para aprendizado por máquina para processamento de conjuntos de dados extremamente grandes, tanto para execução em clusters de instâncias de Hadoop ou em uma única máquina. O Mahout é uma ferramenta desenvolvida em linguagem de programação Java dentro do projeto de computação distribuída Hadoop.

O projeto Mahout possui implementações de algoritmos de classificação e clustering, como o algoritmo $K$-means que possui grande relevância para a implemetação proposta nesta pesquisa.

\subsection{TRATAMENTO DOS DADOS NO MODELO DE INTERNET DAS COISAS}

Esta seção tem por objetivo ilustrar o volume de dados gerados pela IoT, os mecanismos de gerenciamento de dados em IoT como, coleta e análise de dados, sensores virtuais e processamento de eventos complexos e caracterizar os tipos de dados presentes no modelo de IoT.

\subsubsection{Volume de dados gerados com a IoT}

A IoT envolve uma grande quantidade de nós interconectados que possuem diferentes tecnologias e padrões de comunicação. Observa-se que, nesse novo modelo de rede, existirá um grande número de nós produzindo, transmitindo e gravando dados, que serão processados, integrados, analisados, requisitados e consumidos, por outro grande conjunto de nós (JAMES et al., 2009) (JEFFERY, 2009), para os quais serão necessárias tecnologias de gerenciamento de dados específica (FAN; CHEN, 2010).

Bin, Yuan e Xiaoyi (2010) destacam que a utilização da IoT produzirá um grande volume de dados. Pode-se tomar como exemplo um processo de cadeia de suprimentos em um hipermercado, no qual, se a empresa adotar a tecnologia de RFID, no formato do Código Eletrônico de Produto (EPC) para identificação dos objetos e necessitar de informação de localização e sobre o tempo em que o objeto esteve à venda, serão necessários 18 bytes para armazenamento dos dados de um único objeto. Em um hipermercado, que possui em torno de 1.000.000 de produtos ou, nesse exemplo tarjas de RFID, serão gerados 18 Mega Bytes (MB) de dados por segundo e 1,16 Tera Bytes (TB) a cada dezoito horas, caso a frequência de evento de leitura dos dados seja a cada segundo.

Cooper (2009) menciona que os dados gerados a partir da IoT podem ser categorizados em alguns tipos básicos. São eles: 
1. endereços ou identificadores únicos dos objetos.

2. dados descritivos dos objetos.

3. dados posicionais ou da localização geográfica.

4. dados de ambiente.

5. dados de redes de sensores.

Esse grande volume de dados requer mecanismos para gerenciamento, análise e mineração de dados na IoT.

Em Bin, Yuan e Xiaoyi (2010) é proposto um modelo em camadas para mineração de dados em IoT. Esse modelo é ilustrado pela Figura 16.

Figura 16 - Modelo em camadas para a mineração de dados para a IoT.

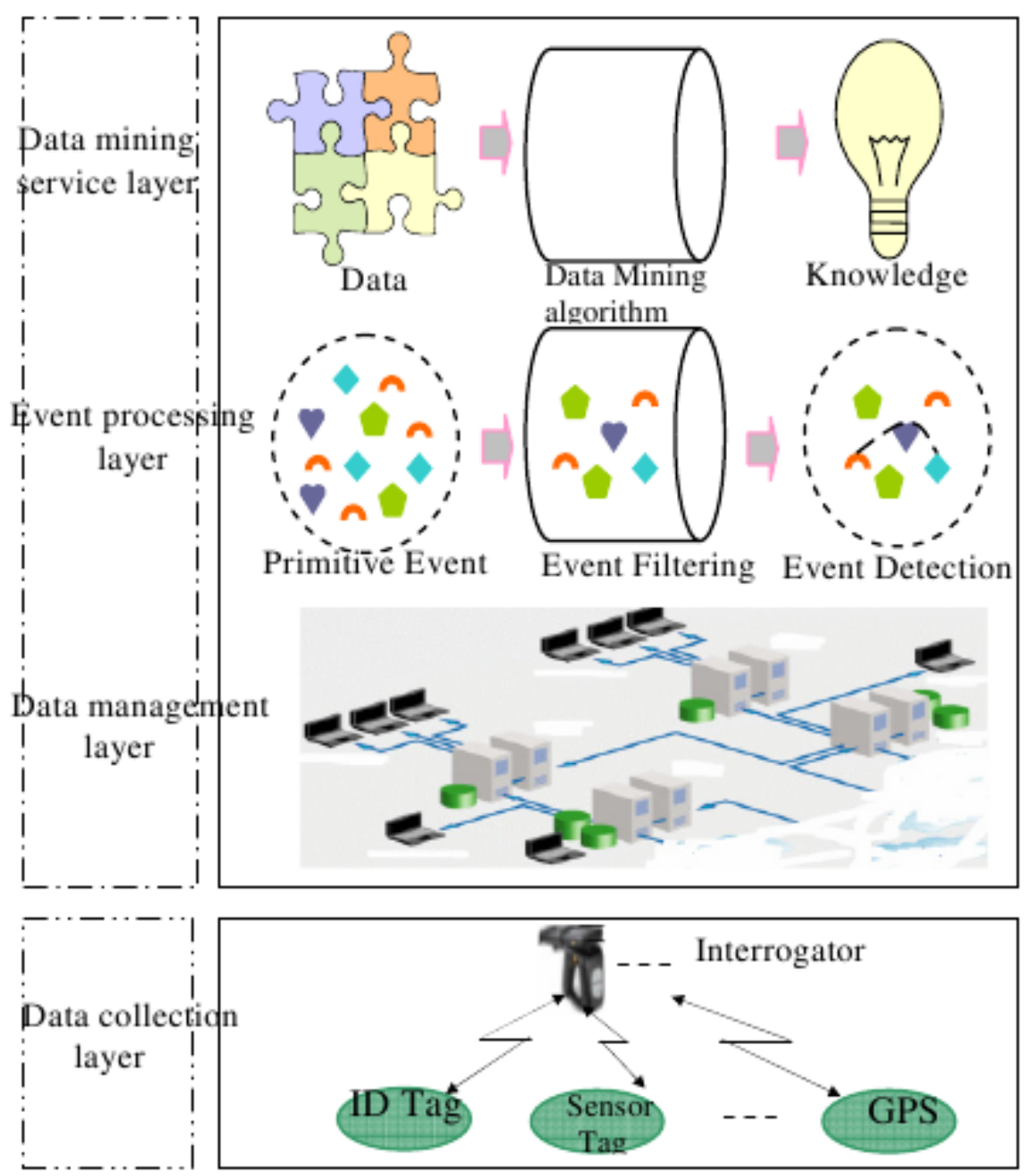

Fonte: (BIN; YUAN; XIAOYI, 2010).

O modelo mostrado na Figura 16 é composto pelas seguintes camadas: a camada inferior que captura os dados, a próxima camada que trata do gerenciamento desses dados, imediatamente após encontra-se uma camada que deve detectar e filtrar os inúmeros eventos que 
ocorram com os objetos e, por fim, a camada superior, que deverá prover serviços para a mineração dos dados capturados.

\subsubsection{Gerenciamento de dados em IoT}

Segundo Aggarwal, Ashish e Sheth (2013) o grande poder do paradigma da IoT está na habilidade de prover, em tempo real, dados sobre muitos e diferentes recursos para outras máquinas, entidades inteligentes ou pessoas, para uma variedade de serviços. Um dos maiores desafios reside em como tratar os dados oriundos de diferentes recursos, extremamente heterogêneos, que podem conter muitos ruídos, em grande escala e de forma distribuída.

Observou-se na Seção 1.2, que o gerenciamento de dados em IoT é importante para o seu desenvolvimento e pode ser dividido em alguns grupos principais de conceitos e tecnologias relevantes para essa pesquisa (SMITH, 2012), conforme a descrição a seguir.

\subsubsection{Coleta e análise de dados (DCA)}

A Coleta e Análise de Dados (DCA) são representadas por módulos ou componentes que devem possuir capacidades de armazenamento e troca de dados para análise ou processamento (SMITH, 2012). Devem ser capazes de prover:

- armazenamento de dados coletados por sensores.

- permitir que sejam adicionados novos sensores no modelo, de modo a acomodar as novas informações coletadas.

- prover API para acesso aos dados coletados.

- prover APIs para acesso em tempo real aos dados coletados, como por exemplo, mecanismos de gerenciamento de eventos (publish, subscribe, foward e notification).

- permitir a criação de regras ou filtros para os eventos.

- permitir ao usuário gerenciar e automatizar processos.

- permitir ao usuário criar seus fluxos de entradas de eventos vindos de um dispositivo.

- prover estruturas multitenant que suporte múltiplas organizações, diferentes tipos de dados, padrões e formatos, descentralização, de modo a permitir uma integração global entre arquiteturas de IoT, prover segurança e mecanismos de mineração de dados. 


\subsubsection{Sensores virtuais}

Um sensor virtual pode ser considerado um produto temporal, espacial ou temático que transforma um dado bruto, produzindo uma informação, ou seja, dados coletados, agregados ou processados a partir de um conjunto de sensores criam um valor para um sensor virtual. Da mesma forma, um atuador virtual pode ser um único ponto para a distribuição de comandos para um conjunto de atuadores (SMITH, 2012).

\subsubsection{Processamento de eventos complexos (CEP)}

O Processamento de Eventos Complexos (CEP) oferece uma coleção de eventos a partir de múltiplas origens, detectando padrões, filtrando, transformando, correlacionando e agregando em eventos complexos (FüLöP et al., 2012).

O processamento de eventos complexos possui relação com os sensores virtuais. Um sensor virtual pode ser usado para se implementar sensores únicos, a partir de eventos complexos e múltiplos sensores ou inúmeras origens de dados (SMITH, 2012).

Os conceitos referentes a $C E P$ podem ser classificados em duas categorias principais: (1) Computation oriented CEP, que tem foco em execução on-line de algoritmos como uma resposta à entrada de eventos no sistema; e (2) Detection oriented CEP, que tem como foco a detecção de combinações de eventos chamados de padrões ou situações (SMITH, 2012).

Em Etzion e Niblett (2010) são definidos alguns conceitos básicos a respeito de CEP. Um Agente de Processamento de Evento (EPA) é um componente que, dado um conjunto de eventos de entrada, se aplica uma lógica para gerar um conjunto de eventos complexos de saída. Uma Rede de Processamento de Eventos (EPN) é uma rede com uma coleção de EPAs, produtores de eventos e consumidores de eventos ligados a canais.

Em Wang, Cao e Zhang (2013) discute-se que as principais ideias da detecção de eventos complexos possuem quatro passos: (1) eventos primitivos que são extraídos de um grande volume de dados; (2) as correlações ou agregação de eventos são detectadas para se criar um evento de negócio com operadores de eventos de acordo com regras específicas; (3) primitivas ou composições de eventos são processadas para se extrair seu tempo, causa, hierarquia e outros relacionamentos semânticos; e (4) a resposta é enviada para o acionador de informações de negócio, de modo a garantir a entrega dos eventos aos seus observadores. 


\subsubsection{Tipos de dados em IoT}

Em James e Cooper (2009) são discutidos os diferentes tipos de dados que estão no contexto de IoT. Os dados oriundos da IoT podem ser discretos ou contínuos, gerados automaticamente ou através de alguma ação humana. Eles foram categorizados em algumas áreas, como se segue: RFID, identificação única ou endereço, dados descritivos, posicionais e dados ambientais, dados de sensores, modelos físicos e dados de comandos.

\subsection{CONSIDERAÇÕES FINAIS}

Neste capítulo foram descritas tecnologias e definições que são de extrema importância para a pesquisa. As características dos modelos de referência para IoT do ITU-T e do IoT-A, no qual pode-se destacar a especificação mais detalhada do modelo proposto pelo IoT-A. Foram elencados diversos middleware de software para IoT, dentre eles, destaca-se o LinkSmart Middeware, que é aderente à arquitetura IoT-A, adequado aos objetivos de desenvolvimento desta pesquisa. O Capítulo 3 apresenta uma análise crítica e comparativa ente o LinkSmart middeware e a plataforma Ubidots de modo a justificar a escolha.

Foram elencadas algumas técnicas de análise e reconhecimento de padrões que poderão servir como base para o desenvolvimento dos recursos que se pretende integrar à aquitetura de IoT.

Por fim, foram descritos alguns métodos de coleta e análise de dados existentes. A tecnologia de Big Data, comumente aplicada na camada de aplicação. Em especial, a técnica de processamento de eventos complexos, que poderá ser aplicada ao modelo de IoT, com o intuito de se agregar dados para nós ou aplicações que precisem utilizar dados em níveis mais altos.

Foge ao escopo desta pesquisa o desenvolvimento de técnicas de reconhecimento de padrões ou de Big Data, mas de propor a integração de técnicas conhecidas e validadas ao LinkSmart middeware para se ter um framework de desenvolvimento de aplicações e serviços de IoT poderoso, robusto e flexível. 


\section{NOVA ARQUITETURA PARA INTERNET DAS COISAS COM RECONHECIMENTO DE PADRÕES E BIG DATA}

Este capítulo descreve a solução proposta, mostra como a solução foi desenvolvida e detalha aspectos de implementação. As soluções são caracterizadas elencando os objetivos destacados na Seção 1.4 .

Este capítulo está organizado da segunte maneira: a Seção 3.1 ilustra a análise comparativa entre os modelos de referência para IoT descritos; a Seção 3.2 faz uma análise crítica entre os middlewares de IoT descritos na pesquisa; a Seção 3.3 descreve a solução proposta em nível arquitetural dos serviços propostos no modelo de IoT; a Seção 3.4 descreve aspectos técnicos da implementação da solução proposta; a Seção 3.5 descreve a técnica de sensores virtuais; e, por fim, a Seção 3.6 resume as considerações finais a respeito deste capítulo.

\subsection{ANÁLISE DE MODELOS DE REFERÊNCIA EM IOT}

Essa análise vai ao encontro do objetivo secundário 1, apresentado na Seção 1.4.

O modelo de referência do ITU-T possui a especificação em camadas e uma breve descrição das principais funcionalidades necessárias a um sistema de IoT.

O modelo de referência proposto pelo IoT-A define sub-modelos e a interação entre eles. Define uma arquitetura de referência que funciona como um modelo para a especificação, implementação e implantação de sistemas para IoT. As especificações partem dos requisitos e diagramas para a especificação do sistema e vai até a especificação de tecnologias para as camadas, como hardware, software, modelo de rede e comunicação dos dispositivos.

Ambos são modelos de referência, porém o modelo definido pelo IoT-A, parte do modelo de referência e chega até a arquitetura de referência, que guia o design do sistema de IoT.

A arquitetura implementada no Linksmart Middleware tem relação com a arquitetura proposta nos documentos que descrevem a arquitetura IoT-A (JOACHIM; WALEWSKI, 2012). $\mathrm{Na}$ especificação da arquitetura são mencionadas as camadas de implementação, no nível de comunicação, arquitetural e conceitual. O Channel Model for IoT Communication tem relação com os níveis de abstração dos dados ou informações que são passados para um próximo nó ou camada de nível de informação ou aplicação.

Esta pesquisa sugere estender o modelo IoT-A, para se estabelecer classes de dispositivos, que especifiquem capacidades de filtragem, de estimação de valores, detecção de outlier e análise de clustering, conforme os objetivos elencados, e destaca-se a importâcia de inserir a comunicação cross-layer na arquitetura IoT-A. É interessante adotar o modelo proposto pelo IoT-A nas especificações de futuras aplicações e pesquisas. 


\subsection{ANÁLISE CRÍTICA E COMPARATIVA ENTRE O LINKSMART MIDDLEWARE E PLATAFORMA UBIDOTS}

Esta seção compara as plataformas LinkSmart e Ubidots. A Tabela 2 mostra os atributos de cada uma das plataformas.

Tabela 2 - Tabela comparativa entre o LinkSmart Middleware e a plataforma Ubidots.

\begin{tabular}{|c|c|c|}
\hline Atributo & LinkSmart Middleware & Plataforma Ubidots \\
\hline \hline Nível de escalabilidade & Alto & Não conhecido \\
\hline Nível de modularização & $\begin{array}{c}\text { Alto tendo em vista } \\
\text { basear-se em (OSGI) }\end{array}$ & Não conhecido \\
\hline \hline $\begin{array}{c}\text { Estensão do framework/ } \\
\text { acesso ao código fonte }\end{array}$ & Código aberto & Código fechado \\
\hline \hline Nível de dificuldade para uso da API & Médio & Baixo \\
\hline \hline $\begin{array}{l}\text { Integração com outras } \\
\text { linguagens de programação }\end{array}$ & Java e WebServices & Python, Java, C, PHP, \\
\hline \hline Interface com dipositivos diversos & Sim LabVIEW \\
\hline \hline Segurança/Criptografia & Sim & Sim \\
\hline \hline Tempo de acesso/latência & Baixo & Sim \\
\hline \hline Instalação on-site \\
do framework
\end{tabular}

Fonte: Elaborada pelo autor.

Dentre os diversos atributos elencados, destacam-se a possibilidade de estensão, de criação de inúmeros tipos de variáveis ou instâncias, o nível de gerenciamento de eventos e dados e a modularização presentes no LinkSmart Middleware e que se mostram deficientes 
na plataforma Ubidots.

O fato da plataforma Ubidots não permitir a criação de instâncias, que contenha mais de um atributo em um objeto, obriga que a implementação de controle seja feita no gateway ou no dispositivo da camada física. Para criar esse controle o gateway deve enviar simultaneamente os vários atributos, porém, não há nenhuma ligação explícita entre eles, o que pode gerar inconsistências para a aplicação.

A Figura 17 ilustra a execução de uma aplicação experimental que utiliza a plataforma Ubidots.

Figura 17 - Aplicação de teste com a plataforma Ubidots.

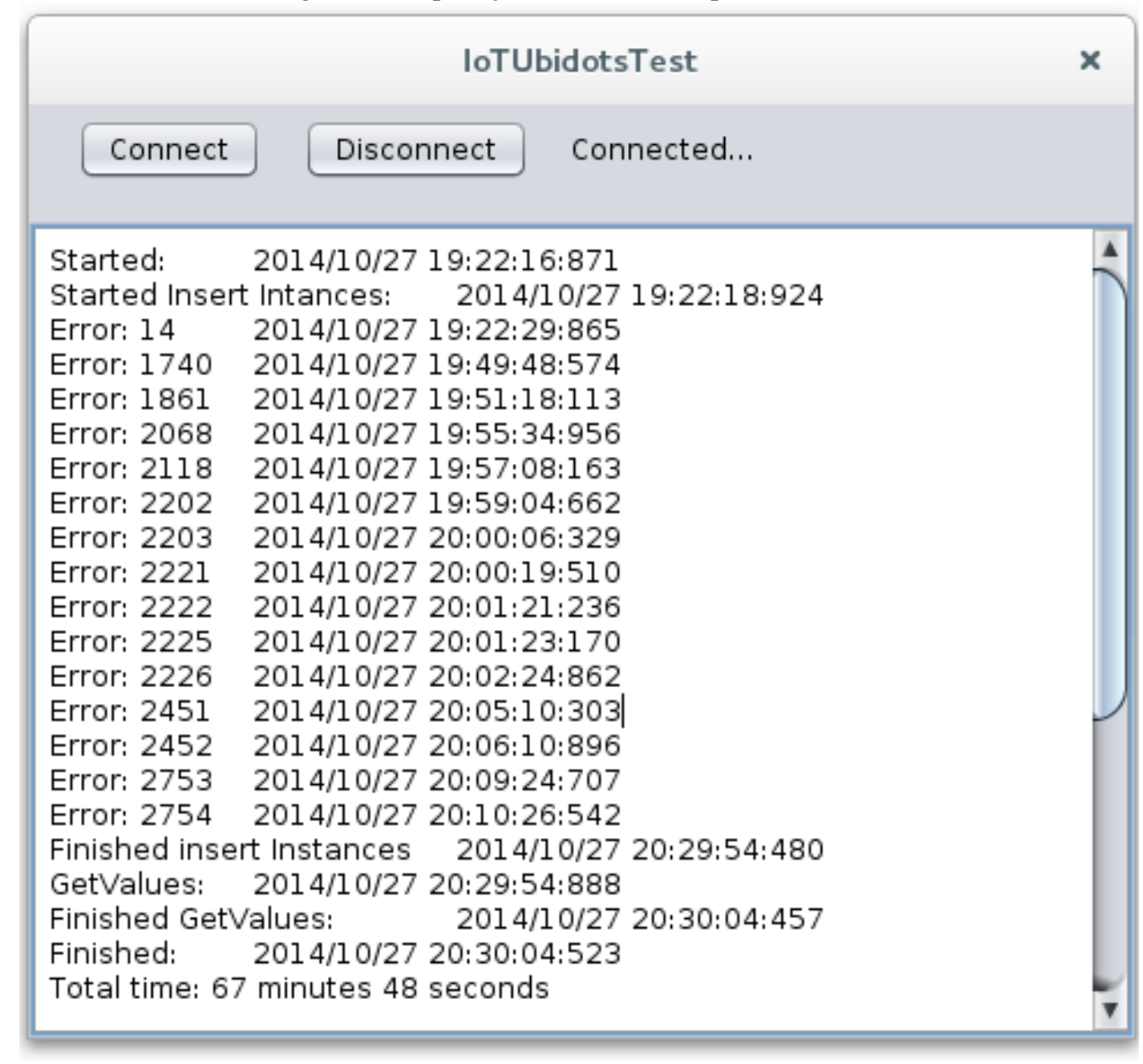

Fonte: Elaborada pelo autor.

A aplicação de teste inseriu 5000 instâncias, com três atributos: luminosidade, temperatura e horário da leitura como variável inteira. Cada atributo foi inserido individualmente, somando-se 15000 registros na plataforma Ubdots, que apresentou 15 erros ao inserir o conjunto total de instâncias. Através da API não é possível resgatar cada valor, somente o conjunto total com todos os registros. O tempo decorrido para a inserção dos registros foi de aproximadamente uma hora e seis minutos, para o resgate do conjunto completo o tempo decorrido foi de aproximadamente 7 segundos. O tempo total decorrido foi relativamente 
alto.

A Figura 18 ilustra a execução de uma aplicação experimental que utiliza LinkSmart middleware.

Figura 18 - Aplicação de teste com o LinkSmart middleware.

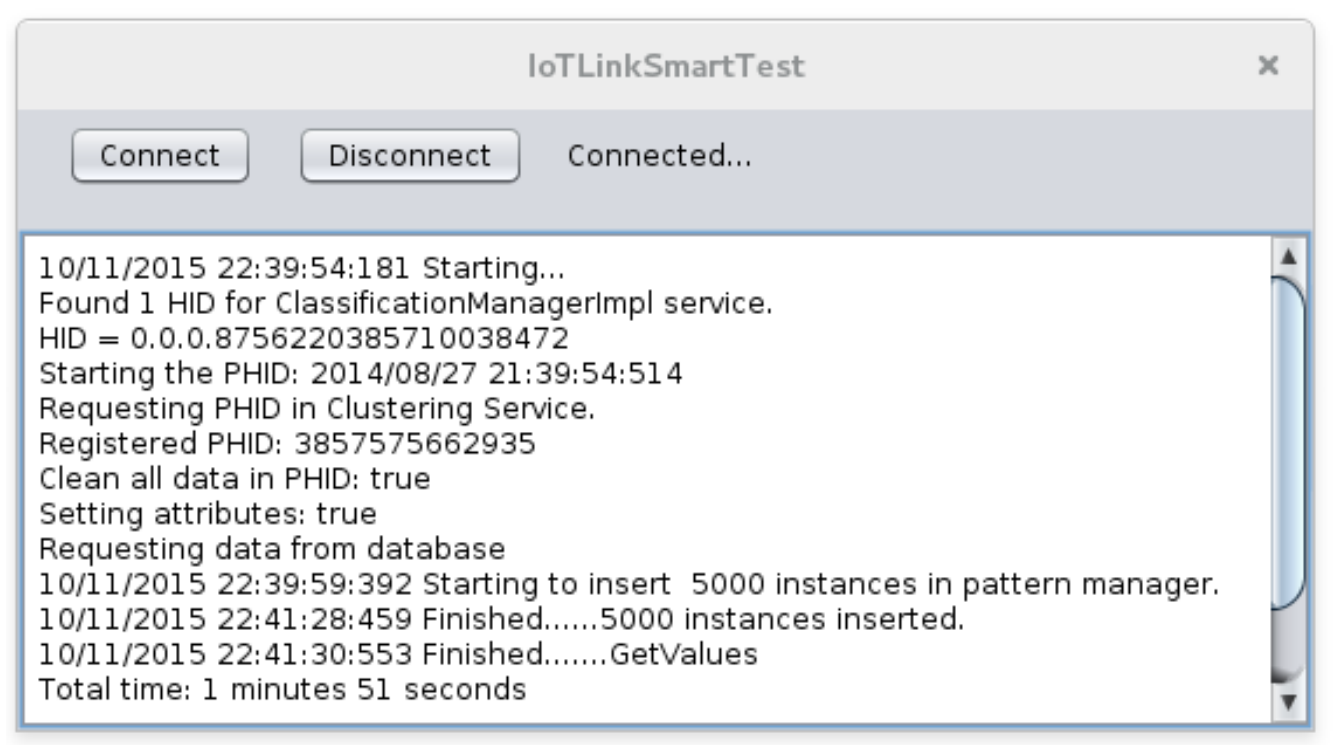

Fonte: Elaborada pelo autor.

A aplicação de teste inseriu 5000 instâncias, com três atributos: luminosidade, temperatura e horário da leitura como variável inteira, essa execução não apresentou erros ao inserir o conjunto total de instâncias. O tempo decorrido para a inserção dos registros foi de aproximadamente um minuto e quarenta e nove segundos, para o resgate do conjunto completo de dados o tempo decorrido foi de quase 2 segundos. O tempo total decorrido foi baixo se comparado à plataforma Ubidots, porém ele não pode ser um parâmetro relevante para a escolha de plataforma, tendo em vista que pode haver variações da banda de rede disponível no momento da execução da aplicação.

A plataforma Ubidots permite apenas a inserção de variáveis inteiras ou reais, não permitindo, portanto, valores como data, hora, textos ou outros tipos quaisquer que, dependendo do contexto da aplicação poderão ser importantes.

Esses fatores justificam a opção em se desenvolver a arquitetura estendendo o LinkSmart Middleware.

\subsection{ANÁLISE E RECONHECIMENTO DE PADRÕES NAS CAMADAS DE MIDDLE- WARE/SERVIÇO E DE DISPOSITIVO/GATEWAY NO MODELO DE IOT}

A solução descrita nesta Seção vai ao encontro do objetivo principal, de se acrescentar mecanismos de análise e reconhecimento de padrões nas camadas do modelo de IoT e do 
objetivo 3 de se criar uma estrutura para processamento distribuído para IoT.

Essa solução acrescenta os mecanismos de análise e reconhecimento de padrões nas camadas de: (1) middleware e serviço no modelo de IoT; (2) na camada de dispositivos ou entidades físicas, nesse caso dentro de dispositivos de IoT que estejam na classe de dispositivos com reduzido poder computacional; e (3) no dispositivo de gateway de IoT. Cabe destacar que a normalização e sincronização dos dados e diferentes fontes não estão no escopo dessa solução e devem ser uma decisão de projeto e arquitetura da aplicação ou sistema cliente do módulo aqui descrito.

Optou-se por usar como base o LinkSmart middleware como uma plataforma para criação de aplicações para a IoT, que era uma necessidade apontada em Chartier (2011). Nessa solução acrescenta-se uma sub-camada para o reconhecimento de padrões ao LinkSmart middleware, na qual se inserem os novos serviços para análise e reconhecimento de padrões ao abstrair algoritmos para detecção de outliers, estimação de valores e algoritmo de clustering, permitindo que eles sejam aplicados a diversos ambientes e com diversos tipos de dispositivos. Dessa forma as aplicações passam a poder resgatar informações do middleware, ao invés de resgatar dados capturados diretamente dos objetos interconectados.

A Figura 19 ilustra a alteração proposta na estrutura em camadas do LinkSmart middleware.

A sub-camada Pattern Layer, destacada pelo retângulo possui três gerenciadores clustering manager, outlier manager e estimation manager, nos quais são implementadas as funcionalidades para o reconhecimento de padrões.

Essa implementação possui três aspectos importantes:

1. Alteração nos Application Elements, à esquerda na Figura 19, com foco na camada de middleware ou serviço.

2. Alteração nos Device Elements, à direita na Figura 19 , elementos de dispositivos que podem ser embutidos em futuros dispositivos para IoT, que venham a utilizar o LinkSmart Middleware como base para seu firmware. Os elementos de dispositivos podem ser incorporados aos gateways de IoT.

3. Para classes de dispositivos que não possam ter os elementos de dispositivos do LinkSmart Middleware embutidos, pretende-se criar especificações de algoritmos que sejam incorporados ao firmware. Essa implementação tem o foco voltado à Physical layer ou camada de entidades físicas.

A utilização de algoritmos de estimação de valores, de clustering e de deteç̧ão de outliers (DOUGHERTY, 2012) (THEODORIDIS; KOUTROUMBAS, 2008) irá contribuir para a 
Figura 19 - Proposta de nova estrutura em camadas do LinkSmart middleware com os mecanismos de análise e reconhecimento de padrões.

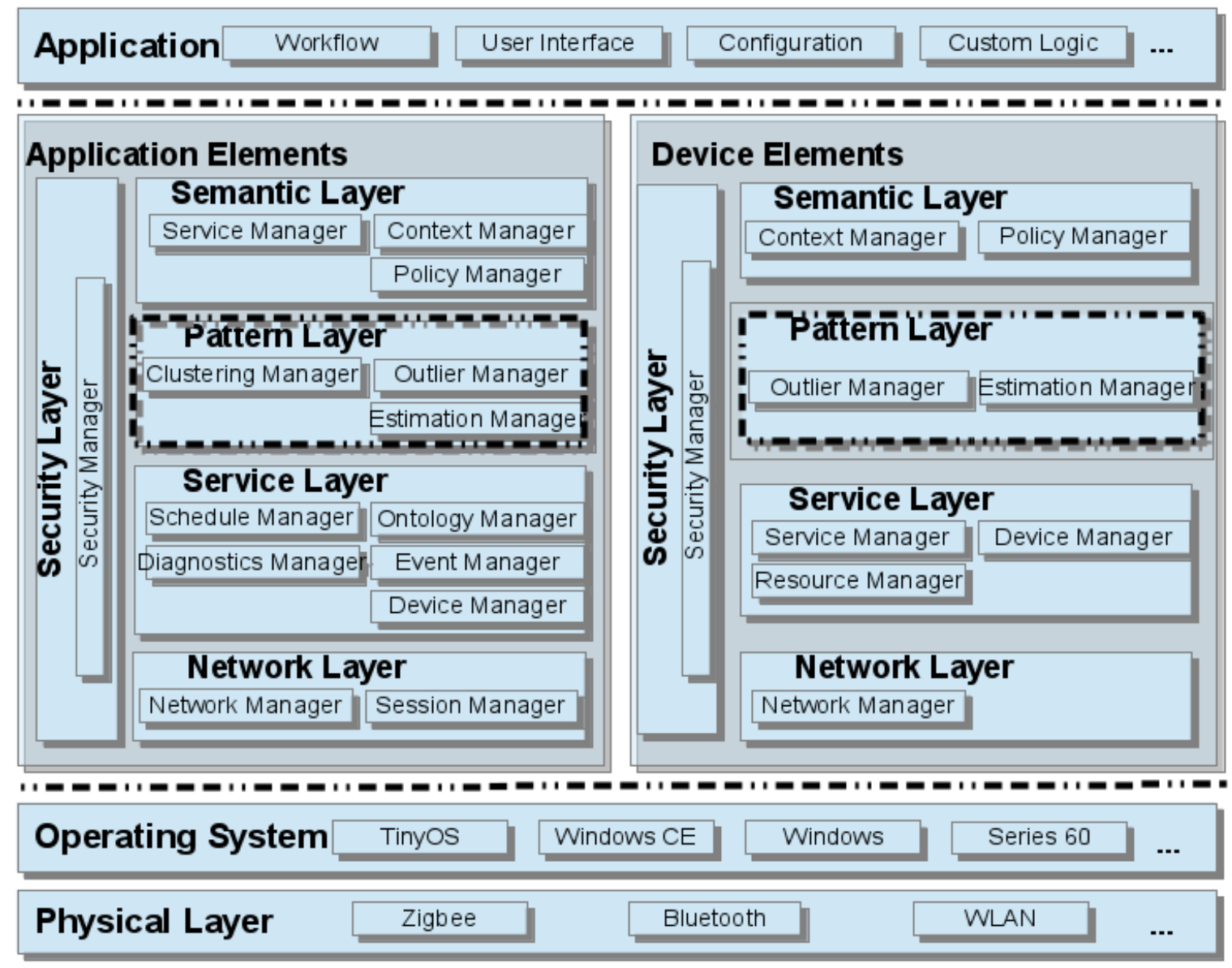

Fonte: Elaborada pelo autor.

minimização do tráfego de rede na modelo de IoT proposto, tendo em vista que não haverá a necessidade de enviar todos os dados à camada superior, pois serão pré-processados no próprio middleware de IoT. Aos algoritmos, soma-se a arquitetura distribuída Big Data para a mineração de dados que pretende distribuir o armazenamento e processamento, utilizando recursos do Framework Hadoop e do LinkSmart Middleware.

Para essa implementação utilizam-se algoritmos de:

- Regressão linear para estimação de valores.

- Algoritmo k-means para o clustering dos valores oriundos de sensores ligados aos dispositivos ou de dados que já tenham sido entregues ao LinkSmart Middleware.

- Para a detecção de outliers utiliza-se o algoritmo de clustering k-means e medida de distância dos centróides para a detecção de outliers (DOUGHERTY, 2012) (PAMULA; DEKA; NANDI, 2011) (LEI et al., 2012) (SOUZA; AMAZONAS, 2015). 
A Figura 20 ilustra o fluxo de dados e informações na arquitetura e implementação propostas.

Figura 20 - Representação gráfica do fluxo de dados e informações na arquitetura proposta.

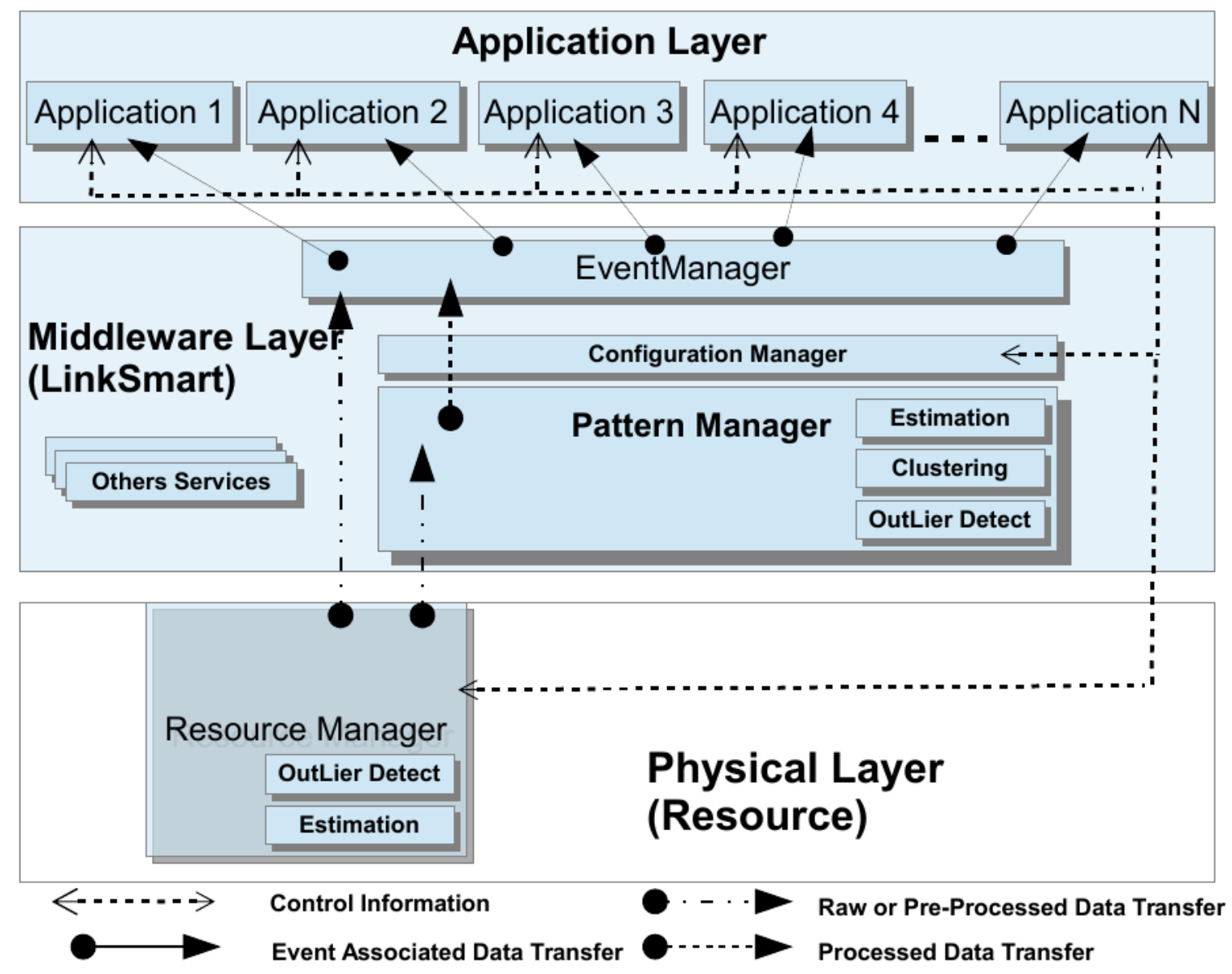

Fonte: Elaborada pelo autor.

O aspecto mais importante dessa implementação é o novo módulo para reconhecimento de padrões inserido no LinkSmart Middleware. Essa implementação segue a arquitetura proposta pelo modelo de referência IoT-A, descrito na seção 2.2.2, e possui as seguintes camadas:

- Physical layer ou Camada física: essa camada de recursos físicos, que será chamada deste ponto em diante de Resource Layer, é representada por sensores e dispositivos inteligentes. O gerenciador de recursos físicos ou Resource Manager, representa os drivers de dispositivos ou gateway que são responsáveis por fazer a interface com o LinkSmart Middleware e enviar os dados brutos ou dados pré-processados por algoritmos de estimação de valores ou detecção de outliers. Caso os dados gerados por um Resource Manager sejam processados nessa camada, ele deverá informar ao gerenciador de configuração, chamado deste ponto em diante de Configuration Manager, no 
LinkSmart Middleware ou diretamente à aplicação. Tanto o Resource Manager quanto a aplicação poderão alterar parâmetros no Resource Manager de modo a desativar o pré-processamento e ele passe a enviar os dados brutos para a camada superior. A partir dessa camada o fluxo de informação pode ir para a camada de middleware.

- Middleware layer ou Camada de Middleware: essa camada é representada pelo LinkSmart Middleware, modificado nessa implementação pela inclusão dos serviços de reconhecimento de padrões e o Configuration Manager. O Event Manager, já existente, possui grande relevância nessa arquitetura, porém os outros serviços presentes no middleware não são relevantes para a implementação aqui descrita. O Pattern Manager implementa três serviços: estimação de valores, clustering e detecção de outliers. O Configuration Manager permite que as aplicações ou o Resource Manager possam configurar parâmetros no Pattern Manager, definir quando os algoritmos executarão ou o quanto de dados deverá ser armazenado, habilitar ou desabilitar os serviços de reconhecimento de padrões ou limpar os dados armazenados. Depois do processamento dos dados o serviço de reconhecimento de padrões pode enviar as informações contextualizadas para o Event Manager, que por sua vez, envia os novos eventos aos clientes. O Event Manager provê a escalabilidade, tendo em vista que ele possui recursos para enviar os eventos para um único ou milhões de clientes, dependendo da estrutura de implantação do LinkSmart.

O Event Manager pode ser acessado diretamente pelo Resource Manager, que neste caso, não habilitou os serviços de reconhecimento de padrões. Essa característica pode ser escolhida no projeto da aplicação e pode ser alterada através do Configuration Manager.

Essa camada implementa a comunicação cross layer, tendo em vista que ela pode receber ou enviar parâmetros de configuração ao Resource Manager ou para as aplicações. Esse é o aspecto mais relevante da comunicação cross layer, na qual, o dado bruto pode ser aberto, processado ou interpretado nessa camada, que de outra forma, seria uma função específica da camada de aplicação, conforme o modelo OSI (COMER, 2015).

- Application layer ou Camada de aplicação: essa camada representa as aplicações clientes ou suas ações de configuração. As aplicações recebem os eventos a partir do Event Manager, sendo os dados brutos ou informações processadas. As ações de configuração são responsáveis por configurar os parâmetros no Configuration Manager ou por enviar parâmetros ao Resource Manager ou ao Middleware, para controlar seu comportamento ou os serviços de reconhecimento de padrões, ativando-os ou desativando-os. Essa comunicação é bidirecional. 
A comunicação cross layer é um requisito importante nessa arquitetura e foi implementada conforme a descrição mencionada. A arquitetura proposta permite o processamento distribuído ou em várias camadas, tendo em vista que a informação pode ser processada em cada nó físico, ou de rede como cada nó do middleware, ou por nós de aplicação. A comunicação cross layer proposta nessa arquitetura permite essa funcionalidade, que nesta pesquisa é relevante para o contexto de aplicações de IoT.

\subsection{ASPECTOS DE IMPLEMENTAÇÃO DO MÓDULO DE RECONHECIMENTO DE PADRÕES E O PROCESSAMENTO COM BIG DATA}

O LinkSmart Middleware foi implementado usando a arquitetura OSGI (BAKKER; ERTMAN, 2013). Para se criar um novo módulo nesse middleware deve-se usar essa arquitetura, estender seus pacotes e criar as Interfaces e contratos para os novos serviços.

A Figura 21 ilustra o principal diagrama de classes do Pattern Manager implementado.

O diagrama de classes ilustrado pela Figura 21 descreve a estrutura dos novos pacotes criados e incluídos no LinkSmart. Esses novos pacotes possuem as seguintes classes:

- ClassificationManager: é uma Interface que define os contratos para as chamadas de métodos para os novos serviços. Os serviços e métodos implementados no Pattern Manager são: register e unregister que serverm respectivamente para registrar ou remover um Pattern Hardware Identification (PHID), que é um valor único assinado para cada fonte de dados, listar todos os PHIDs, submeter um novo dado bruto, remover dados a partir de um PHID, executar os algoritmos, definir atributos para os algoritmos, dentre outros métodos que possuem as mesmas características para os outros serviços.

- ClassificationManagerImpl: é uma classe concreta que implementa os métodos definidos na Interface ClassificationManager e agrega outros métodos para a implementação do serviço $O S G I$. Essa classe gerencia as instâncias de classes que implementam os algoritmos para análise e reconhecimento de padrões e todos os PHIDs existentes no Pattern Manager.

Diversas outras classes foram desenvolvidas para se implementar os algoritmos de reconhecimento de padrões e integrá-los à plataforma de Big Data Hadoop e serão descritas juntamente com seus respectivos serviços. Nas próximas Seções serão descritos os serviços desenvolvidos como clustering, estimação de valores e detecção de outliers e a comunicação cross layer, respectivamente. 
Figura 21 - Diagrama de classes do Pattern Manager incluindo os pacotes, a Interface e a classe que a implementa.

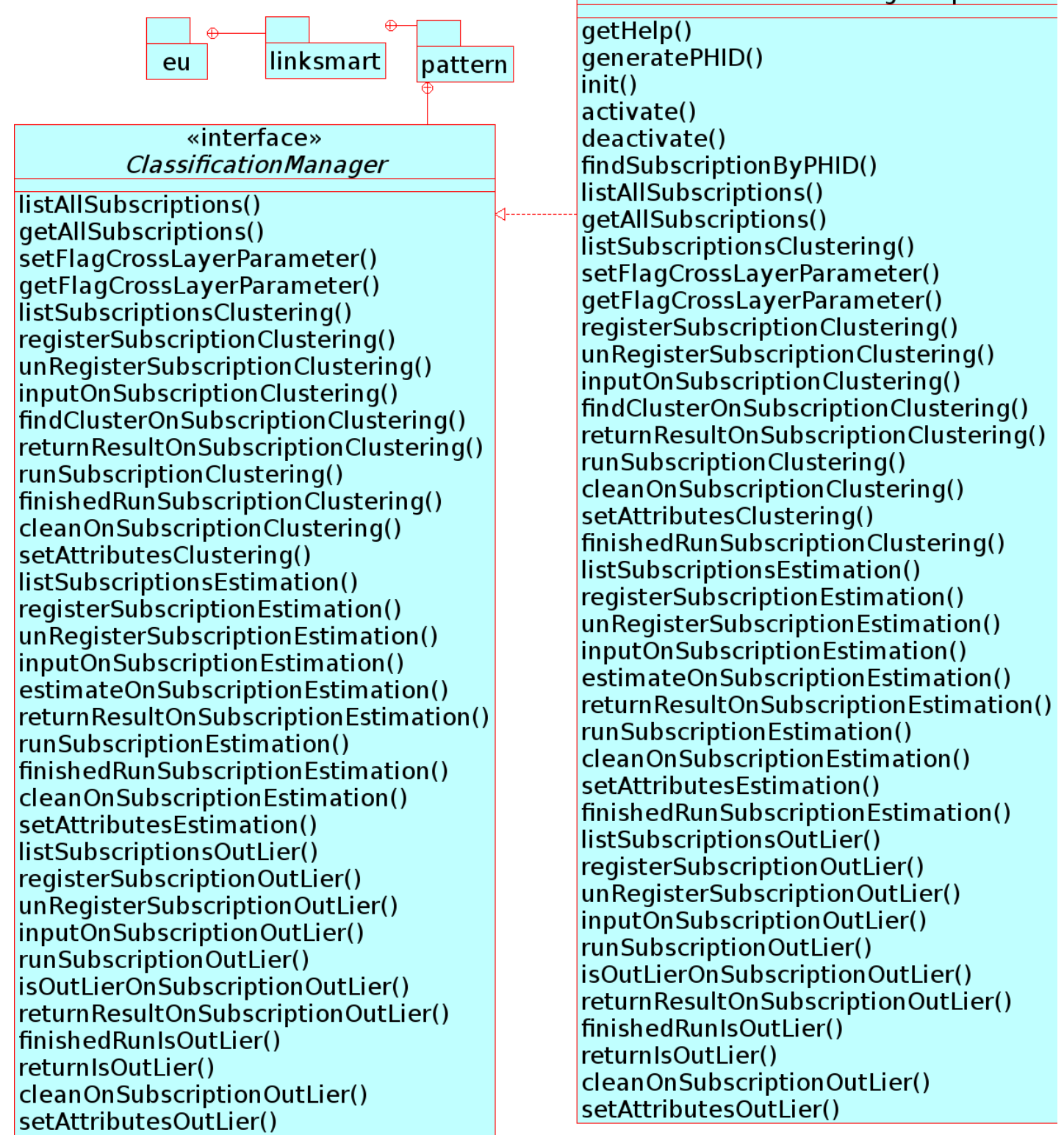

Fonte: Elaborada pelo autor.

\subsubsection{Implementação do serviço de clustering}

A Figura 22 exibe o diagrama de classes que implementa o serviço de clustering no módulo Pattern Manager.

A Figura 22 apresenta o pacote existente eu.linksmart.pattern e os novos pacotes clusterer e hadoop, com as seguintes classes:

- PatternSubscription: essa classe cria a estrutura com os atributos para as novas classes, que implementam os serviços no módulo Pattern Manager. Essa classe define os atributos que informam o tipo de algoritmo, se é clustering, detecção de outlier ou estimação 
Figura 22 - Diagrama de Classes com a implementação do serviço de clustering no módulo Pattern Manager.

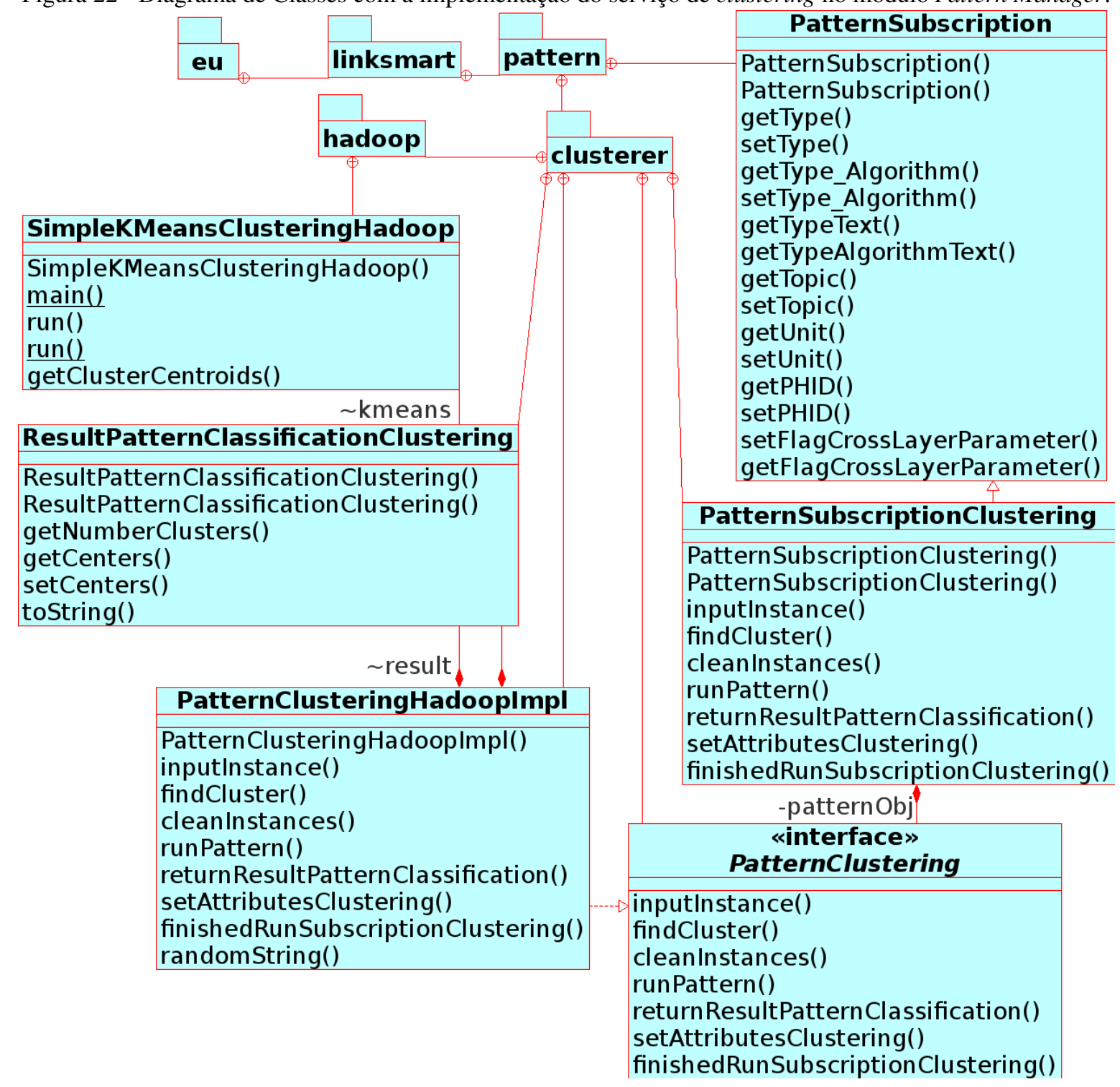

Fonte: Elaborada pelo autor.

de valores, tipos de atributos, se são numéricos, textos, classes ou datas, e o valor de PHID.

- PatternSubscriptionClustering: essa classe estende a classe PatternSubscription e acrescenta novos métodos para o serviço de clustering, como o inputInstance para se inserir instância de dado para o processamento, findCluster que retorna a qual cluster uma instância é mais semelhante ou está mais próxima, setAttributesClustering que define parâmetros para o algoritmo de clustering, runPattern que inicia a execução do algoritmo, finishedRunSubscriptionClustering que notifica quando o processo de clustering foi finalizado e o returnResultPatternClassificationClustering que retorna o resultado do processamento. Note que essa classe não implementa o algoritmo de clustering, 
mas ela possui um objeto ao qual ela delega esse processamento. Essa solução permite o desacoplamento entre o módulo e a implementação concreta e, por fim, permite a introdução de novas implementações.

- PatternClustering: essa Interface define a estrutura para que uma classe possa implementar os métodos necessários para ser um objeto de PatternClustering. Ela define os seguintes métodos: inputInstance, findCluster, runPattern, returnResultPatternClassificationClustering, setAttributesClustering e finishedRunSubscriptionClustering, todos relacionados aos métodos definidos na classe PatternSubscriptionClustering.

- ResultPatternClassificationClustering: essa classe contém os atributos necessários de um resultado de execução de um algoritmo de clustering. Esse objeto pode ser retornado a uma aplicação, de modo que as informações sobre os clusters, possam ser utilizadas na aplicação para se contextualizar e gerar conhecimento sobre os dados processados na camada de middleware. O resultado contém todos atributos de cada centróide de cada cluster e seus respectivos raios.

- PatternClusteringHadoopImpl: essa é uma importante classe no serviço de clustering, ela é uma implementação concreta da Interface PatternClustering e de todos os seus métodos propostos. Ela implementa o algoritmo de clustering $k$-means, integrado ao Hadoop para processamento distribuído com Big Data. A implementação do algoritmo utiliza o Framework Mahout. O principal método implementado na classe cria um thread para iniciar o processo na instância de Hadoop. Quando o processo é finalizado o método altera o estado de um flag de modo a informar e enviar o resultado ao LinkSmart EventManager e dessa maneira, todos os clientes que estiverem inscritos, receberão a notificação com um novo valor ou conjunto de dados.

- SimpleKMeansClusteringHadoop: essa classe implementa a integração e executa um thread do algoritmo k-means na instância do Hadoop.

Essa implementação da arquitetura permite que qualquer outra classe possa implementar a Interface PatternClustering e ser acoplada ao módulo. Em implementações prévias, foi utilizado o framework Weka como base para implementação do algoritmo de clustering, porém, não se obtiveram resultados satisfatórios quanto aos tempos de execução no contexto de IoT com os conjuntos de bases de dados para experimentos. A partir desses resultados insatisfatórios optou-se por utilizar a tecnologia de Big Data com o Hadoop e a implementação algorítmica do Mahout. A implementação com Big Data permite a criação de clusters de processamento com instâncias de Hadoop, o que permite uma escalabilidade grande de poder computacional e que seja transparente para o módulo desenvolvido. 


\subsubsection{Implementação do serviço de estimação de valores}

O serviço de estimação de valores possui estrutura semelhante à estrutura do serviço de clustering. A classe PatternSubscription possui papel fundamental para o acoplamento do algoritmo à principal estrutura do módulo Pattern Manager.

A Figura 23 ilustra o diagrama de classes que implementa o serviço de estimação de valores no módulo.

Figura 23 - Diagrama de classes do serviço de estimação de valores no módulo Pattern Manager.

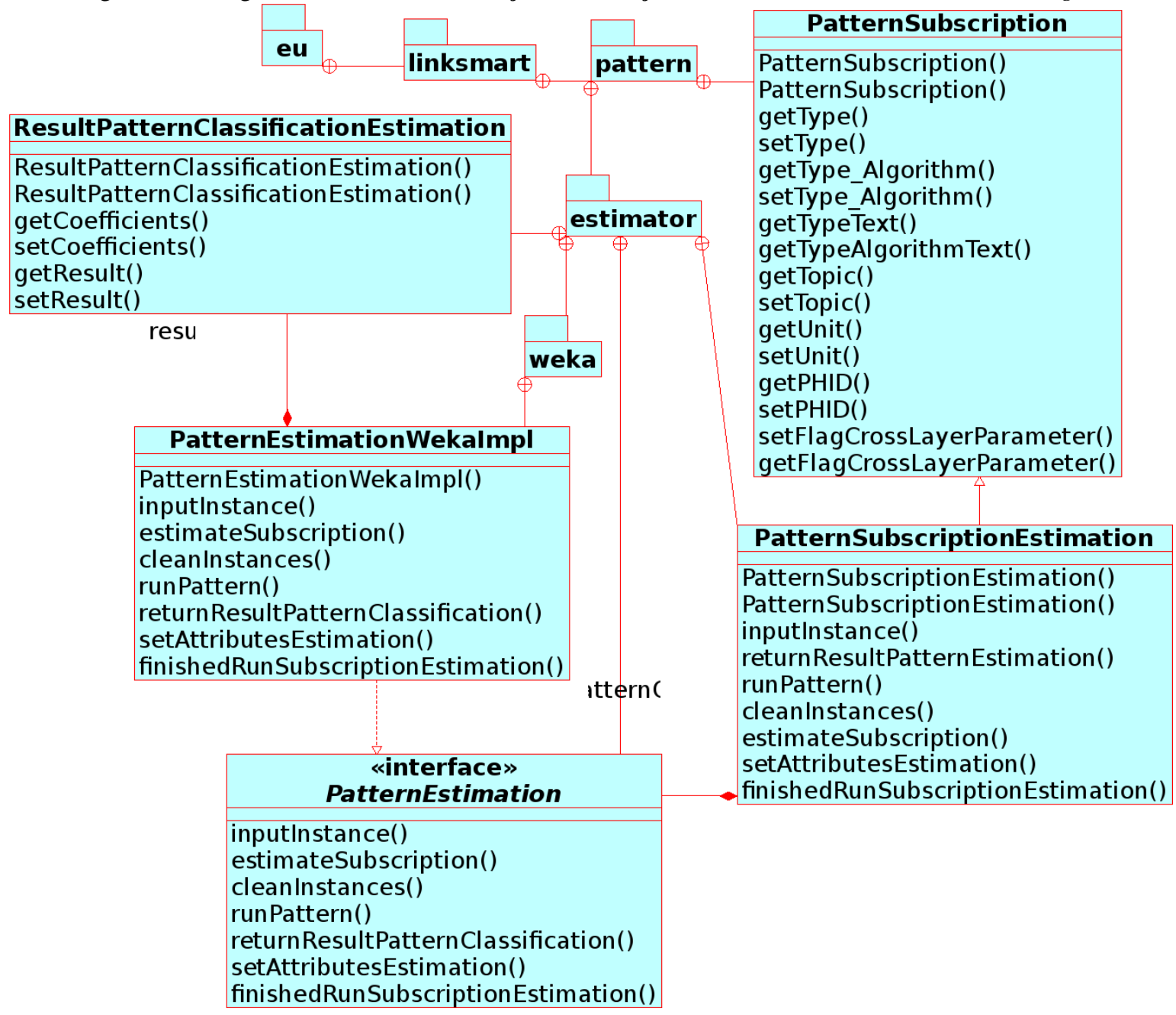

Fonte: Elaborada pelo autor.

A Figura 23 mostra o pacote existente eu.linksmart.pattern e os novos pacotes adicionados estimator e Weka. As seguintes classes foram desenvolvidas:

- PatternSubscription: essa é a mesma classe descrita no serviço de clustering e possui a mesma estrutura já descrita na Seção 3.4.1.

- PatternSubscriptionEstimation: essa classe estende a classe PatternSubscription e agrega 
novos métodos para esse serviço, como inputInstance, que possui a mesma função descrita no serviço de clustering, estimateSubscription para estimar um valor específico dada uma instância, setAttributesEstimation para definir parâmetros para o algoritmo de estimação como, por exemplo, o atributo alvo que deve ser estimado, runPattern para iniciar a execução do processo de estimação finishedRunSubscriptionEstimation para notificar quando o processo de estimação é finalizado e o método returnResultPatternEstimation que retorna o resultado do processo de estimação. Essa classe não implementa o algoritmo de estimação, mas ela possui uma instância de PatternEstimation, à qual é delegada a implementação do algoritmo. Assim como no serviço de clustering, essa estrutura de orientação a objetos permite o desacoplamento entre o módulo e a implementação concreta dos algoritmos, permitindo assim, novas implementações e novos algoritmos futuros.

- PatternEstimation: essa interface define a estrutura para novas classes que venham a implementar os métodos necessários para que ela seja um PatternEstimation. Essa classe define os seguintes métodos: inputInstance, estimateSubscription, runPattern, returnResultPatternClassification, setAttributesEstimation e finishedRunSubscriptionEstimation.

- ResultPatternClassificationEstimation: essa classe possui todos os atributos necessários para o resultado ser retornado por um algoritmo de estimação. Um objeto de ResultPatternClassificationEstimation pode ser enviado para uma aplicação cliente com as informações sobre o resultado do algoritmo, de modo a permitir que a própria aplicação possa ter a equação de regressão do conjunto de dados (DOUGHERTY, 2012), embora, para a grande maioria dos contextos, o middleware poderá estimar o valor da instância e apenas sinalizar para a aplicação que o algoritmo de estimação foi utilizado, tornando o processo mais transparente para a aplicação.

- PatternEstimationWekaImpl: essa é a classe mais importante no serviço de estimação, ela implementa a Interface PatternEstimation e todos os seus métodos propostos. Ela implementa o algoritmo de regressão linear usando a implementaçãpo do framework Weka para o processamento dos dados. O principal método implementado nessa classe cria e inicia um thread que inicia o processo de execução do algoritmo com as classes do framework Weka. Quando o processo é finalizado o método altera o valor de um flag, que informa e envia o resultado do processamento para o LinkSmart Event Manager. Esse é um ponto importante na estrutura de orientação a objetos que permite a integração com outras implementações como, por exemplo, usando o processamento em 
Big Data. Esse processo teve resultados satisfatórios quanto aos tempos de execuação, não havendo a necessidade de se implementar usando a tecnologia de Big Data.

\subsubsection{Implementação do serviço de detecção de outlier}

O serviço de detecção de outlier possui a mesma estrutura dos serviços de clustering e de estimação de valores.

Figura 24 - Diagrama de Classes do serviço de detecção de outlier implementado no módulo Pattern Manager.

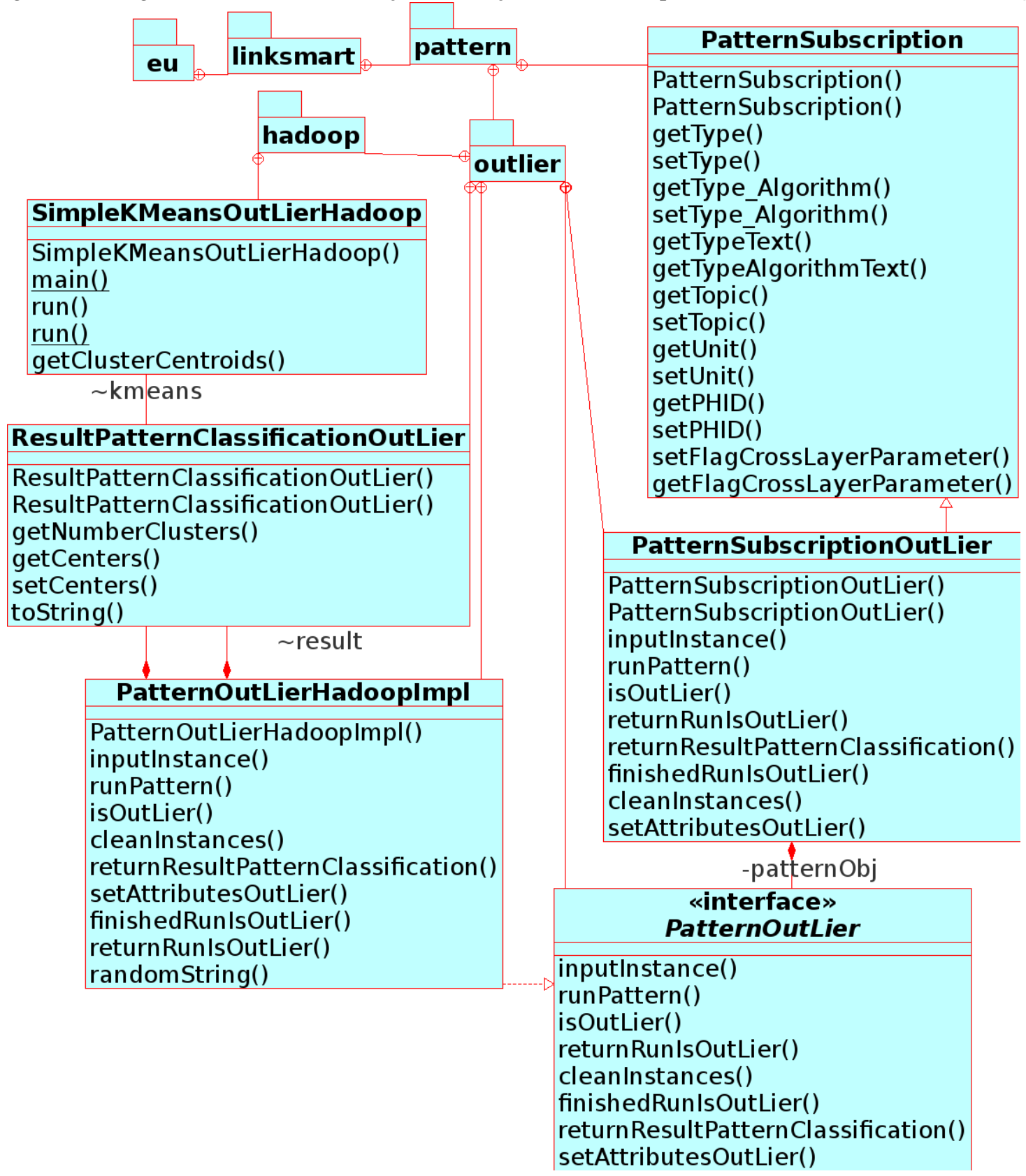

Fonte: Elaborada pelo autor.

A Figura 24 ilustra o diagrama de classes implementado nesse serviço. Nela observa-se o pacote existente eu.linksmart.pattern e os novos pacotes adicionados outlier e hadoop. As 
seguintes classes foram implementadas:

- PatternSubscription: essa classe possui a mesma estrutura criada nos serviços de clustering e estimação de valores.

- PatternSubscriptionOutLier: essa classe estende a classe PatternSubscription e agrega novos métodos relacionados ao serviço de detecção de outlier, métodos como: inputInstance, que possui a mesma função descrita no serviço de clustering, isOutLier que estima se uma dada instância é ou não um outlier, setAttributesOutLier que define os parâmetros a serem usados pelo algoritmo, runPattern que inicia a execução de um processo de detecção de outlier, finishedRunIsOutLier que notifica o término de um processo de detecção de outlier e, por fim, o método returnResultPatternClassification que retorna o resultado do processamento. Essa classe, assim como nos outros serviços, não implementa o algoritmo, ela possui uma instância de PatternOutLier que delega a implementação e execução do processo para outra classe. Essa solução permite o desacoplamento do módulo e da implementação concreta do algoritmo e facilita a introdução de novas implementações ou de novos algoritmos.

- PatternOutLier: essa Interface define a estrutura e métodos para que uma classe seja um PatternOutLier. Ela define a estrutura dos seguintes métodos: inputInstance, isOutLier, runPattern, returnResultPatternClassification, setAttributesOutLier e finishedRunIsOutLier.

- PatternOutLierHadoopImpl: essa é a classe mais importante desenvolvida no serviço de detecção de outlier. Ela implementa a Interface PatternOutLier e todos os seus métodos propostos. Ela implementa o algoritmo de clustering k-means e calcula o raio de cada grupo encontrado, informação que é utilizada para estimar se uma dada instância é ou não um outlier. Essa implementação também está integrada à tecnologia de Big Data, Hadoop e Mahout para a implementação e execução do algoritmo k-means.

- SimpleKMeansOutLierHadoop: essa classe implementa a integração e execução do algoritmo em um thread na instância do Hadoop.

- ResultPatternClassificationOutLier: essa classe contém os atributos necessários de um resultado de execução do algoritmo de detecção de outlier. Um objeto de ResultPatternClassificationOutLier pode ser enviado para uma aplicação para que ela possa usar as informações sobre a identificação dos outliers. Esse resultado possui informações sobre os grupos encontrados no algoritmo de agrupamento, os respectivos centróides de cada cluster e seu respectivo raio. 
$\mathrm{Na}$ implementação inicial, foi utilizado o algoritmo de detecção de outliers presente no framework Weka, mas que não forneceu resultados satisfatórios no contexto de IoT, quanto aos tempos de execução. Optou-se pela busca de implementações de algoritmos de detecção de outliers utilizando a tecnologia de Big Data e não foi encontrado. O desenvolvimento e abordagem aqui descritos são uma contribuição original desta pesquisa, conforme discutido em Souza e Amazonas (2015)c.

Os algoritmos implementados podem ser substituídos por novas implementações devido à estrutura de orientação a objetos desenvolvida, que permite esse desacoplamento. Essa abstração é um importante aspecto da arquitetura de IoT aqui desenvolvida.

\subsubsection{Algoritmo de detecção de outlier usando Big Data e o algoritmo de clustering k- means}

De acordo com Zaki e Meira (2014), abordagens que utilizam medidas de proximidade podem ser utilizadas para a detecção de outlier. Lei et al. (2012)b desenvolveram abordagens que utilizam algoritmos de clustering para a detecção de outliers. Tomando como base essas descrições, foi desenvolvida a proposta de algoritmo de detecção de outlier utilizando a tecnologia de Big Data e algoritmo de clustering k-means.

Essa implementação possui os seguintes passos:

1. A aplicação insere os dados brutos para a criação do modelo de clustering.

2. É executado o algoritmo de clustering Canopy (NAYAK et al., 2015), com os dados iniciais para se propor a quantidade de clusters existentes no modelo, usando a implementação presente no framework Mahout.

3. Se executa o algoritmo k-means, com a quantidade de centróides retornadas pelo algoritmo Canopy, de modo a criar o modelo de clusters, também usando a implementação presente no framework Mahout (GIACOMELLI, 2013).

4. São resgatadas as informações sobre os clusters, os centróides e os respectivos raios, gerados pela execução do algoritmo k-means.

5. Com base nesses valores o método isOutLier pode ser usado. Sua implementação calcula a distância Euclidiana (DOUGHERTY, 2012) de uma dada instância para todos os centróides e caso essa distância seja maior que o raio para cada cluster e centróide a instância é classificada como um outlier.

A Figura 25 ilustra a abordagem proposta. 
Figura 25 - Detecção de Outlier: são observados três clusters e respectivamente seus raios e dois pontos considerados outlier.

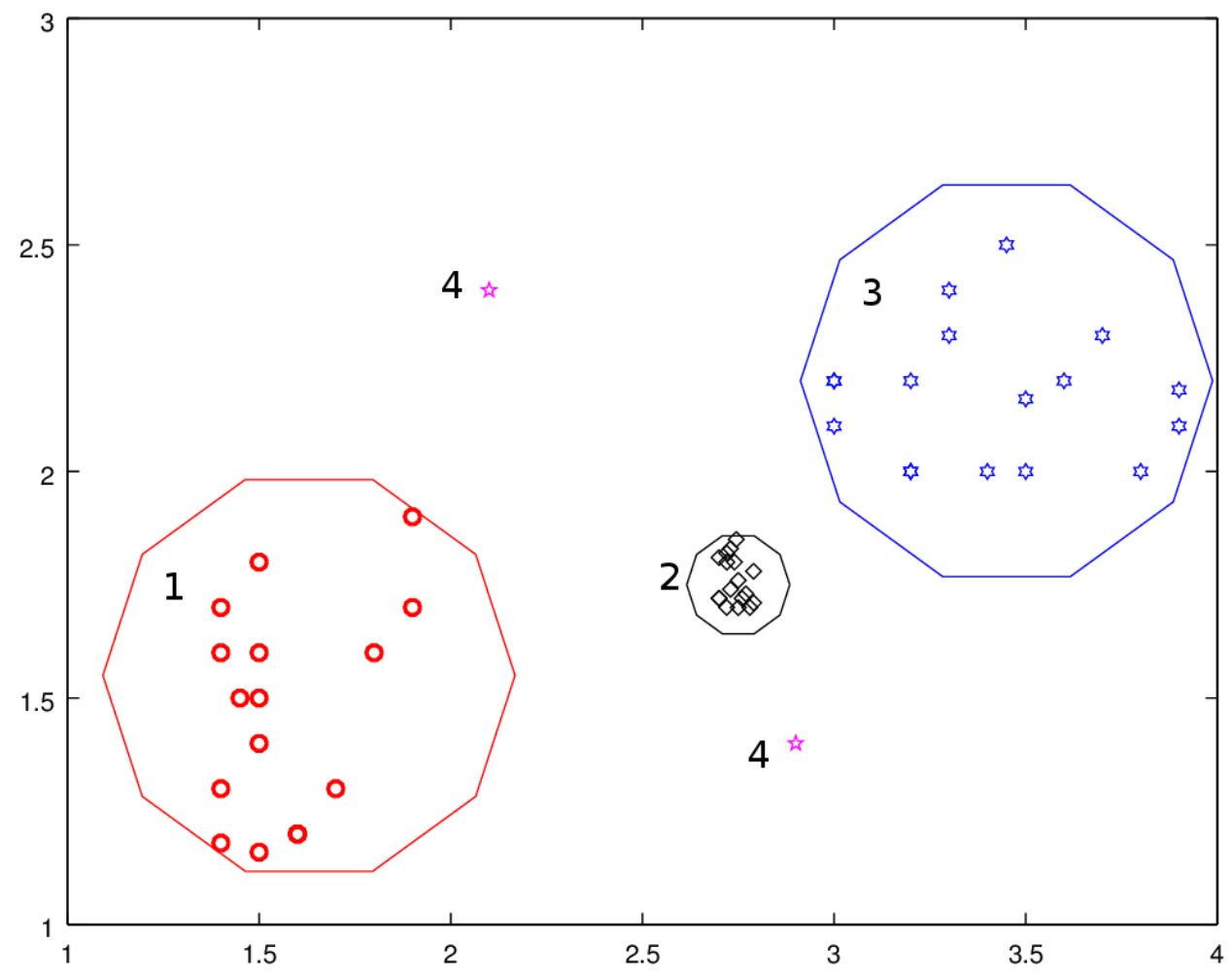

Fonte: Elaborada pelo autor.

Na Figura 25 são observados três clusters gerados: cluster (1) representado pelos círculos, cluster (2) representado pelo diamantes e cluster (3), presentados pelas estrelas, e dois outliers representados pelo sinal + e marcados com o número 4, que estão fora dos círculos de cada cluster, que representam seus respectivos raios.

\subsubsection{Implementação da comunicação cross layer no modelo de IoT}

Esta especificação de implementação da comunicação cross layer no modelo de IoT vai ao encontro do objetivo secundário 3, destacado na Seção 1.4. Os requisitos dessa comunicação são:

- do dispositivo para o Middleware ou serviço: sempre que o dispositivo estiver utilizando os algoritmos de estimação de valores ou detecção de outliers, o middleware ou camada superiores deverão ser avisados. Sendo assim, foram definidos os formatos de mensagens para essa troca de informação. 
- do Middleware/serviço ou aplicação para o dispositivo: o modelo desenvolvido permite que a aplicação ou o middleware escolham se o dispositivo deve desativar ou ativar o uso dos algoritmos propostos, sendo assim, foram definidos os formatos de mensagens para se permitir o controle dessas funcionalidades nos dispositivos, de modo que se consiga ativar ou desativar cada função específica.

A implementação dessa comunicação poderá ser incorporada nos elementos de dispositivo e elementos de aplicação do LinkSmart Middleware e para dispositivos que não o tenham embutido, caberá a especificação das interfaces e contratos de como se utilizar essas funcionalidades, para que ele possa implementá-lo e fazer uso dos mecanismos propostos.

A Figura 26 ilustra a estrutura específica da comunicação cross layer proposta e implementada por meio do diagrama de classes.

O diagrama de classes representa a estrutura orientada a objetos desenvolvida. Há duas classes que representam os parâmetros de comunicação cross layer: (1) a Interface CrossLayerParameter que cria a principal estrutura de um parâmetro cross layer. Pode-se observar os contratos dos métodos como, setLayer que é responsável por definir se a dada camada deverá ou não processar os dados, getLayer que é responsável por retornar a camada em que está sendo feita a alteração, setFlag método responsável por definir uma variável binária que informa se o dado serviço na determinada camada está ou não ativo. A classe CrossLayerParameterImpl é a implementação concreta dos métodos definidos na Interface CrossLayerParameter.

As classes ClassificationManager e ClassificationManagerImpl definem a estrutura e implementação dos serviços de reconhecimento de padrões inseridos no LinkSmart. Novas aplicações poderão usar a estrutura e serviços implementados no LinkSmart Middleware, mas para isso precisam definir os parâmetros para as camadas física e a de middleware. A qualquer momento, em tempo de execução, os parâmetros e comportamento das camadas físicas ou de middleware poderão ser alterados. O software de driver de dispositivo ou o gateway de IoT responsáveis por conectar os dispositivos e o LinkSmart devem usar e interpretar esses parâmetros e alterar o comportamento dos dispositivos. A implementação e abstração orientada a objetos desenvolvida permitem futuras alterações ou inserção de novos parâmetros.

\subsection{UTILIZAÇÃO DE TÉCNICAS DE SENSORES VIRTUAIS E PROCESSAMENTO DE EVENTOS COMPLEXOS NO MODELO DE IOT}

Essa especificação de implementação vai ao encontro do objetivo secundário 2, destacado na Seção 1.4. O processamento de eventos e dos dados ao longo do caminho que os dados 
Figura 26 - Diagrama de classes com os parâmetros da comunicação cross layer no módulo de Pattern Manager.

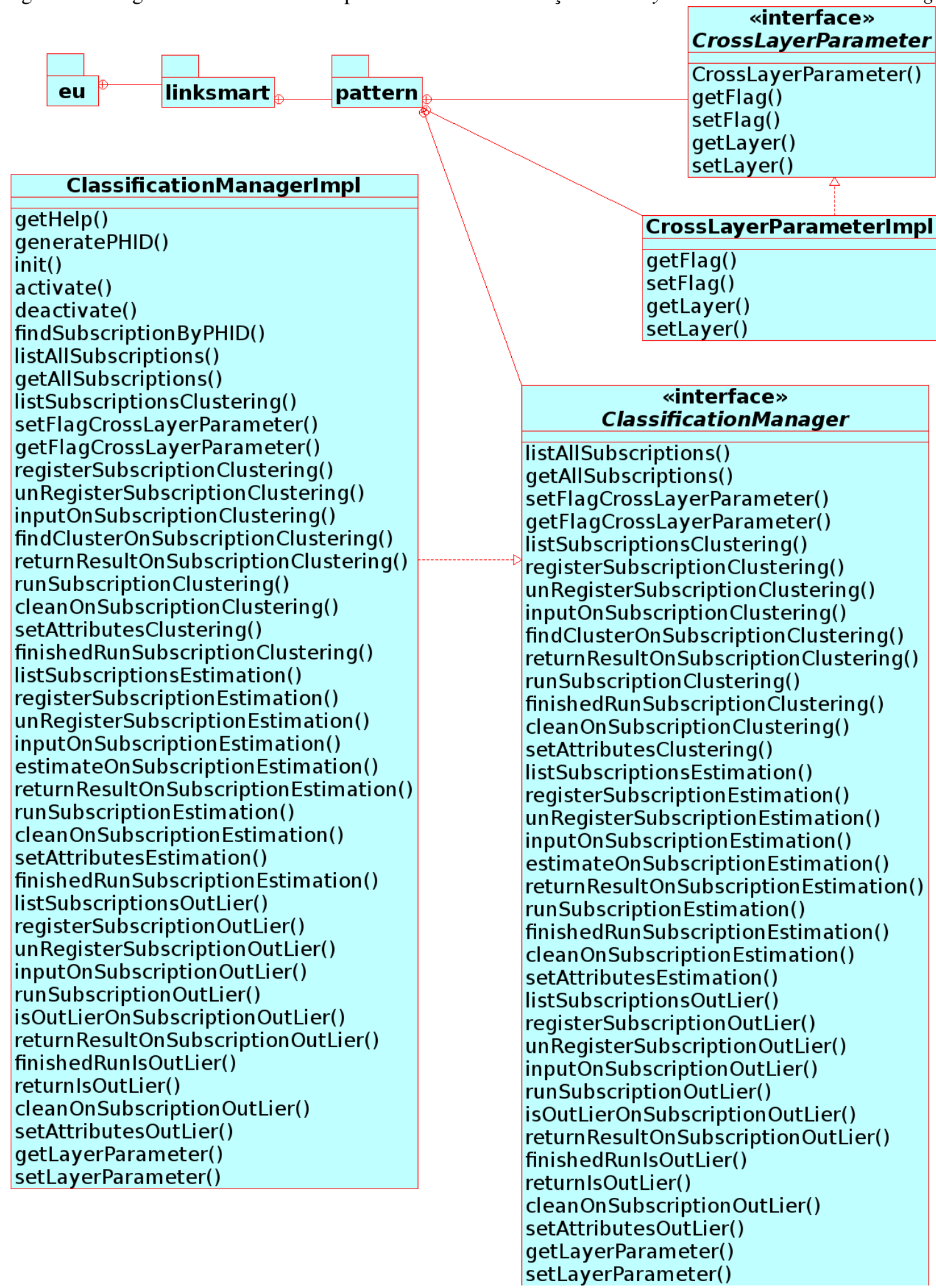

Fonte: Elaborada pelo autor.

percorrem na rede, é similar ao sugerido em Gluhak et al. (2009), A cada salto na rede, não necessariamente saltos em camada de rede, de acordo com o modelo OSI (COMER, 2015), os dados e eventos são analisados e filtrados e ainda poderão ser agregados a outros eventos, 
criando assim valores e sensores virtuais, também filtrados e analisados, e ao final, observase que ao longo do caminho ações podem ter sido executadas nos diversos ambientes e todo o conhecimento agregado torna-se um conhecimento global do ambiente. A Figura 27]ilustra um exemplo de aplicação do processamento dos eventos de dados gerados pela IoT.

Figura 27 - Exemplo de aplicação do processamento de eventos complexos e criação de sensores virtuais em IoT.

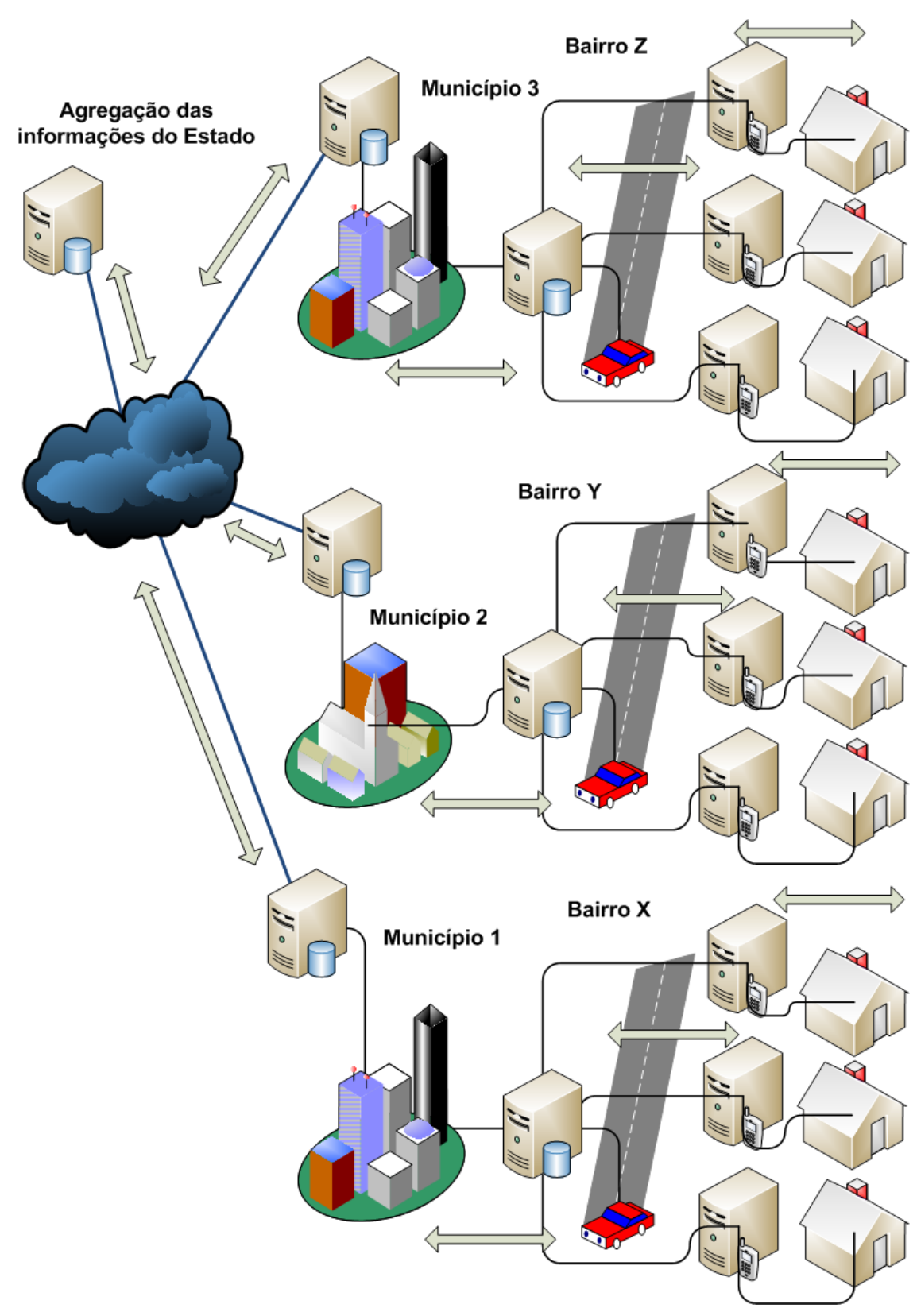

Fonte: Elaborada pelo autor.

No exemplo, se observa a aplicação da proposta de processamento dos eventos e criação dos sensores virtuais, no contexto de consumo de energia em uma residência, onde os diversos dispositivos eletrônicos poderão, de maneira autônoma, monitorar e criar um escalonamento local para utilização e redução do consumo de energia elétrica. Os dados de uma residência podem ser analisados e agregados aos dados de outras residências numa 
mesma rua, com o objetivo de criar escalonamento entre todos os dispositivos, que por sua vez, poderão ser agregadas às informações de outras ruas, bairros, municípios e estados que possam ser atendidos por um mesma fornecedora de energia elétrica. A cada salto, as informações são analisadas e agregadas e ainda são executadas ações em cada ambiente, desde o maior ao menor nível de granularidade conforme se observa nas setas em sentido duplo.

Para as análises utilizam-se os mecanismos de reconhecimento de padrões inseridos no LinkSmart Middleware, como estimação ou clustering, bem como para a criação dos valores dos sensores virtuais, a partir da agregação dos valores oriundos de camadas inferiores no contexto de sensores virtuais e inserindo os novos valores ou sensores virtuais como novas fontes de dados para o middleware.

\subsection{CONSIDERAÇÕES FINAIS}

Neste capítulo foram descritas as soluções propostas e seus aspectos de implementação. As soluções vão ao encontro dos objetivos e hipóteses levantados na Seção 1.4 e contribuem para a análise experimental, que visa validar as hipóteses levantadas, de modo a contribuir originalmente para a área de pesquisa em questão.

Os aspectos relevantes de implementação são a abstração desenvolvida através da orientação a objetos, nesse caso, permitindo futuras implementações de algoritmos e serviços e fácil acoplamento ao módulo desenvolvido. A integração com a tecnologia de Big Data de maneira transparente para a camada de aplicação e para o próprio middleware é outro aspecto relevante a ser destacado na arquitetura proposta.

Todos os objetivos de pesquisa foram incorporados à arquitetura proposta, com a implementação de algoritmos de reconhecimento de padrões, como detecção de outliers e estimação de valores na camada física ou Resource Manager ou na camada de middleware ou serviço, com algoritmos como, detecção de outliers, clustering e estimação de valores, e, por fim, a comunicação cross layer, que possibilita a integração entre todas as camadas e funcionalidades disponibilizadas. 


\section{VALIDAÇÃO E EXPERIMENTOS COM A NOVA ARQUITETURA PARA INTERNET DAS COISAS}

Este capítulo tem por objetivo documentar os experimentos e aplicações desenvolvidas para a validação da arquietura proposta e, adicionalmente, os algoritmos em execução no módulo de reconhecimento de padrões desenvolvido. Este capítulo está organizado da segunte maneira: a Seção 4.1 descreve o cenário experimental utilizado em todas as aplicações desenvolvidas para os experimentos; a Seção 4.2 descreve a execução do módulo de reconhecimento de padrões juntamente com o LinkSmart Middleware; a Seção 4.3 descreve a execução de uma aplicação que valida a comunicação cross layer proposta; a Seção 4.4 descreve uma aplicação que valida o algoritmo de clustering; a Seção 4.5 descreve uma aplicação que valida o algoritmo de detecção de outlier; a Seção 4.6 descreve a execução de uma aplicação que valida o algoritmo de estimação de valores e, por fim, a Seção 4.7 que descreve uma aplicação mais abrangente que utiliza alguns dos algoritmos propostos num contexto mais próximo do mundo real.

\subsection{CENÁRIO DA VALIDAÇÃO EXPERIMENTAL}

$\mathrm{Na}$ etapa de validação experimental foram desenvolvidas aplicações para experimentos com cada serviço desenvolvido: clustering, detecção de outliers e estimação de valores. Em seguida, a validação como prova de conceito da comunicação cross-layer e, por fim, uma aplicação que testasse a arquitetura como um todo.

Em todas as aplicações experimentais foi utilizado o cenário da cidade inteligente Smart Santander.

\subsubsection{Descrição do Cenário: Cidade Inteligente}

O Projeto Smart Santander propõe um cenário experimental de grande escala para pesquisa, que dá suporte a aplicações e serviços para cidades inteligentes. De acordo com Santander (2014), esse cenário experimental é único, em larga escala, aberto e flexível, que se propõe a estimular o desenvolvimento de novas aplicações para usuário de vários tipos, que incluem pesquisas avançadas sobre IoT.

Os seguintes tipos de monitoramento ou dados estão disponíveis (FACILITY, 2013):

- Monitoramento ambiental: em torno de 2000 dispositivos de IoT, instalados em luzes de rua ou fachadas de edifícios que disponibilizam diferentes tipos de dados como níveis de temperatura, $\mathrm{CO}_{2}$, ruído, luminosidade ou presença de veículos. 
- Gerenciamento de áreas externas de estacionamento: em torno de 400 sensores de estacionamento, instalados abaixo do asfalto em áreas do centro da cidade, para se detectar vagas de estacionamento disponíveis.

- Monitoramento ambiental móvel: essa classe de sensores estende o monitoramento ambiental dos pontos estáticos. Esses dispositivos foram instalados em 150 veículos públicos, que incluem ônibus, táxis e carros de polícia.

- Monitoramento da intensidade de tráfego: em torno de 60 dispositivos foram instalados em localizações da cidade de Santander, de modo a mensurar parâmetros como volume de tráfego, ocupação, velocidade dos veículos ou tamanhos das filas.

- Guia para vagas de estacionamento: as informações das vagas de estacionamento são exibidas em 10 painéis localizados nas esquinas das principais avenidas, de modo a guiar os motoristas às vagas disponíveis.

- Irrigação de parques e jardins: em torno de 50 dispositivos instalados em duas áreas verdes da cidade, monitoram a irrigação, utilizando parâmetros como mistura de temperatura e humidade, pluviômetro e anemômetro, de modo a possibilitar a melhor eficiência na irrigação.

- Realidade aumentada: em torno de 2000 etiquetas Identificação por Radiofrequência (RFID) ou Quick Response (QR) Code estão instaladas nos principais pontos de interesse da cidade, distribuem informações dos pontos turísticos, shoppings, lugares públicos, praças, parques, dentre outros. A Figura 28 ilustra a aplicação disponível, que utiliza o conceito de realidade aumentada e as informações existentes.

- Participação no sensoriamento: nesse cenário os usuários que utilizam os dispositivos móveis enviam informações de sensoriamento, como coordenadas de Sistema de Posicionamento Global (GPS), bússula, dados ambientais como ruído, temperatura, dentre outros. Os usuários podem se inscrever para receberem ou relatarem informações sobre os tipos de eventos específicos, que estejam ocorrendo em determinados locais da cidade.

Um dos principais objetivos do projeto é abastecer a comunidade científica de facilidades de experimentação, usuários finais e prover serviços de modo a diminuir barreiras tecnológicas e sociais com relação ao conceito IoT no dia-a-dia. A ideia é atrair o interesse se demonstrando a utilidade da plataforma Smart Santander, com um aspecto que aborda a inclusão de um conjunto de aplicações; aplicações em áreas que possuem alto potencial de impacto 
Figura 28 - Aplicação disponível com realidade aumentada e as informações na cidade de Santander.
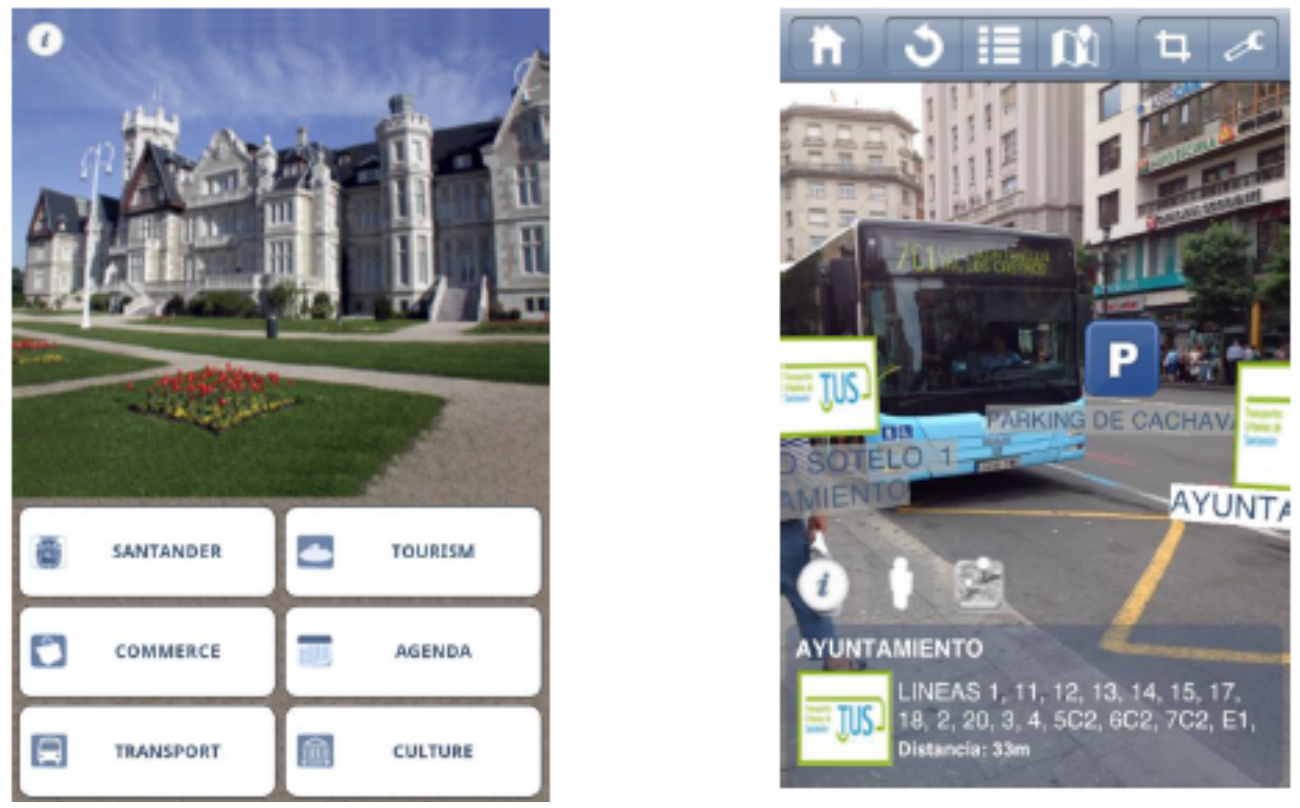

Fonte: (FACILITY, 2013).

para os cidadãos, demostrando diversidade, dinamismo e escala, essencialmente no avanço em soluções e protocolos, atrair indústrias, comunidades de usuário, pesquisadores e outras entidades que poderão desenvolver novos serviços, aplicações, protocolos e algoritmos (FACILITY, 2013) (KRČO et al., 2012).

\subsubsection{Dados obtidos}

Os dados obtidos do projeto Smart Santander estão disponíveis em Jara, Genoud e Bocchi (2014). Foram coletados dados de temperatura, longitude, latitude do ponto de coleta, data e hora e o identificador do sensor, conforme os períodos descritos na Tabela 3 .

Tabela 3 - Tabela com a descrição dos dados de temperatura obtidos no projeto Smart Santander.

\begin{tabular}{|c|c|c|c|c|}
\hline Mês & Dia Inicial & Dia Final & Qtd. Pontos de Coleta & Qtd. Reg. \\
\hline \hline Abril & 01 & 07 & 83 & 140845 \\
Julho & 29 & 30 & 66 & 45064 \\
Agosto & 01 & 04 & 70 & 98900 \\
Dezembro & 02 & 08 & 83 & 199075 \\
\hline
\end{tabular}

Foram coletados dados de tráfego com os atributos como a quantidade de veículos, taxa de ocupação do local, longitude, latitude, data e hora e o identificador do sensor, conforme os períodos descritos na Tabela 4

Todos os dados foram inseridos num banco de dados Mysql (AFFILIATES, 2014), em 
Tabela 4 - Tabela com a descrição dos dados de tráfego obtidos no projeto Smart Santander.

\begin{tabular}{|c|c|c|c|c|}
\hline Mês & Dia Inicial & Dia Final & Qtd. Pontos de Coleta & Qtd. Reg. \\
\hline \hline Abril & 01 & 07 & 38 & 407786 \\
Julho & 29 & 30 & 38 & 109516 \\
Agosto & 01 & 04 & 38 & 218784 \\
Dezembro & 02 & 08 & 38 & 436112 \\
\hline
\end{tabular}

duas tabelas, que servirão para simular as camadas 1 e 2, para as aplicações e experimentos a serem desenvolvidos.

Observa-se que o cenário proposto vai ao encontro dos diversos requisitos propostos na literatura encontrada, como desenvolvimento de uma plataforma para o desenvolvimento de aplicação para a IoT, desenvolvimento de um modelo distribuído para mineração de dados na IoT, desenvolvimento de novos mecanismos para processamento, armazenamento e gerenciamento dos dados intrinsecas à arquiteturada da rede, inferência de comportamentos e otimização de tráfego e uso de energia.

\subsection{MÓDULO DE RECONHECIMENTO DE PADRÕES EM EXECUÇÃO}

A Figura 29 exibe uma página WEB com o status de execução do LinkSmart com todos os seus serviços iniciados. Pode-se observar o nome do serviço ClassificationManagerImpl sublinhado, que está em execução e registrado no LinkSmart middleware com o HID 0.0.0.7721126273323016844.

Foi desenvolvido um Servlet para a visualização de todos os PHID registrados no Pattern Manager. A Figura 30 ilustra o Servlet em execução.

Na Figura 30, pode-se observar o HID ao qual o Pattern Manager foi registrado como serviço no LinkSmart, nesse caso com o valor 0.0.0.7721126273323016844, e os 5 PHIDs registrados no Pattern Manager, com suas respectivas classes de serviços e a quantidade de instâncias de dados inseridas no módulo de reconhecimento de padrões.

\subsection{APLICAÇÃO DE TESTE DA COMUNICAÇÃO CROSS LAYER}

Foi desenvolvida uma aplicação que simula o resource manager e uma aplicação cliente de teste.

Os dados utilizados nesse experimento e em todos os próximos experimentos descritos nas próximas seções são provenientes da Guildford's facility proposto no projeto Smart Santander (NATI et al., 2013). 
Figura 29 - Página com o status do LinkSmart.

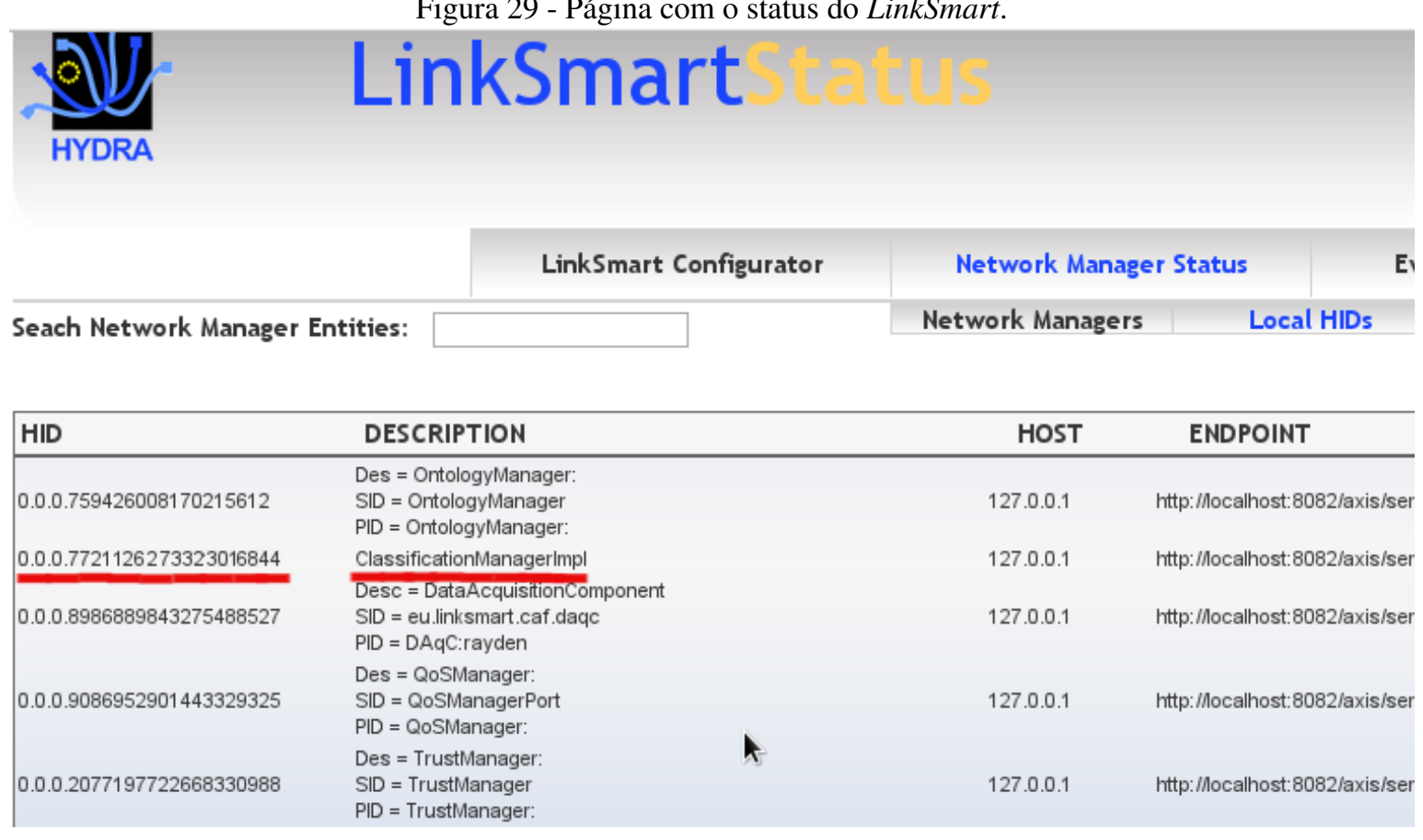

Fonte: Elaborada pelo autor.

Figura 30 - Página de status gerada pelo Servlet do gerenciador de padrões.

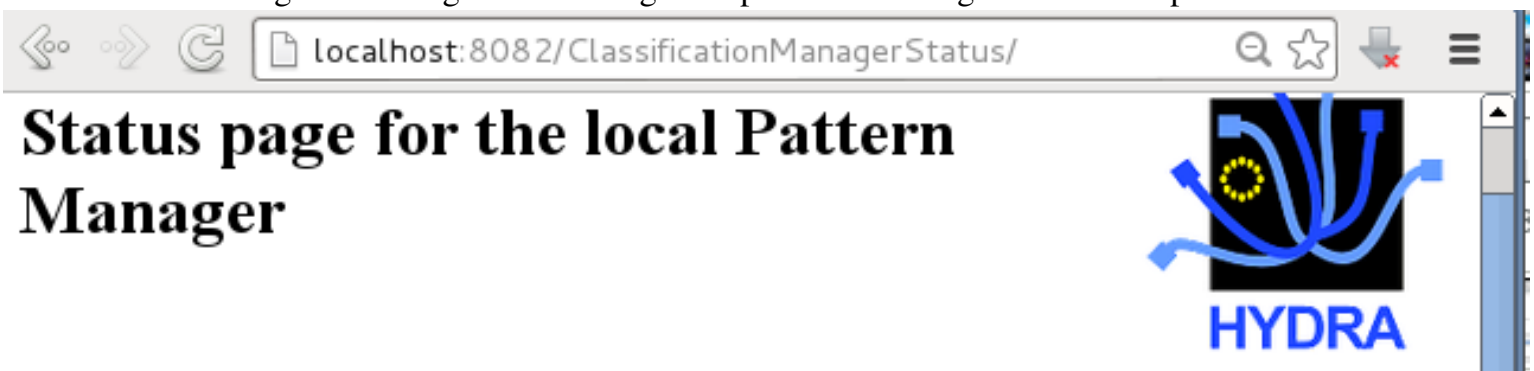

\section{Pattner Manager $\mathrm{HID}=$ \\ 0.0.0.7721126273323016844}

\section{List Patterns HID:}

\begin{tabular}{l|l|l|l||}
\hline PHID & TYPE & TYPE ALGORITHM & INSTANCES \\
\hline 5097083535931 & PUBLISHER & CLUSTERING ALGORITHM & 413 \\
\hline 0774677399488 & PUBLISHER & CLUSTERING ALGORITHM & 2885 \\
\hline 2010306082003 & PUBLISHER & CLUSTERING ALGORITHM & 1447 \\
\hline 9716210192722 & PUBLISHER & CLUSTERING ALGORITHM & 1447 \\
\hline 9167016986134 & PUBLISHER & CLUSTERING ALGORITHM & 8606 \\
\hline \hline
\end{tabular}

Fonte: Elaborada pelo autor.

Os dados requisitados foram inseridos em um banco de dados Mysql (DUBOIS, 2014) e foi desenvolvida uma classe que simula o resource manager. Essa classe provê dados 
como temperatura e luminosidade de um sensor chamado node25. Essa experimentação, bem como as aplicações descritas nas experimentações dos algoritmos de clustering e de detecção de outlier, nas Seções 4.4 e 4.5, respectivamente, são provas de conceito, por isso o uso dos dados de um único sensor, porém a arquitetura desenvolvida está preparada para processar grandes volumes de dados de acordo com o conceito de Big Data.

Para ilustrar a proposta de comunicação cross layer foram criadas duas aplicações: (1) ResourceManager que representa a camada física e é responsável por resgatar os dados a partir do banco de dados Mysql e enviá-los para o pattern manager no LinkSmart Middleware; e (2) a aplicação cliente responsável por controlar o comportamento das camadas de Middleware e física.

Figura 31 - Aplicação que simula o Resource Manager que representa a camada física na validação da comunicação cross layer.

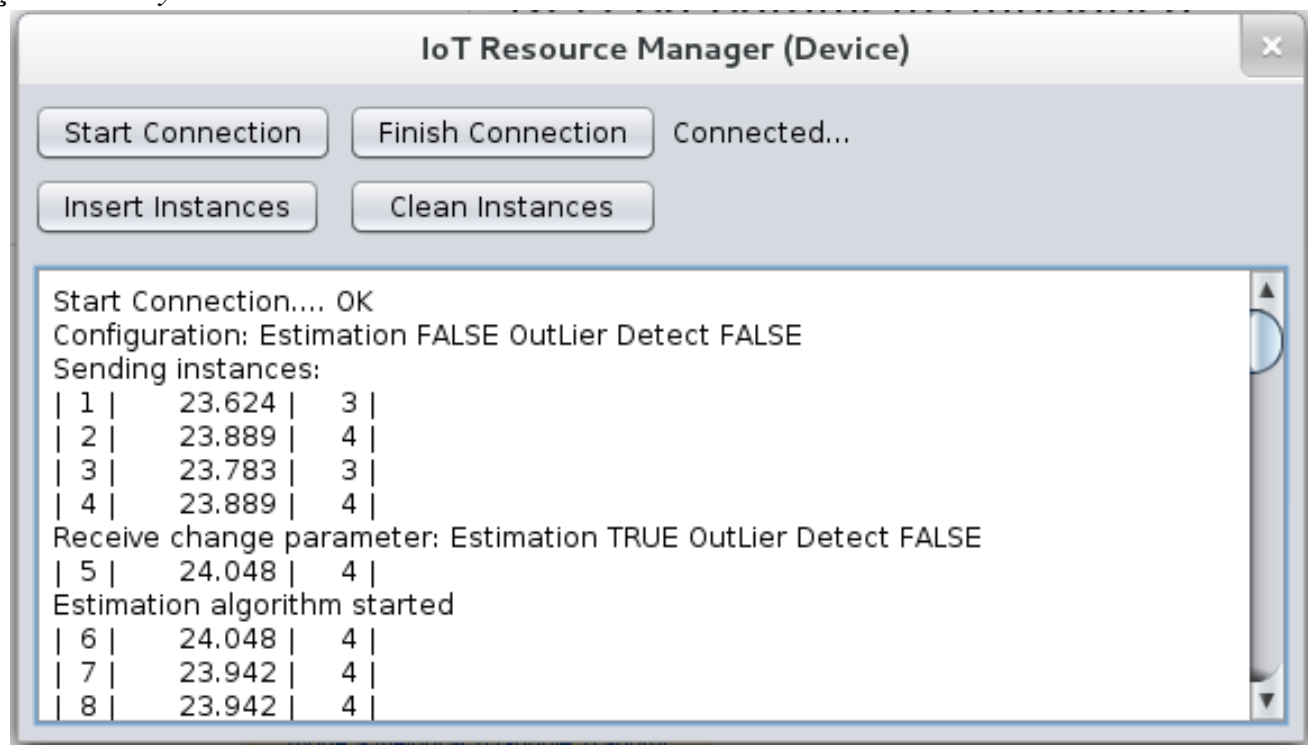

Fonte: Elaborada pelo autor.

A Figura 31 ilustra a execução da aplicação que simula o Resource Manager que representa a camada física. Essa aplicação implementa duas funções: ela possui a implementação do algoritmo de estimação de valores, de modo a estimar valores caso o dado real seja perdido e seja relevante no contexto da aplicação; e a implementação do algoritmo de detecção de outlier, caso um dado com valor errado represente um problema para a aplicação, conforme o proposto em Souza e Amazonas (2013).

Outro aspecto relevante dessa aplicação é a capacidade de enviar e receber parâmetros a partir e para as camadas de Middleware e aplicação. A aplicação inicia a conexão com a camada de Middleware, informa o estado dos serviços e começa a enviar as instâncias com valores de temperatura e intensidade de luminosidade do ambiente. Em um dado momento a camada física recebe uma mensagem alterando o estado do parâmetro de estimação de valores de modo a iniciar esse serviço nessa camada. Essa execução ilustra como a comunicação 
cross layer altera o comportamento da camada de física em tempo de execução.

A Figura 32 ilustra a execução da aplicação cliente desenvolvida para o experimento.

Figura 32 - Execução da aplicação cliente desenvolvida para o experimento da comunicação cross layer.

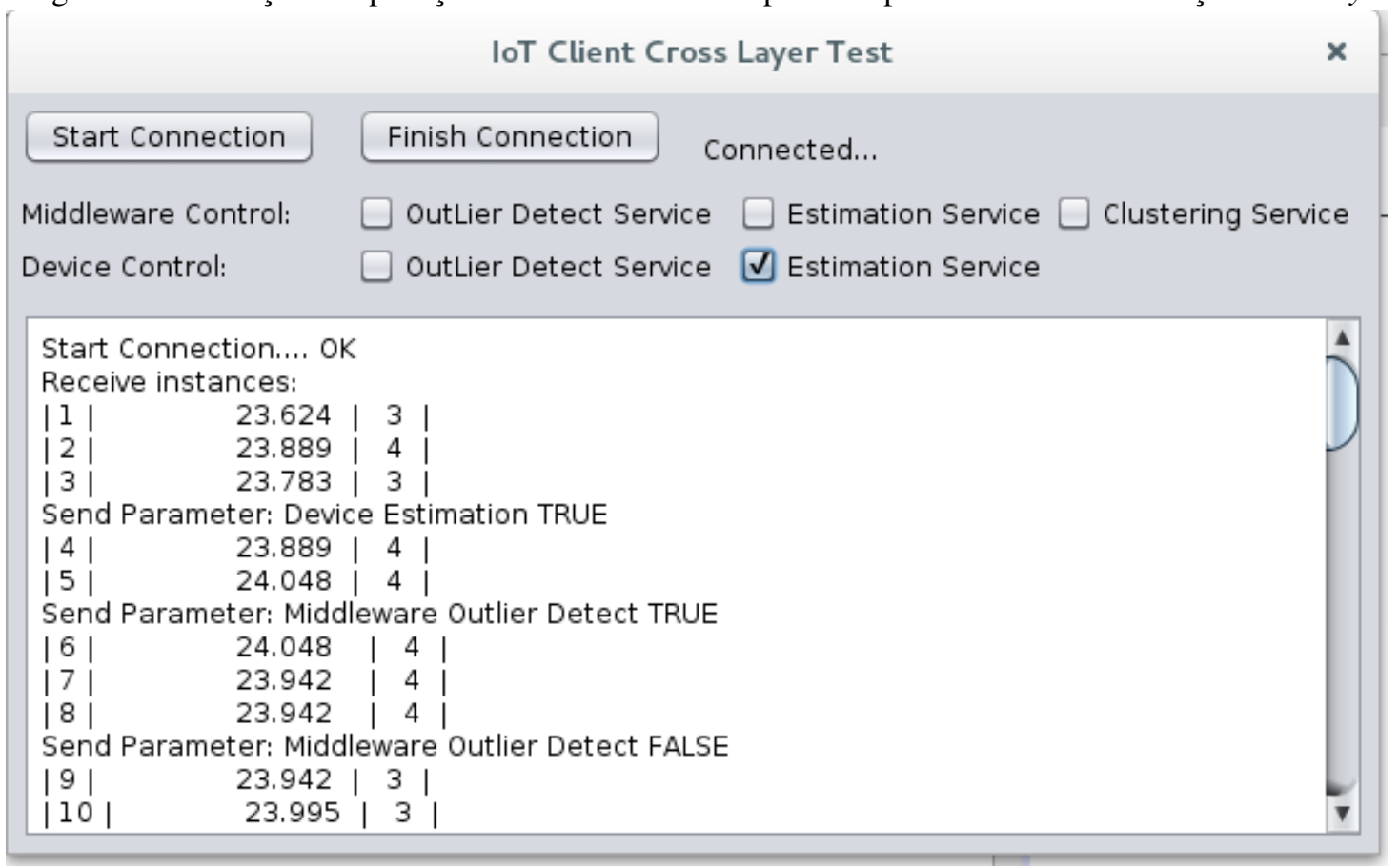

Fonte: Elaborada pelo autor.

A aplicação ilustrada pela Figura 32 possui duas funções: $(i)$ ilustrar a aplicação cliente da camada de Middleware; (ii) implementar a função de controle do comportamento da camada física e da middleware. A partir da interface gráfica da aplicação o usuário pode desativar ou ativar os serviços de estimação de valores e detecção de outlier na camada física e os serviços de estimação de valores, detecção de outlier e clustering presentes na camada de middleware.

Na execução da aplicação ilustrada pela Figura 32, pode-se observar que o programa inicia a conexão com o LinkSmart e começa a receber as instâncias com seus respectivos valores. No momento posterior, o usuário seleciona o checkbox solicitando a execução do serviço de estimação de valores na camada física. Logo após, o usuário marca o checkbox para iniciar o serviço de detecção de outlier na camada de middleware e, logo após, o desmarca para desabilitar o mesmo serviço na camada de middleware, ações que ilustram como a comunicação cross layer se faz necessária para o gerencimeto do comportamento dos serviços nas camadas inferiores do modelo de IoT proposto.

A Figura 33 ilustra um trecho do arquivo de $L O G$ gerado pela execução dos serviços implementados no ClassificationManager embutido no LinkSmart Middleware.

Na Figura 33 pode-se observar o trecho do arquivo de $L O G$ que se refere à execução do ClassificationManager no momento de execução experimental das aplicações de Resource 
Figura 33 - Trecho do arquivo de $L O G$ de execução dos serviços do ClassificationManager.

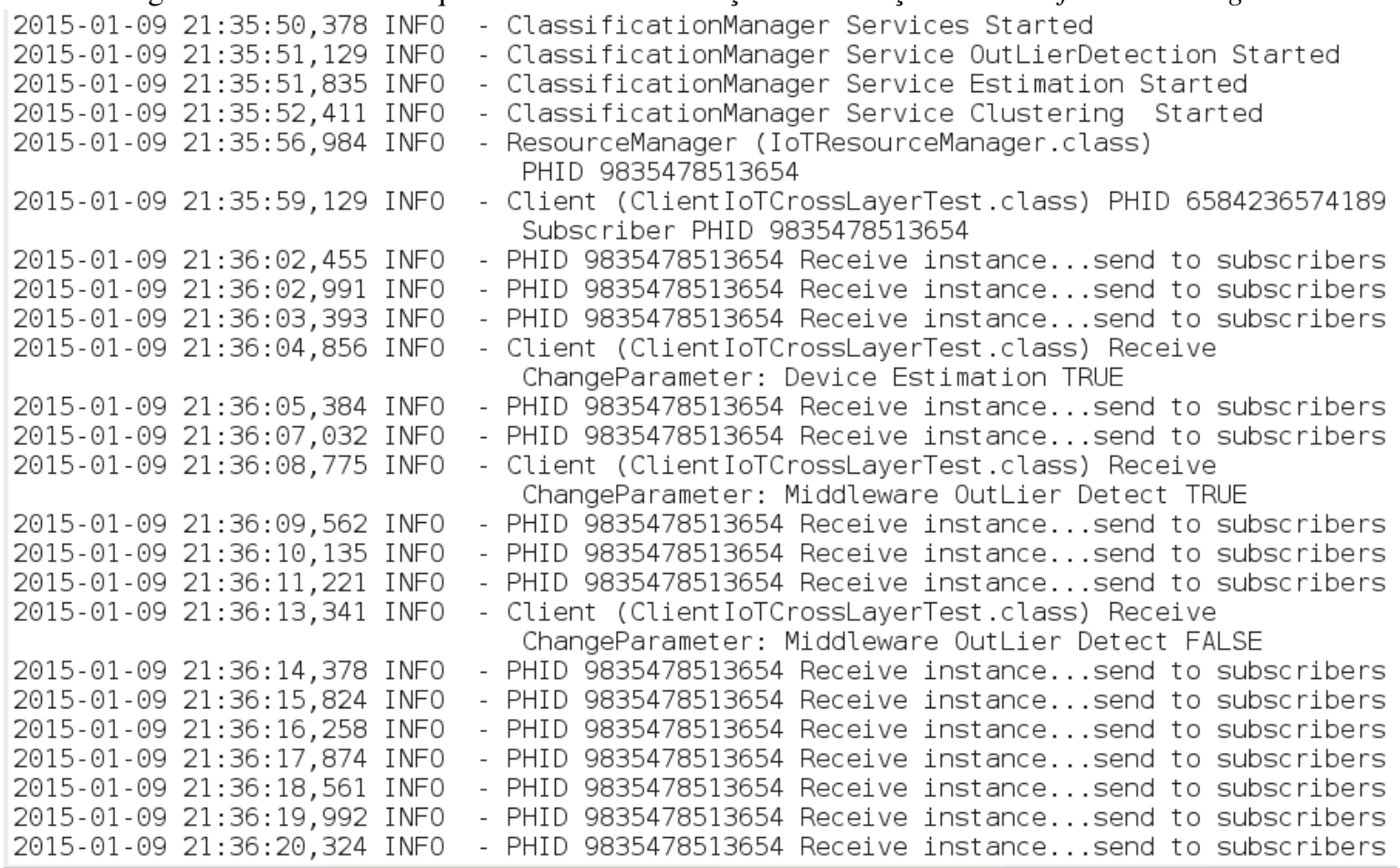

Fonte: Elaborada pelo autor.

Manager e cliente. O trecho de $L O G$ exibe algumas linhas referentes à inicialização do ClassificationManager e dos serviços de reconhecimento de padrões, seguido pelas ações das aplicações IoTResourceManager, que representa a camada física e ClientIoTCrossLayerTest, que representa a camada de aplicação. Observa-se a sequência de ações ilustradas na execução das aplicações, como o Resource Manager enviando as instâncias para o LinkSmart, a aplicação cliente enviando mensagens para a camada física com o parâmetro para inciar o serviço de estimação de valores. A camada de aplicação enviando as mensagens para a camada de Middleware para iniciar e, posteriormente, para desativar o serviço de deteção de outlier nessa camada.

Percebe-se pela experimentação descrita que a camada de aplicação se comunica com as camadas física e de middleware de modo a alterar seus comportamentos.

\subsubsection{Conclusões da experimentação da comunicação cross layer}

Nesse experimento foi validada a implementação da estrutura de comunicação cross layer na arquitetura de IoT. A estrutura integra-se à nova arquitetura de IoT implementada através da estensão do LinkSmart Middleware com os serviços de detecção de outlier, estimação de valores e algoritmo de clustering na camada de middleware, e a implementação de serviços para a detecção de outlier e estimação de valores na camada física. 
A implementação da estrutura proposta permite que a camada de aplicação interaja com as camada inferiores no modelo de IoT e modifique seus comportamentos, mais especificamente nas camadas física e de middleware. A camada de aplicação pode habilitar ou desabilitar os serviços existentes.

As aplicações desenvolvidas para o experimento validam a proposta de comunicação cross layer integradas à arquitetura de IoT, com serviços de reconhecimento de padrões e dados reais provinientes do projeto Smart Santander.

\subsection{APLICAÇÃO DE TESTE DO SERVIÇO DE CLUSTERING}

A classe Resource Manager requisita um PHID de modo a se registrar como um nova origem de dados no Pattern Manager. Nesse momento é passado parâmetro de configuração de algoritmo, que pode ser de detecção de outlier, estimação de valores ou de clustering. No próximo passo, a classe pode enviar os dados ao Pattern Manager.

Figura 34 - Execução da classe Resource Manager para experimentação do serviço de clustering na camada de middleware.

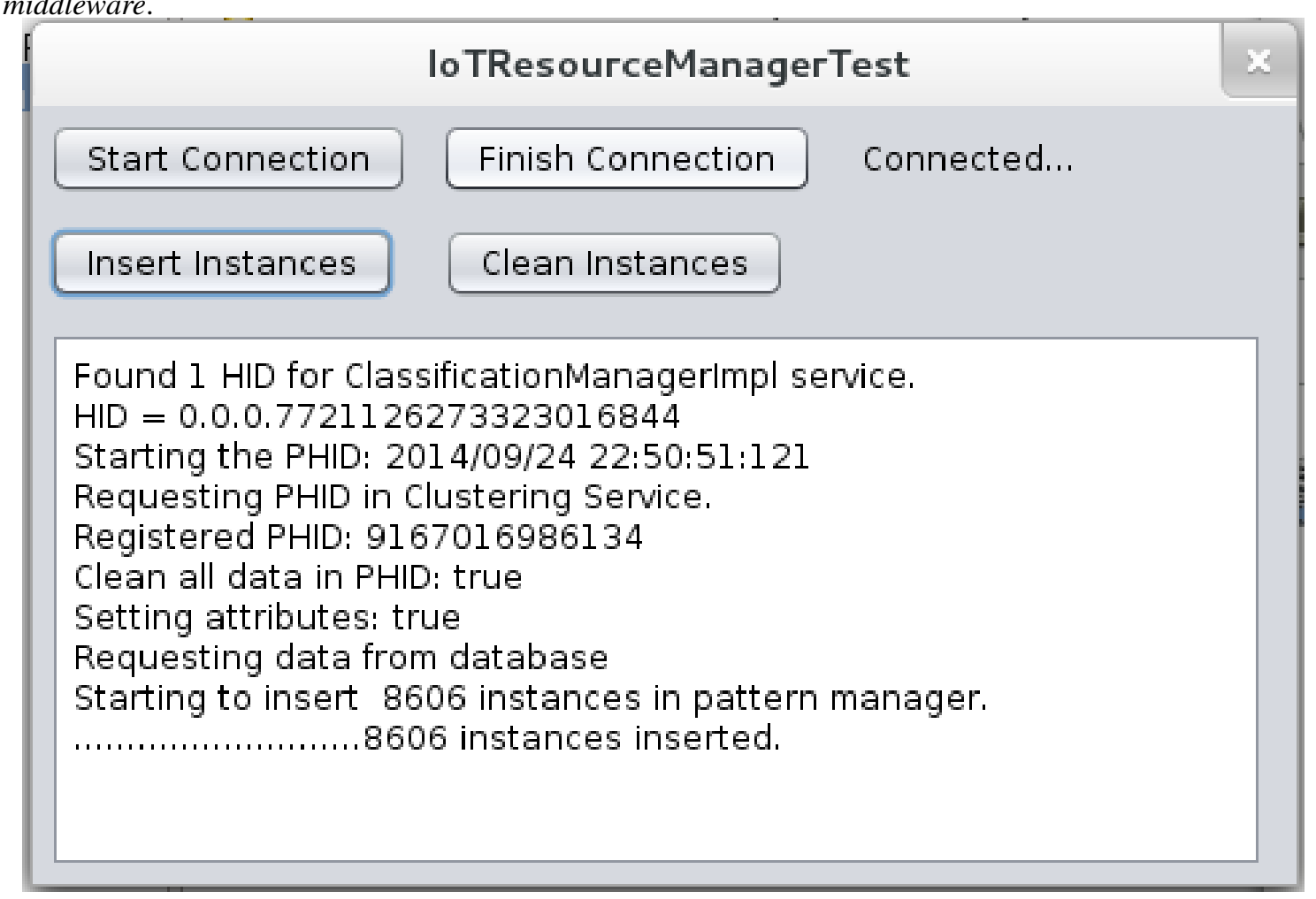

Fonte: Elaborada pelo autor.

A Figura 34 ilustra a aplicação que simula o Resource Manager em execução. A aplicação requisita o serviço ClassificationManagerImpl, que representa o serviço do Pattern Manager e solicita um PHID, de modo a se registrar no módulo. Observa-se que a aplicação foi registrada com o PHID 9167016986134 e ela passa a enviar as instâncias de dados para o 
Pattern Manager. Esses dados correspondem a dados de temperatura e luminosidade da base de dados no dia 01/02/2014, no horário entre $00: 00: 00$ e $23: 59: 59$.

A aplicação cliente desenvolvida, implementa duas funções: (i) utilizar o módulo de Pattern Manager como cliente; e (ii) usar os serviços do novo módulo como um coordenador, de modo a controlar a execução do algoritmo. A Figura 35 ilustra a execução dessa aplicação.

Figura 35 - A aplicação cliente para experimentação do serviço de clustering na camada de middleware.

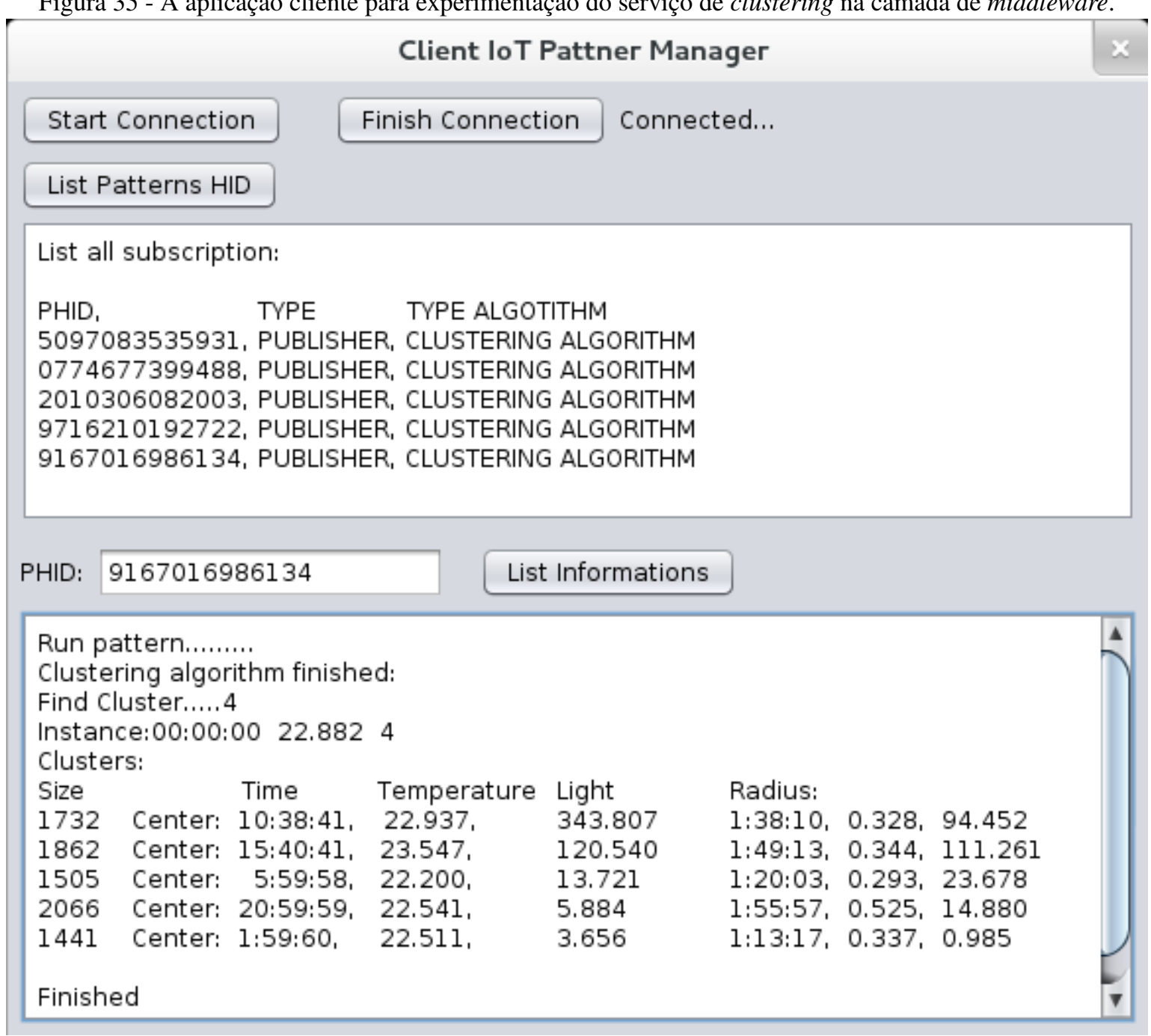

Fonte: Elaborada pelo autor.

Na Figura 35 pode-se observar a aplicação cliente requisitando e listando todas as classes Resource Manager registradas no Pattern Manager. Em seguida, a classe inicia a execução do algoritmo de clustering. Quando a execução do algoritmo é finalizada a classe recebe uma notificação enviada pelo serviço do LinkSmart Event Manager. Logo após, a classe solicita a classificação de uma nova instância e as informações sobre os clusters encontrados pelo algoritmo. A instância passada como parâmetro foi classificada no cluster 4, sendo assim, ela é composta por valor de tempo, temperatura e intensidade de luz que está mais próxima 
do centróide 4, sem exceder o raio do cluster encontrado.

Pode-se observar que os 5 clusters encontrados, expressam consistentemente a classificação existente na variação dos dados de temperatura e luminosidade em um dia. A Figura 36 exibe todas as instâncias em um gráfico em $3 D$.

Figura 36 - Todas as instâncias mostradas em um gráfico 3D e todos os clusters identificados por números e diferentes cores.

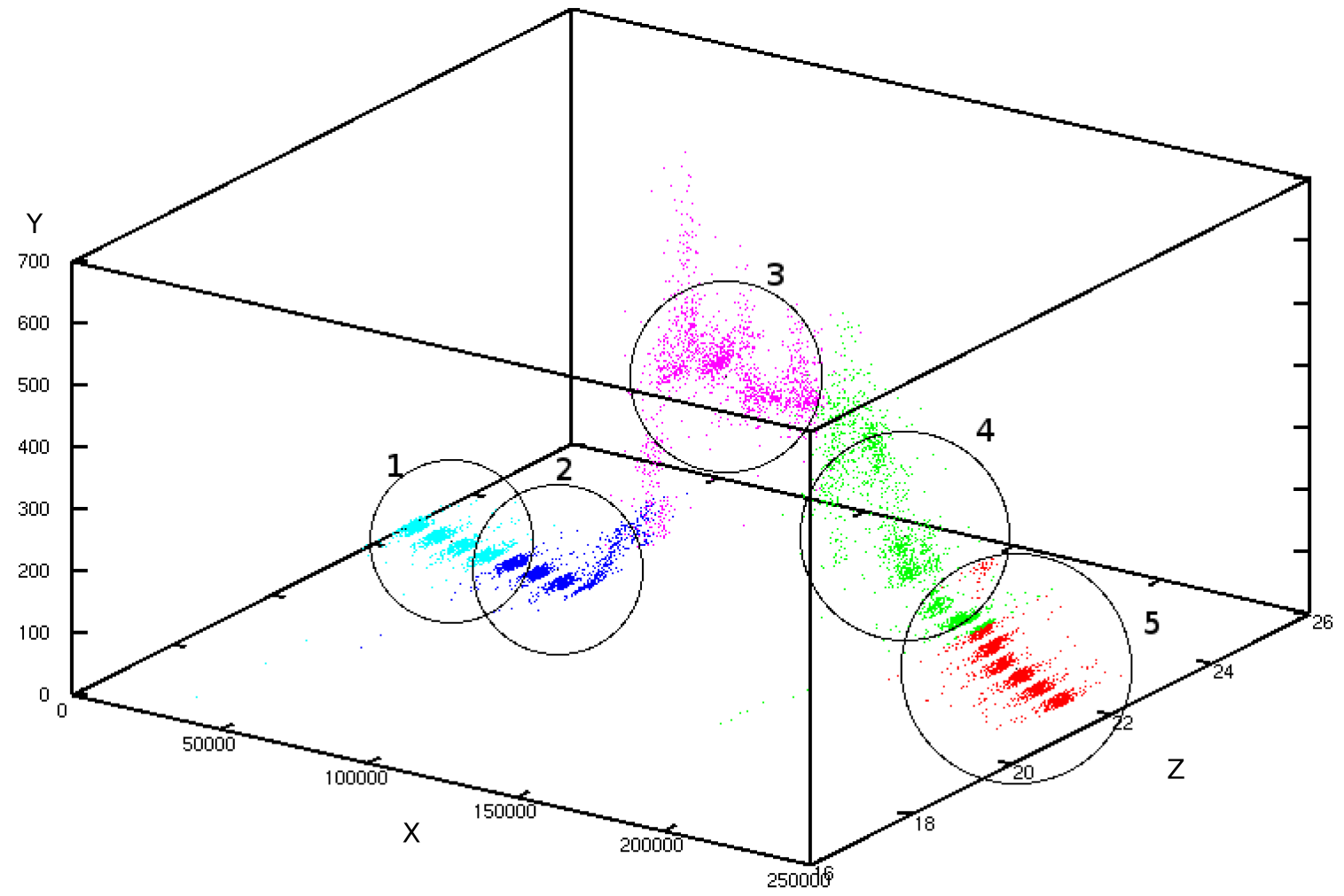

Fonte: Elaborada pelo autor.

Na Figura 36 os clusters estão identificados por números e diferentes cores. O eixo $x$ representa a variação de tempo, entre 00:00:01 e 23:59:59, porém, no gráfico não exibidos sem a sepração por “:"; o eixo y representa a intensidade de luz, que varia entre 0 e 700, porém o sensor de luminosidade retorna valores mínimos e máximos entre 0 e 1024; e o eixo $z$ representa a temperatura, que varia entre 16 e 24 graus Celsius. Pode-se observar que o algoritmo cria clusters consistentes ao separar todas as instâncias nos 5 clusters, conforme a seguir: cluster (1) representado em ciano, cluster (2) representado em azul, cluster (3) representado em magenta, cluster (4) representado em verde, e, por fim, o cluster (5) representado em vermelho. Em cada centro de cluster, estão localizados círculos pretos, que representam os centróides de cada cluster encontratos pelo algoritmo e um círculo maior, que representa o raio de cada cluster.

O modelo proposto pelo algoritmo foi validado através do Sum of the Square Errors (SSE) 
e pelo Silhouette Coefficient, sugerido em Zaki e Meira (2014), Para se encontrar a quantidade ideal de clusters optou-se por se mininizar o valor de SSE, porém não se chegar a zero. Ao se desenhar o gráfico de decaimento do SSE observa-se a acentuação da curva ou um ponto de mergulho.

Os valores obtidos pelo decaimento do SSE são mostrados na Figura 37.

Figura 37 - Decaimento do SSE pela quantidade de clusters.

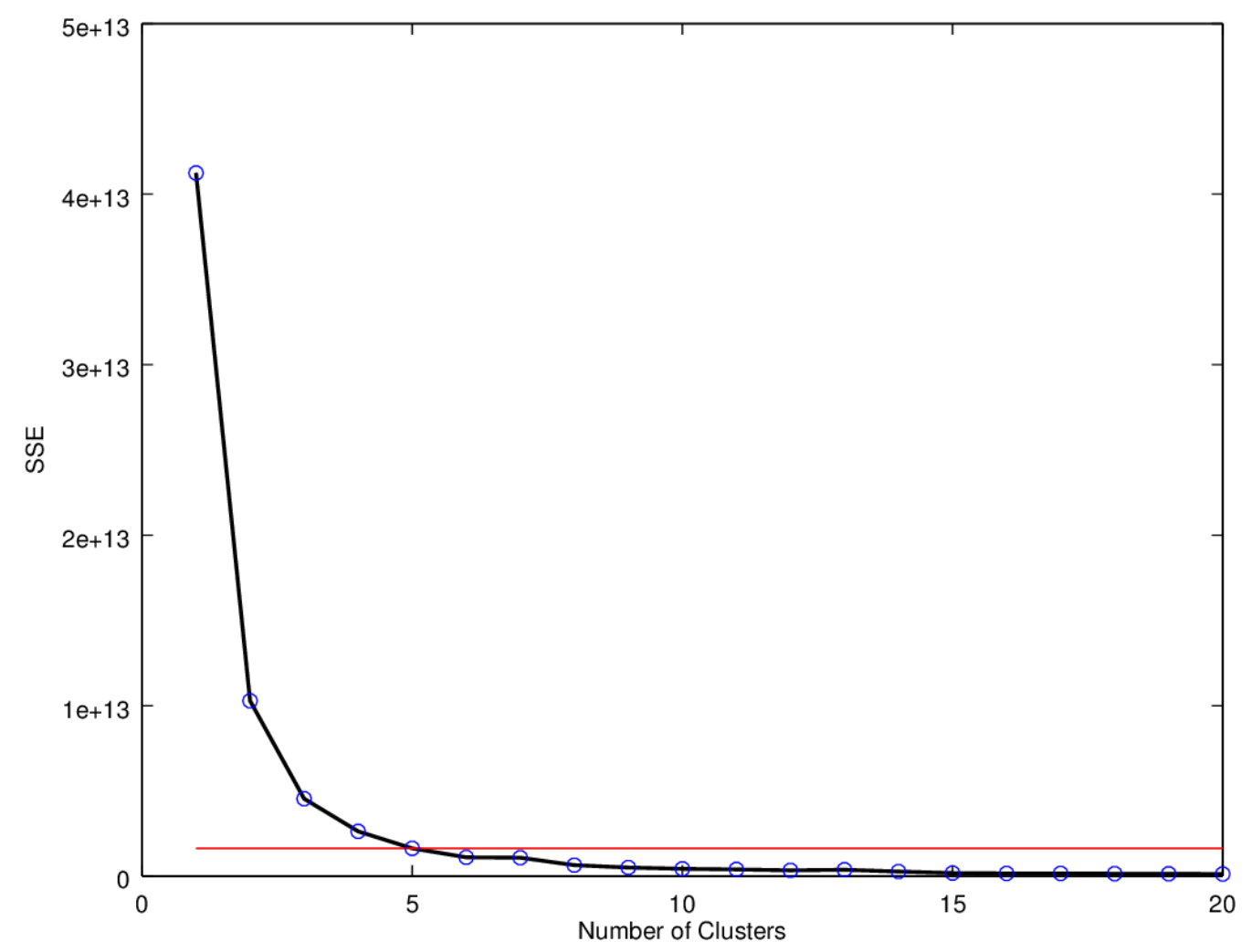

Fonte: Elaborada pelo autor.

Na Figura 37 observa-se o decaimento do valor de ESS, no qual no eixo das abscissas está a quantidade de clusters e no eixo das ordenadas os valores de SSE. Adotando o critério de SSE $<1.63145$ como ponto de mergulho da curva, pode-se verificar no gráfico que o valor ideal de clusters é 5.

O silhouette coefficient fornece valores entre 0 e 1 , sendo que a quantidade ideal de clusters deve possuir um valor mais próximo de 1 . Os valores obtidos pelo cálculo do Silhouette coefficient são mostrados na Figura 38, com os valores de Silhouette coefficient no eixo das ordenadas e as respectivas quantidades de clusters no eixo das abscissas. O ponto com valor de Silhouette coefficient mais próximo de 1 é 5.

Assim, a quantidade ideal de clusters para o modelo proposto é de 5 clusters e a implementação proposta propõe e classifica o modelo a contento, demonstrando que a arquitetura 
Figura 38 - Valores do Silhouette coefficient pela quantidade de clusters.

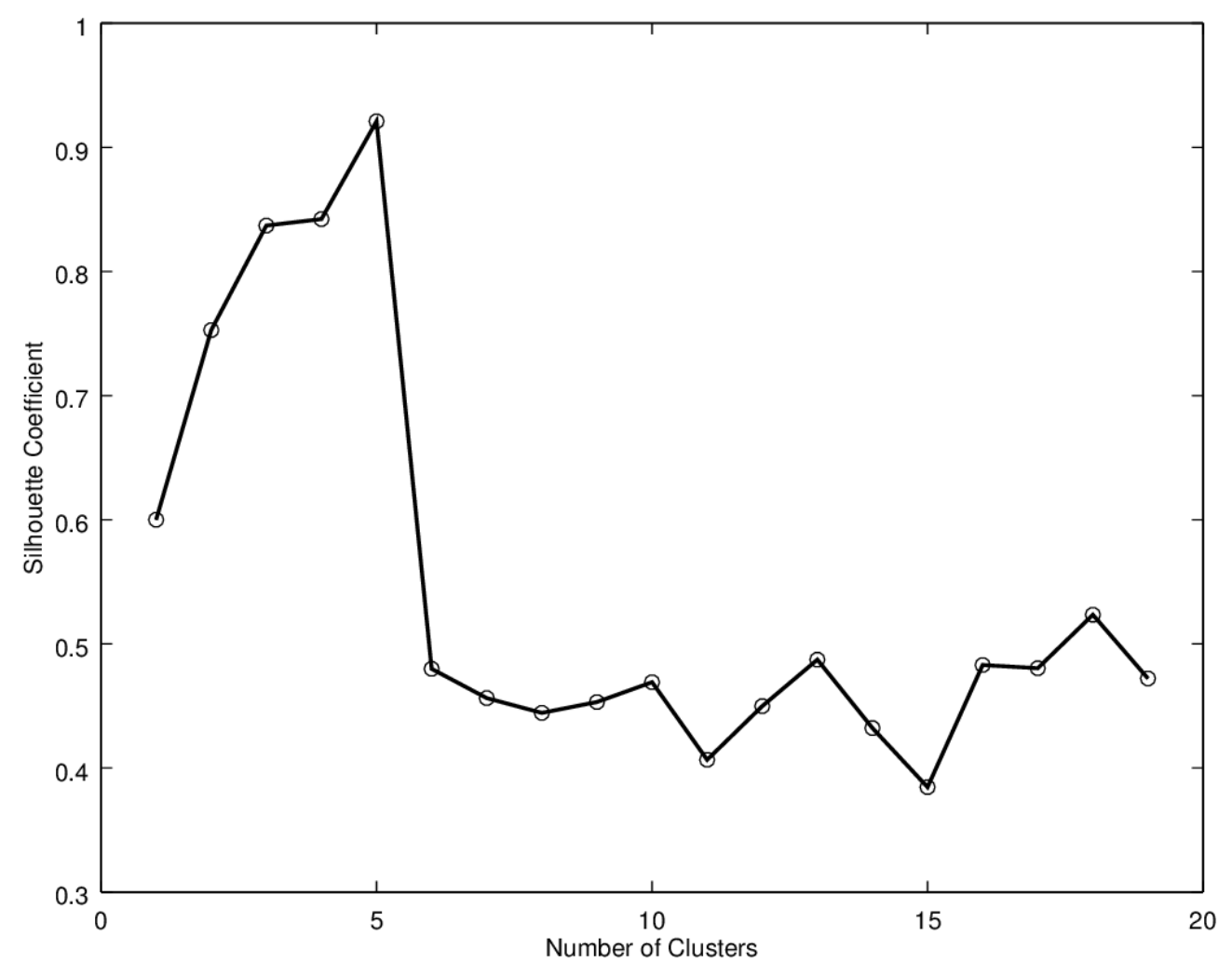

Fonte: Elaborada pelo autor.

e a implementação do serviço de clustering produzem resultados satisfatórios.

\subsubsection{Conclusões da experimentação do serviço de clustering}

O desenvolvimento de uma aplicação específica está fora do escopo desta pesquisa, pois o principal objetivo e contribuição é a arquitetura e o processameto nas camadas inferiores do modelo de IoT e não somente na camada de aplicação, como ocorre no modelo OSI. A abordagem modular desenvolvida permite a incorporação de diferentes implementações algorítmicas e garante a independência entre a implementação dos algoritmos e arquitetura.

A implementação da aplicação de teste ilustra a validação da arquitetura e do serviço de clustering com bases de dados reais do projeto Smart Santander. Sua execução permite verificar que a nova arquitetura com o módulo de análise reconhecimento de padrões com Big Data, baseada na arquitetura IoT-A em funcionamento com o LinkSmart Middleware consegue modelar dados do mundo real na camada de middleware e diminuir a carga de processamento na camada de aplicação.

O serviço de clustering pode ser útil para a contextualização e classificação dos dados 
oriundos das diferentes fontes de dados no contexto de IoT, pode ser utilizado para a criação de sensores virtuais, como por exemplo, uma aplicação que necessite apenas do contexto de temperatura e taxa de ocupação de determinadas áreas da cidade, que não necessite dos dados reais e precisos dos diversos sensores. O serviço de clustering poderia apenas informar se a temperatura e a taxa de ocupação estão altos ou baixos

\subsection{APLICAÇÃO DE TESTE DO SERVIÇO DE DETECÇÃO DE OUTLIER}

A aplicação cliente desenvolvida neste experimento possui três funções: (i) ser um $R e$ source Manager que resgata os dados e os insere no Middleware, (ii) ser um cliente do módulo de reconhecimento de padrões; e (iii) usar o módulo como coordenador, de modo a configurar e controlar a execução do algoritmo de detecção de outlier.

A Figura 39 ilustra a execução da aplicação de teste do serviço de detecção de outlier desenvolvido.

Essa aplicação inicia a conexão com o LinkSmart Middleware, resgata e insere todas as instâncias no módulo, cria o modelo com as instâncias reais e, por fim, o resgata do $M i$ ddleware. No próximo passo, a aplicação gera novas instâncias para a análise, submete cada instância ao modelo criado e exibe os resultados na interface gráfica.

Conforme se observa em Han, Kamber e Pei (2011) e Zumel, Mount e Porzak (2014), para se avaliar o desempenho de um preditor ou classificador pode-se construir uma curva Receiver Operation Characteristics (ROC), mas se faz necessário reduzí-la a um valor escalar. Para isso, pode-se calcular a área abaixo da curva ou Area Under Curve (AUC), que assumirá valores entre 0 e 1 . Um classificador perfeito possui $A U C$ igual a 1 e classificadores aleatórios possuem valores de $A U C$ iguais a 0,5 . Observa-se que o ponto $(0,1)$ no espaço $R O C$ representa um classificador perfeito e qualquer classificador que estiver acima da linha diagonal que vai do ponto $(0,0)$ ao ponto $(1,1)$ é dado como melhor do que um classificador aleatório e possuirá valor de AUC acima de 0,5 (ZUMEL; MOUNT; PORZAK, 2014). A Figura 40 exibe a curva ROC gerada considerando os resultados do classificador criado a partir do modelo de dados real gerado pelo algoritmo de detecção de outlier proposto.

A sua $(A U C)$ com o valor de 0.8967 , que é considerado um bom resultado para um classificador.

Para esse modelo de teste criado, foram inseridas 8595 instâncias reais, 8595 instâncias outliers criadas com valores aleatórios a partir de instâncias reais. O conjunto com as instâncias reais e as instâncias outliers foram submetidas à análise do algoritmo de detecção de outlier implementado. A aplicação desenvolvida exibe todas as instâncias submetidas ao modelo, respectivamente com o resultado de sua classificação se é outlier, com o resultado 
Figura 39 - Execução da aplicação de teste do serviço de detecção de outlier desenvolvido.

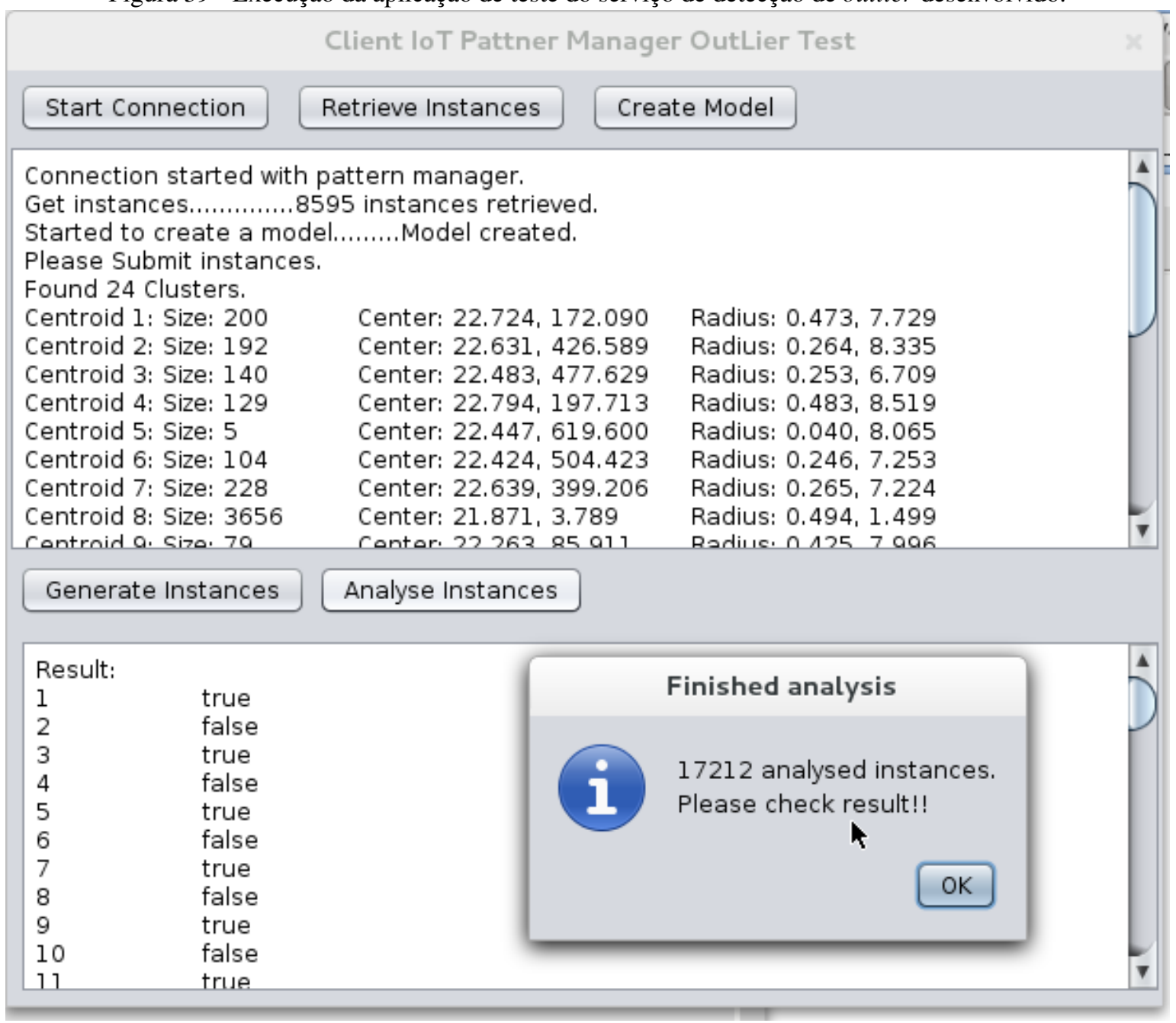

Fonte: Elaborada pelo autor.

verdadeiro ou falso. Este conjunto de resultados foi utilizado para gerar a curva $R O C$.

A execução da aplicação utilizou dados com a temperatura e luminosidade referentes ao período entre $01 / 02 / 2014$ às $00: 00: 00$ e 01/02/2014 às $23: 59: 59$. Foram executados testes utilizando valores obtidos em períodos diários para todos os dias do mês de fevereiro. Obteve-se respectivamente os seguintes valores de mínimo, médio e máximo AUC 0.8456, 0.8762 e 0.9465 para os testes executados. A partir destes resultados pode-se observar que o algoritmo teve um desempenho satisfatório.

A aplicação desenvolvida verifica as duas funções de: $(i)$ implementar a coordenação de execução e parametrização do algoritmo, de se carregar as instâncias e, posteriormente, criar o modelo no pattern manager; e (ii) verificam a arquitetura integrada ao LinkSmart Middleware. Uma aplicação que utilize a arquitetura desenvolvida com o serviço de detectção de outlier receberá todas as instâncias sem nenhum outlier, eliminando uma carga maior de processamento em se analisar essa situação no conjunto completo de dados. A arquitetura 
Figura 40 - Curva $R O C$ gereda a partir os resultados do classificador gerado com o modelo criado pelo algoritmo de detecção de outlier desenvolvido.

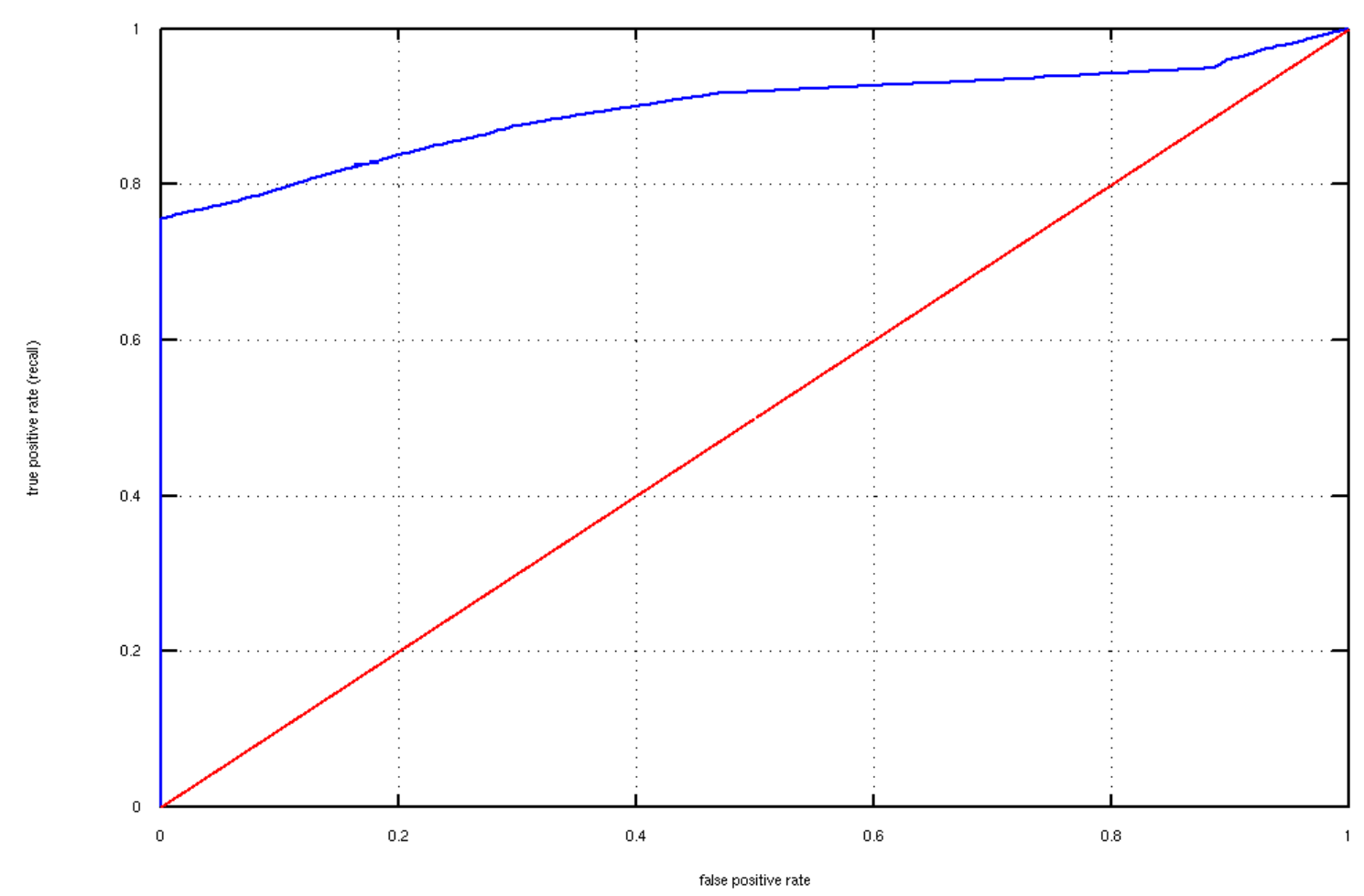

Fonte: Elaborada pelo autor.

envia informações filtradas para todas as aplicações clientes, que reduz o processamento na camada de aplicação, o que contribui para maior eficiência energética e o aumento da escalabilidade, quanto à quantidade de clientes com maior ou menor poder computacional.

\subsubsection{Conclusões da experimentação do serviço de detecção de outlier}

A implementação da aplicação de teste valida o algoritmo proposto e a nova arquitetura de IoT usando bases de dados reais do projeto Smart Santander. A execução ilustrou o funcionamento da arquitetura integrada ao LinkSmart e que o serviço de detecção de outlier, implementado na camada de middleware, consegue criar modelos a partir de dados reais. As curvas $R O C$ geradas a partir dos resultados ilustram o bom desempenho do algoritmo de detecção de outlier proposto, e que é uma das contribuições originais da pesquisa (SOUZA; AMAZONAS, 2015).

O serviço de detecção de outlier será útil para aplicações nas quais a precisão das leituras de dados sejam críticas e quaisquer valores distantes dos reais represetem ações com grandes impactos errônoes no ambiente. 


\subsection{APLICAÇÃO DE TESTE DO SERVIÇO DE ESTIMAÇÃO DE VALORES}

A aplicação desenvolvida nesse experimento possui três funções: (i) ser um Resource Manager que resgata os dados e os insere no Middleware, (ii) ser um cliente do módulo de reconhecimento de padrões; e (ii) usar o módulo como coordenador, de modo a controlar a execução do algoritmo de estimação de valores. Essa classe provê dados como temperatura e luminosidade do sensor node25.

A Figura 41 ilustra a execução da aplicação desenvolvida para os experimentos com o serviço de estimação de valores.

Figura 41 - Execução da aplicação de teste do serviço de estimação de valores desenvolvido.

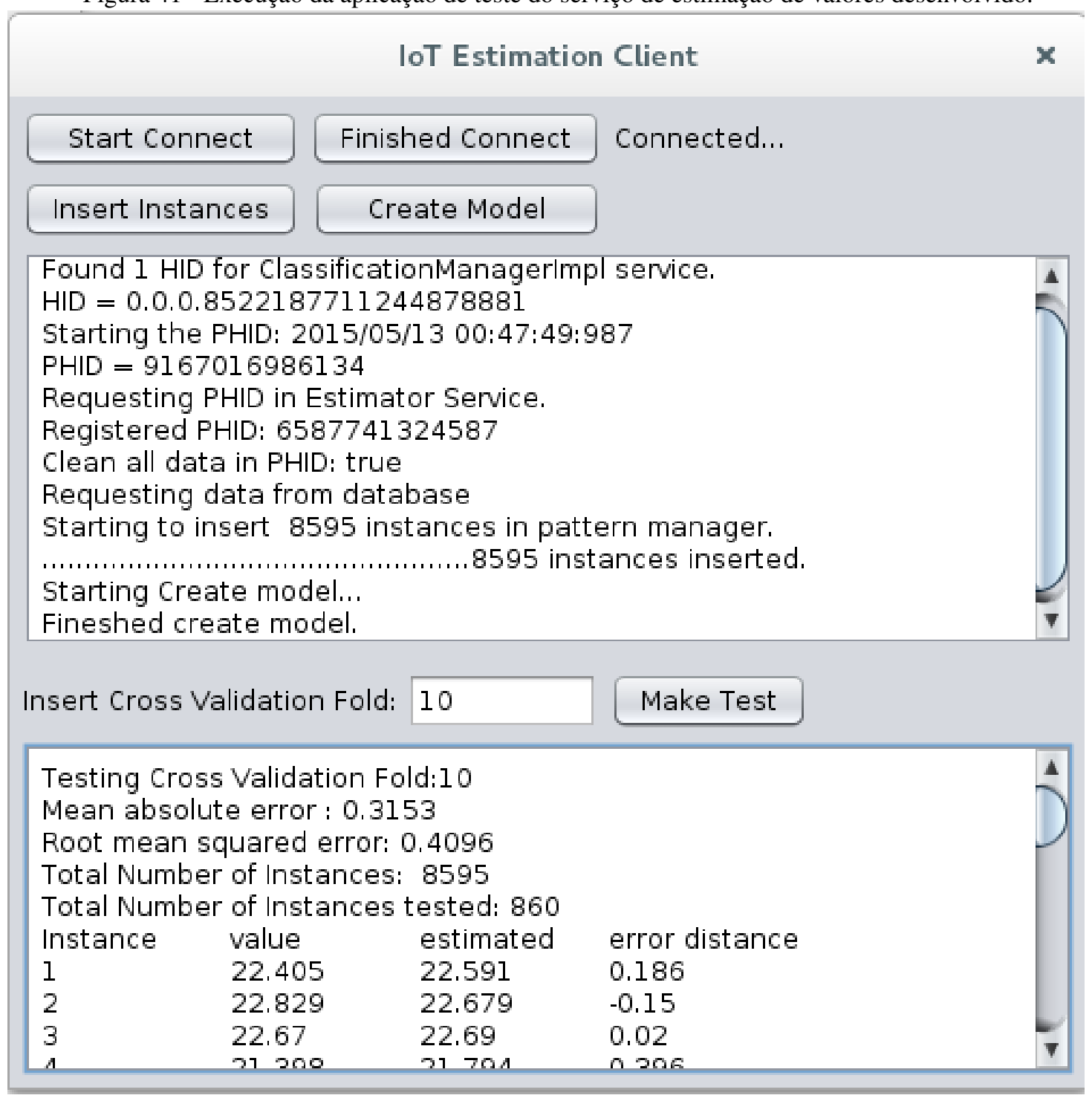

Fonte: Elaborada pelo autor.

Pode-se observar na Figura 41 que a aplicação desenvolvida possui as três funções: $(i)$ de Resource Manager com que ela resgata os dados da base de dados, (ii) como coordenador, inicia a conexão com o LinkSmart, requisita um PHID, nesse caso com o valor 
6587741324587 e, logo após, inicia o envio das instâncias para o PatternManager e no final da inserção a aplicação solicita a criação do modelo de regressão linear no Middleware, (iii) como aplicação cliente, ela solicita o modelo de regressão e faz os testes com a técnica de validação cruzada, de modo a validar o modelo criado pelo Middleware.

Como resultados a aplicação exibe Mean Absolute Error (MAE), com o valor 0,3153, e o Root Mean Squared Error (RMSE) (CHAI; DRAXLER, 2014), com o valor 0,4096, que são indicadores estatísticos de desempenho. A Figura 42 ilustra as instâncias e valores estimados exibidos como resultado na aplicação, no processo de validação cruzada.

Figura 42 - Gráfico com as instâncias reais e seus respectivos valores estimados.

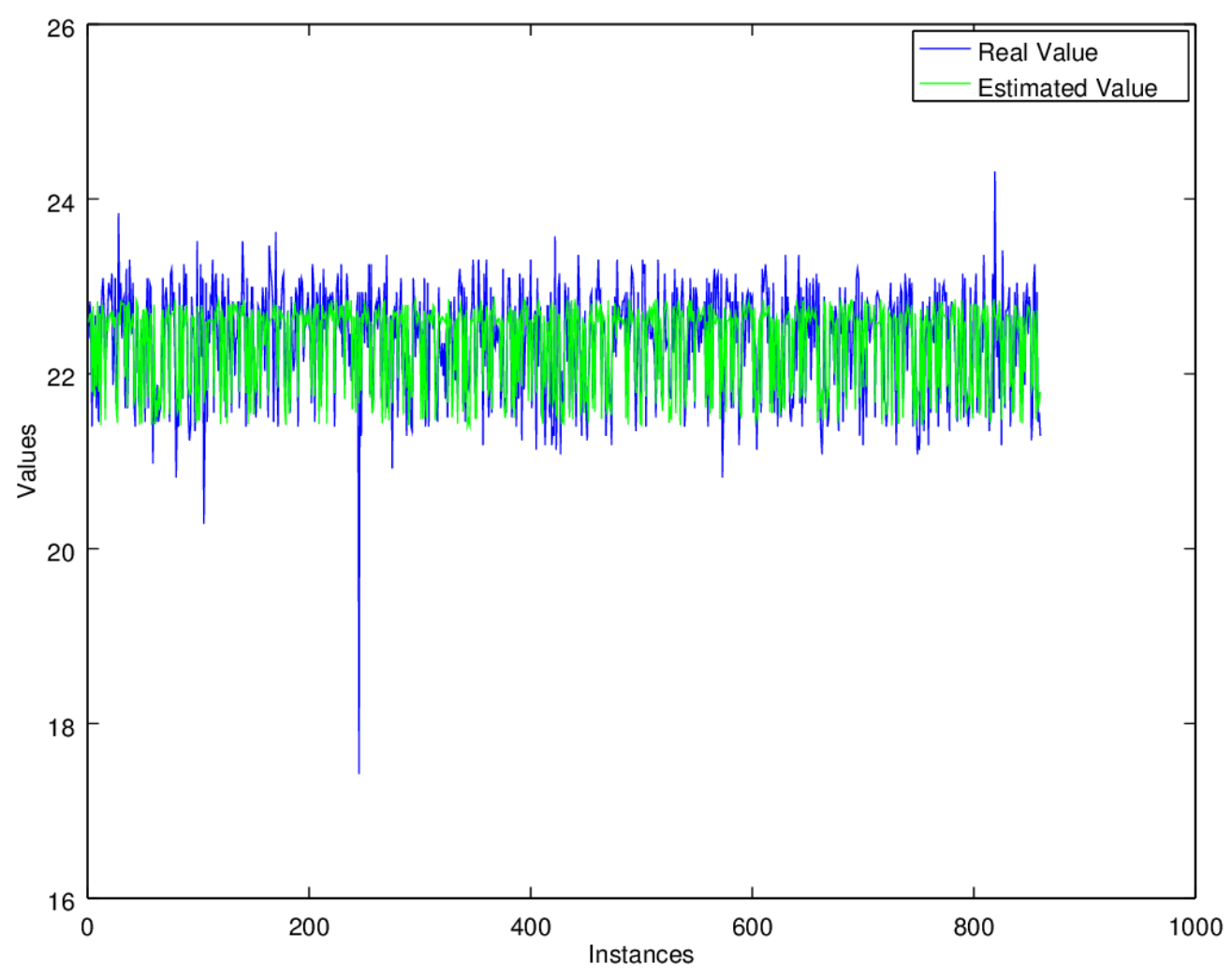

Fonte: Elaborada pelo autor.

Os valores estimados estão próximos dos valores reais e os valores de $M A E$ e $R M S E$ são relativamente baixos, ou seja, o modelo criado pelo PatternManager consegue um bom desempenho para esse contexto de dados ou aplicação.

\subsubsection{Conclusões da experimentação do serviço de estimação de valores}

A aplicação de teste desenvolvida verifica a aplicabilidade e funcionalidade do serviço de estimação de valores no modelo de IoT. Observou-se experimentalmente que o módulo 
desenvolvido conseguiu modelar o conjunto de dados reais e contexto de aplicação adequadamente com desempenho satisfatório.

O serviço de estimação de valores será útil para aplicações nas quais a precisão das leituras de dados sejam críticas, ele poderá ser utilizado sempre ocorreram erros ou elas sejam inexistentes.

\subsection{APLICAÇÃO ABRANGENTE NO CENÁRIO DE CIDADE INTELIGENTE}

Esta seção tem por objetivo descrever uma aplicação para o mundo real que utilize as funcionalidades do novo modelo de IoT proposto, os algoritmos e os serviços de reconhecimento de padrões nas camadas física e de middleware.

Como aplicação experimental foi desenvolvido um aplicativo que cria rotas na cidade de Santander utilizando as prioridades definidas pelo usuário com base nas variáveis existentes, como temperatura, taxa de ocupação e distância em metros. Esse aplicativo realiza uma prova de conceito utilizando o modelo de IoT, com resgate de dados do ambiente e tomada de decisão por parte da aplicação, que inicia ações no ambiente, nesse caso, criando rotas possíveis para o usuário com base em suas preferências e utilize a nova arquitetura proposta com os algoritmos e os serviços de reconhecimento de padrões na camada física e middleware.

A Figura 43 ilustra o diagrama de caso de uso do aplicativo proposto.

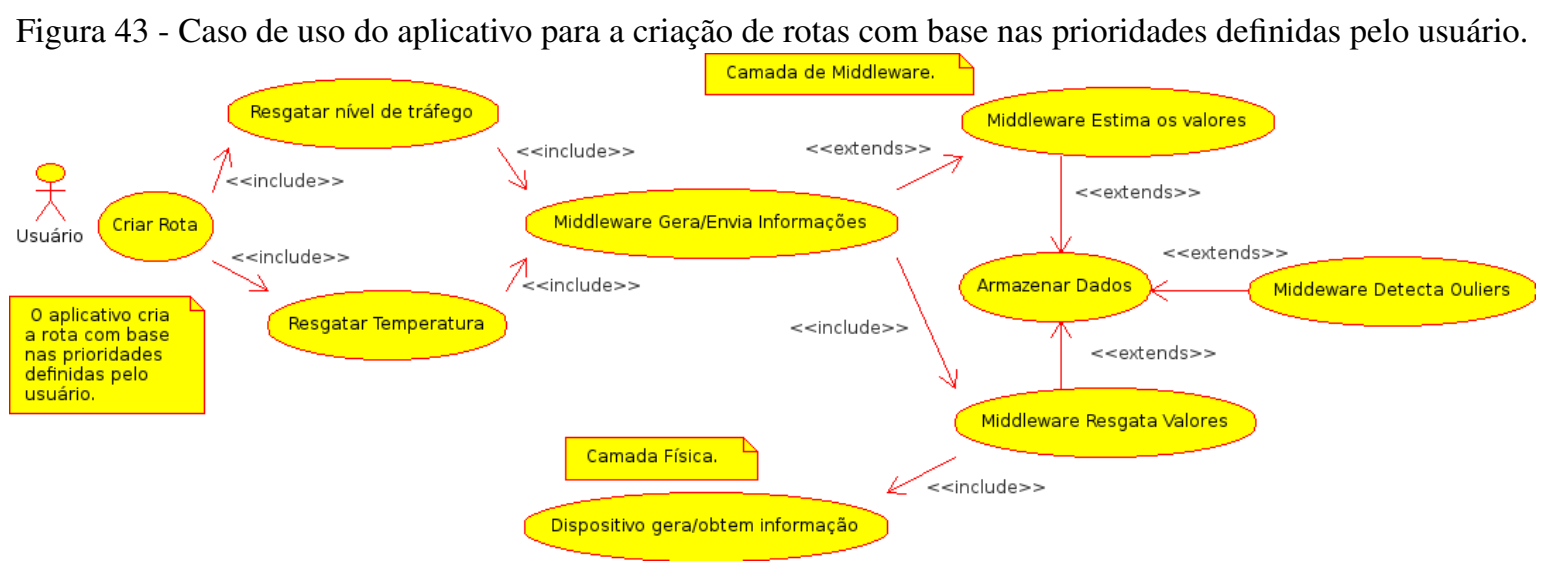

Fonte: Elaborada pelo autor.

O aplicativo gera rotas com base nas prioridades definidas pelo usuário através da interface. O caso de uso "criar rota", inclui a obtenção dos dados através da implementação da interface com o LinkSmart Middleware que, por sua vez, utiliza, estima ou detecta outliers com base nos dados obtidos do ambiente.

A implementação desse aplicativo utiliza os algoritmos da camada física e do módulo 
de análise e reconhecimento de padrões propostos na pesquisa e adicionados ao LinkSmart Middleware. A prova de conceito contempla as seguintes propostas e implementações:

- Detecção de outliers: de modo a detectar anomalias ou mudanças bruscas na temperatura ou nas taxas de ocupação dos ambientes, caso ocorram medições errôneas o middleware ou a camadda física poderão perceber e informar às camadas superiores.

- Predição de valores: caso ocorram as leituras errôneas, falhas de comunicação com os sensores ou sejam detectados outliers a camada física ou de middleware poderão estimar os valores.

- Criação de sensores virtuais: para a agregação e abstração dos valores e tipos de dados para aplicações mais abrangentes no contexto de temperatura e trânsito de bairros e da cidade como um todo, o aplicativo criará um único valor para caracterizar cada uma das rotas possivelmente escolhidas.

- Sugere-se a utilização dos mecanismos de comunicação Cross Layer de modo a permitir o controle do comportamento das camadas física e middleware.

A camada inferior tem por função resgatar os dados do ambiente, através do Framework do Smart Santander ou de outras aplicações móveis e inserí-los no LinkSmart Middleware ou camada imediatamente superior, nesse caso, a implementação é realizada através de classes que resgatam os dados do banco de dados Mysql. Nessa camada, foram implementados os algoritmos de detecção de outlier e de estimação de valores pois, caso, o sensor ou a classe que o representa não tiverem a leitura no dado momento, o algoritmo poderá estimar o valor. Caso ocorra um erro de leitura e esses valores estejam muito distantes dos valores comuns, o algoritmo de detecção de outlier poderá alertar as camadas superiores e inclusive usar o serviço de estimação para um valor mais próximo de um valor real.

A camada imediatamente superior é representada pelo LinkSmart Middleware, ao qual foram agregados os módulos de análise e reconhecimento de padrões a serem utilizados nas implementações. Nesse caso, a implementação recebe os valores da camada inferior e tem a possibilidade de estimar valores ou detectar outliers sobre as leituras recebidas.

A camada superior representa a aplicação cliente, que poderá fazer uso dos dados brutos ou das informações geradas pela execução dos algoritmos na camada de Middleware e física.

Tendo em vista que não há uma aplicação de controle, optou-se por criar uma configuração fixa no aplicativo, nesse caso desabilitando as funcionalidades de detecção de outlier e estimação de valores na camada física e habilitando-as na camada de middleware, desse modo, os algoritmos implementados no LinkSmart estimam valores, caso não existam, ou detectam outliers, que estão presentes nos dados obtidos. 
O aplicativo desenvolvido utiliza os dados de temperatura e taxa de ocupação existentes entre os dias 01 e 07 de abril de 2013. A interação com o usuário ocorre através do navegador de Internet: o aplicativo exibe os pontos de coleta de dados de temperatura e taxa de ocupação, utilizando a Google Maps API (INC., 2014). Para os pontos de coleta de temperatura se exibe um círculo em vermelho com a medição e para cada ponto de coleta de taxa de ocupação se exibe um círculo azul, em ambos os casos o diâmetro do círculo indica a medição existente ou estimada.

Com base nas prioridades que o usuário define para as variáveis, o aplicativo escolhe uma "melhor" rota. Para cada envio de formulário o aplicativo incrementa uma hora nos dados de leitura e a cada vinte e quatro envios o aplicativo incrementa a data, sendo que a data limite é 07 de abril de 2013.

Foi utilizada a Eq.10 de modo a identificar e eleger a rota mais interessante no dado momento, criando assim o sensor virtual.

$$
W_{r i}=\frac{1}{i} \sum_{0}^{i} \frac{\text { temp }_{i}-\text { temp }_{\min }}{\text { temp }_{\max }-\text { temp }_{\min }} \times \omega_{t}+\frac{\text { occupation }_{i} \text {-occupation }_{\min }}{\text { occupation }_{\text {max }}-\text { occupation }_{\min }} \times \omega_{o}+\frac{\text { distance }_{i}^{i+1}-\text { distance }_{\min }}{\text { distance }_{\text {max }}-\text { distance }_{\min }} \times \omega_{d}
$$

Onde, $W_{r i}$ representa a adequação de uma dada rota. Sua composição é o somatório do valor da temperatura normalizado e multiplicado pela prioridade da temperatura, somado ao valor de ocupação normalizado e multiplicada pela prioridade da taxa de ocupação, somado à distância em metros normalizada, do ponto $i$ até o próximo ponto da rota e, por fim, dividido pelo número total de saltos da $\operatorname{rota}_{i}$. $\mathrm{O}$ aplicativo possui valores pré-definidos de prioridades onde, Baixa possui o valor 1, Média Baixa possui o valor 0,75, Média possui o valor de 0,5, Média Alta possui o valor de 0,25 e Alta possui o valor de 0,1 . Assim, a melhor rota deverá possuir o menor valor de $W_{i}$.

Existem 81 pontos de leituras de temperatura e 38 pontos de leitura para a taxa de ocupação. Optou-se por fixar o ponto de origem e destino, de modo a ter um conjunto maior de rotas e de leitura de ambas as variáveis. Desse modo, as rotas definidas pelo aplicativo possuem origem no ponto 175 e destino no ponto 257. Na Figura 44, ambos os pontos estão destacados no mapa.

Observou-se que na base de dados há alguns outliers e, portanto, é importante ativar o serviço de detecção de outliers na camada de middleware. A Figura 45 ilustra o mapa com o serviço de detecção de outlier desativado, exibindo três pontos com leituras errôneas para o dado momento.

A Figura 46 ilustra a rota mais exibida no aplicativo, ao se atribuir prioridade alta para taxa de ocupação e prioridades baixas para temperatura e distância.

O aplicativo exibe a rota desenhada no mapa da cidade de Santander, por quais pontos ela passa e quais as intensidades das leituras de temperatura e taxa de ocupação em cada ponto, 
Figura 44 - Ponto de origem (175) e destino (257) indicados no mapa da cidade de Santander.

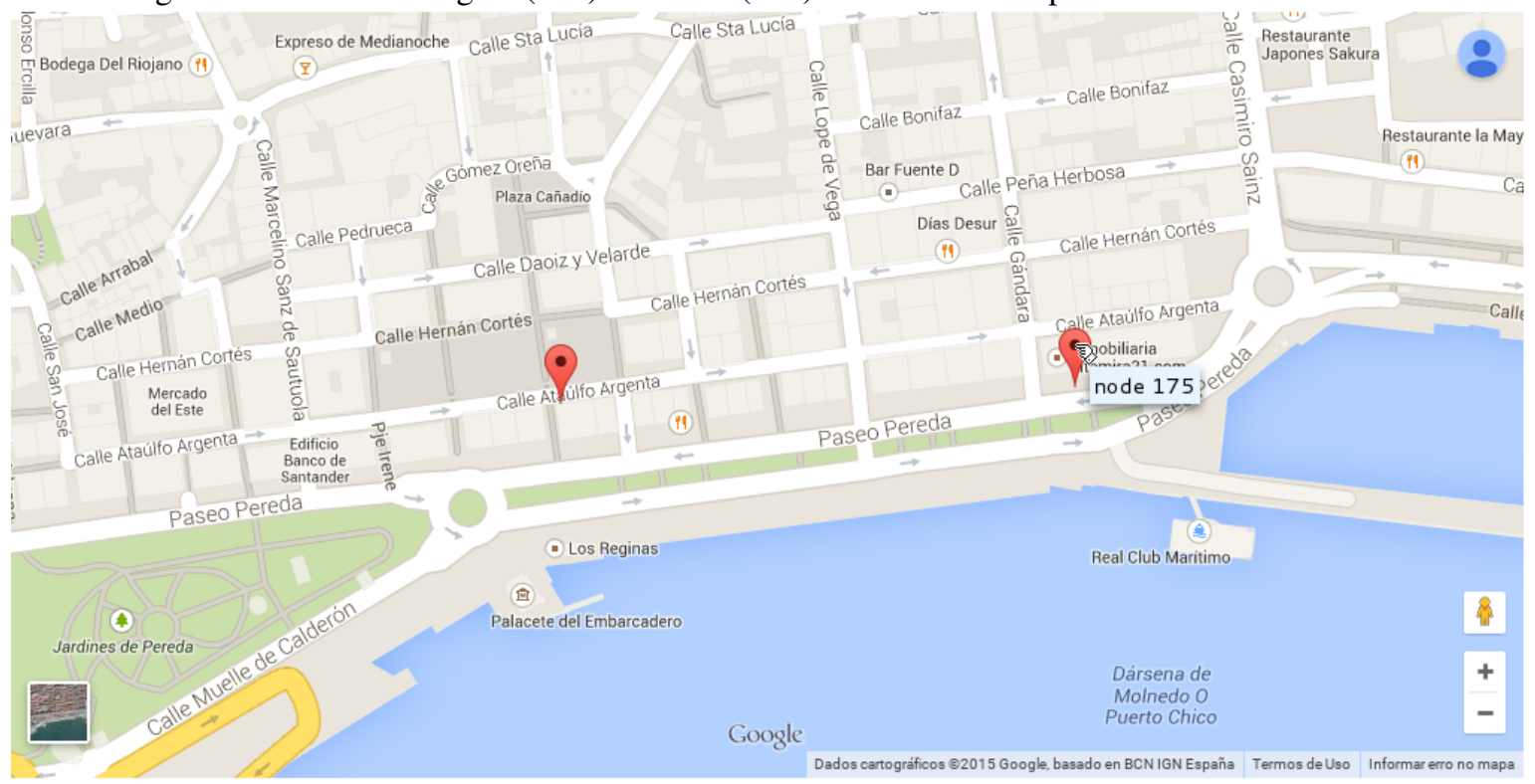

Fonte: Elaborada pelo autor.

Figura 45 - Mapa das cidade de Santander exibindo pontos de temperatura e ocupação com o serviço de detecção de outlier desativado.

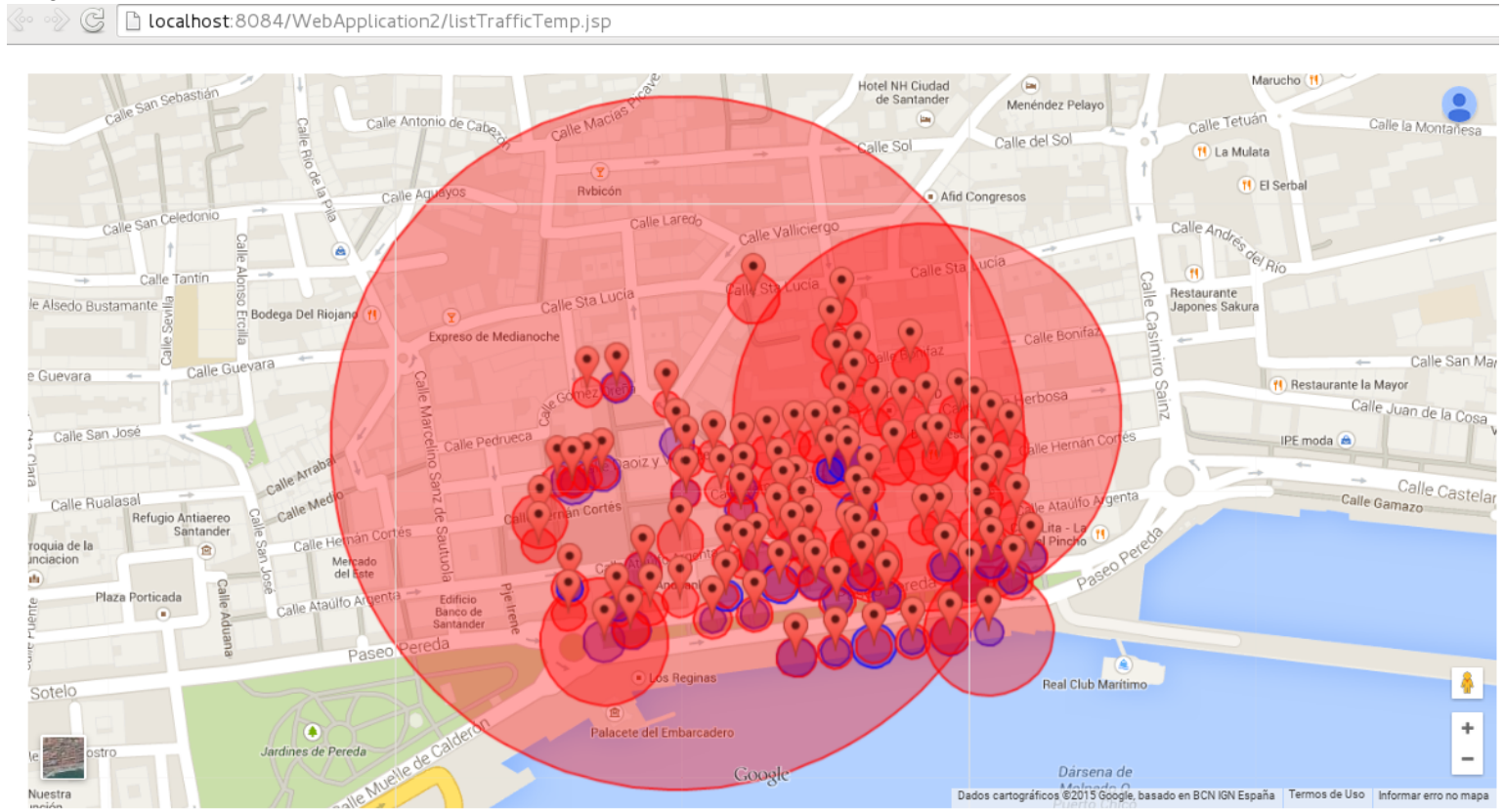

Fonte: Elaborada pelo autor. 
Figura 46 - Primeira rota mais exibida pelo aplicativo.

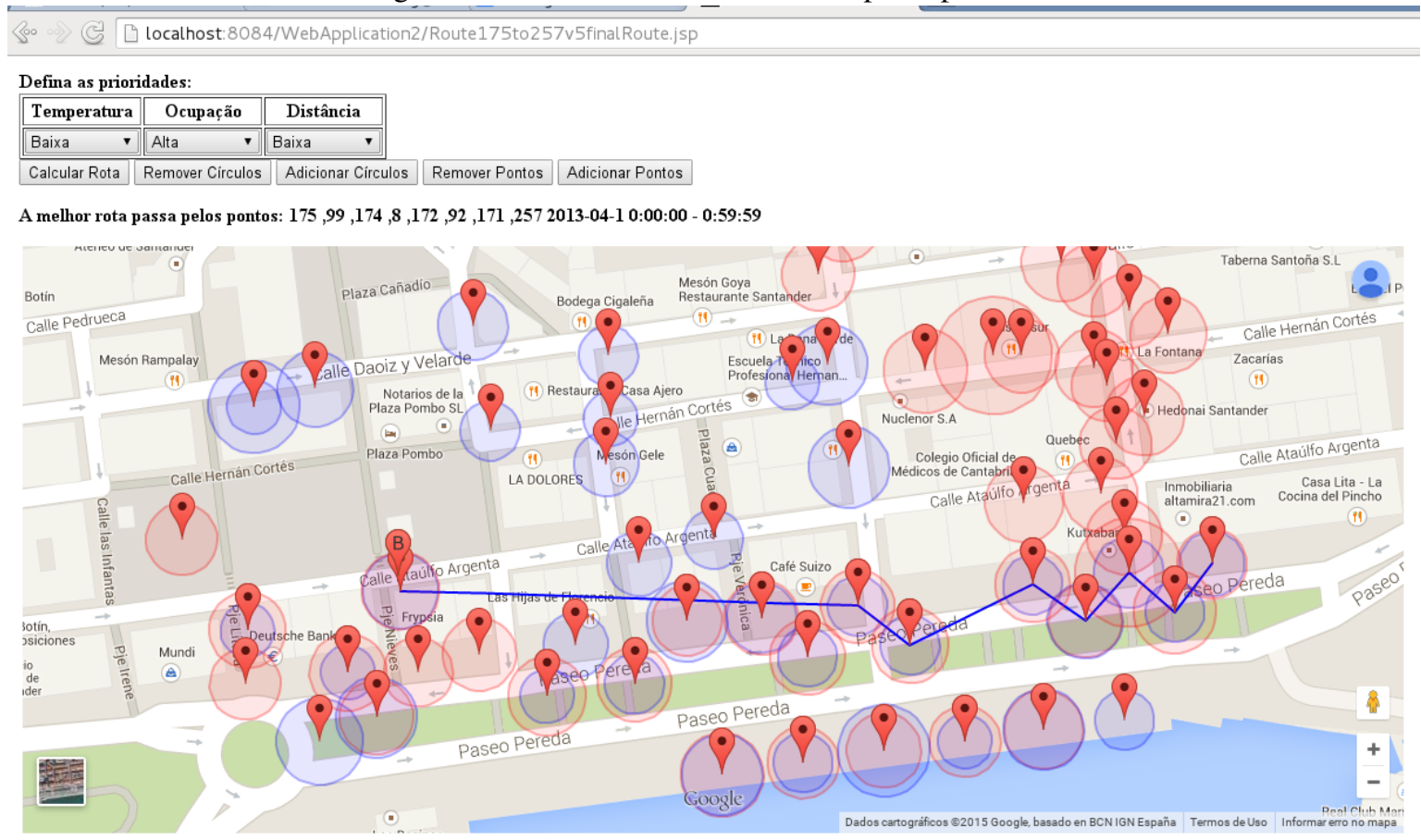

Fonte: Elaborada pelo autor.

no dado momento, nesse caso, às 0h e 59:59 do dia 01 de Abril de 2013.

A Figura 47 ilustra a segunda rota mais exibida no aplicativo, nesse caso ao se atribuir prioridade alta para temperatura, ou seja, o usuário tem preferência por pontos mais frios e prioridades baixas para taxa de ocupação e distância percorrida. Observam-se como opções do aplicativo, a possibilidade de se remover ou exibir os cículos e pontos de leituda da tela, deixando assim, uma visualização mais limpa da rota proposta pelo aplicativo.

A Figura 47 exibe a melhor rota no horário entre 2h e 2:59 do dia 01 de Abril de 2013.

A Figura 48 ilustra a terceira rota mais exibida no aplicativo, nesse caso, ao se atribuir prioridade alta para temperatura e baixas para taxa de ocupação e distância.

A Figura 48 exibe a melhor rota no horário entre 9h e 9:59 do dia 02 de Abril de 2013. Nesse intervalo de tempo a taxa de ocupação tem leituras mais altas, se comparada aos horários anteriores.

A Figura 49 ilustra a quarta possível rota mais exibida, nesse caso também para prioridade alta para temperatura e baixas para taxa de ocupação e distância.

A rota exibida na Figura 49 é a melhor no horário entre 16h e 16:59 do dia 03 de Abril de 2013. 
Figura 47 - Segunda rota mais exibida pelo aplicativo.

So (c) [ocalhost:8080/WebApplication2/Route175to257v5finalRoute.jsp

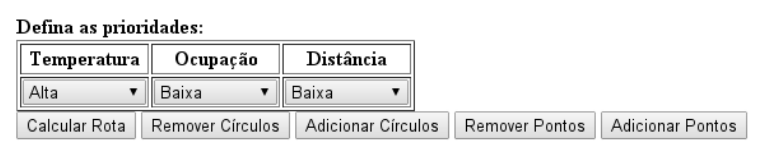

A melhor rota passa pelos pontos: $175,99,174,8,172,92,6,5,257$ 2013-04-1 2:00:00 - 2:59:59

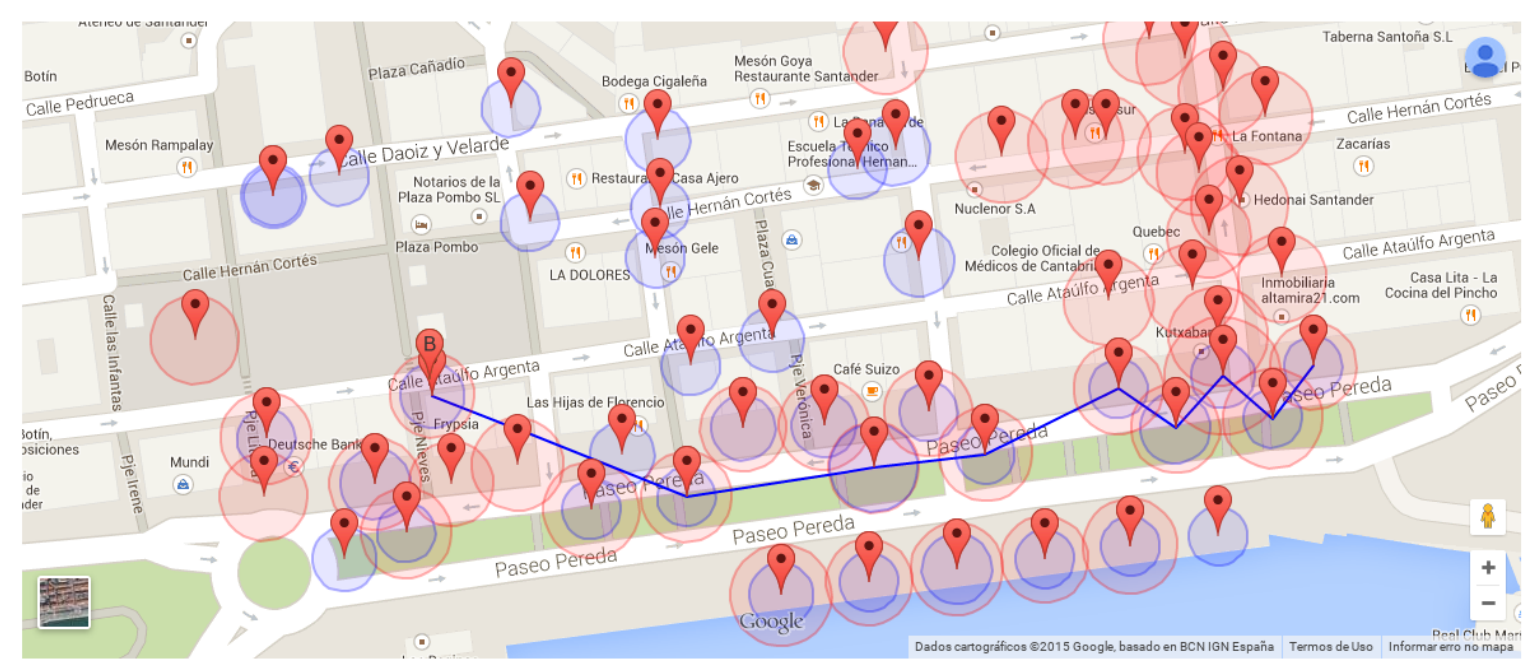

Fonte: Elaborada pelo autor.

Figura 48 - Terceira rota mais exibida pelo aplicativo.

Soo (c) localhost:8080/WebApplication2/Route175to257v5finalRoute.jsp

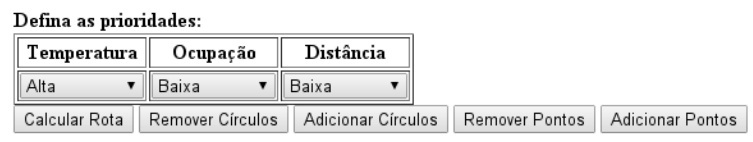

A melhor rota passa pelos pontos: $175,99,174,8,172,92,6,5,270,257$ 2013-04-2 9:00:00 - 9:59:59

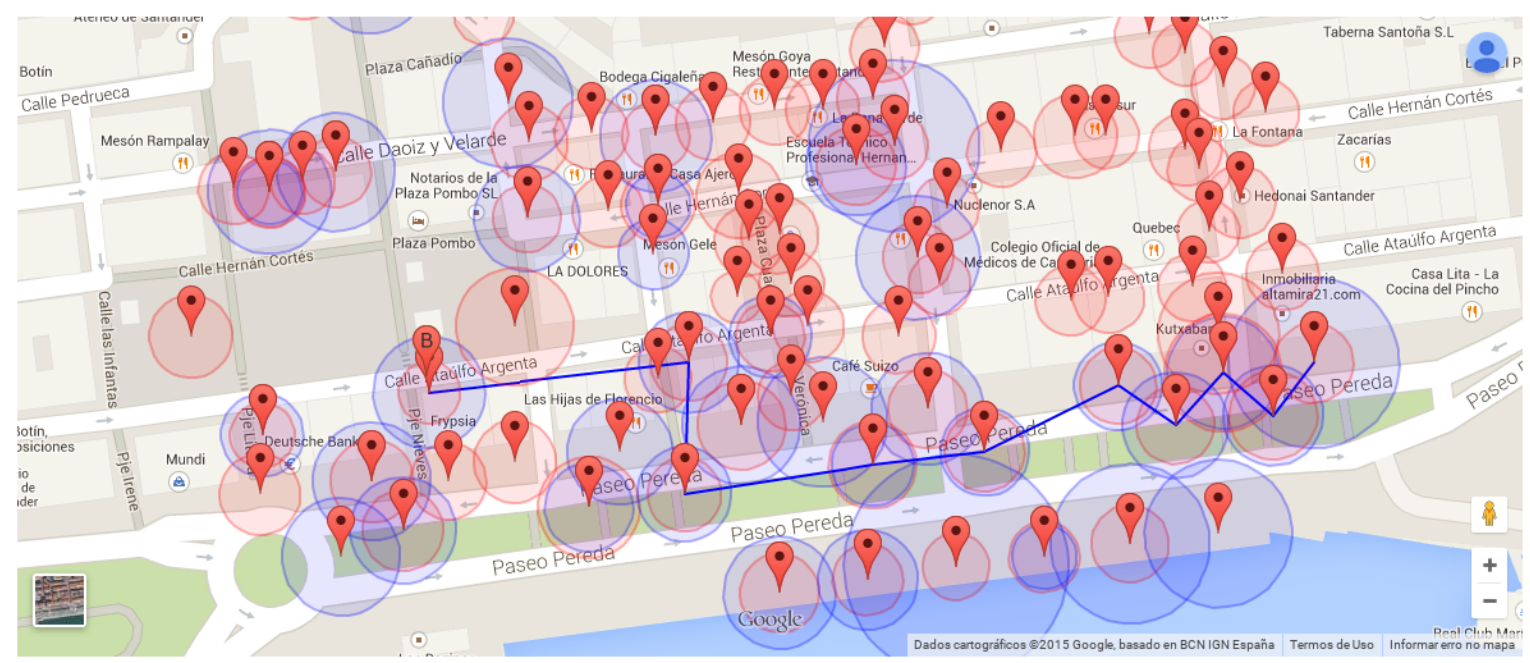

Fonte: Elaborada pelo autor. 
Figura 49 - Quarta rota mais exibida pelo aplicativo.

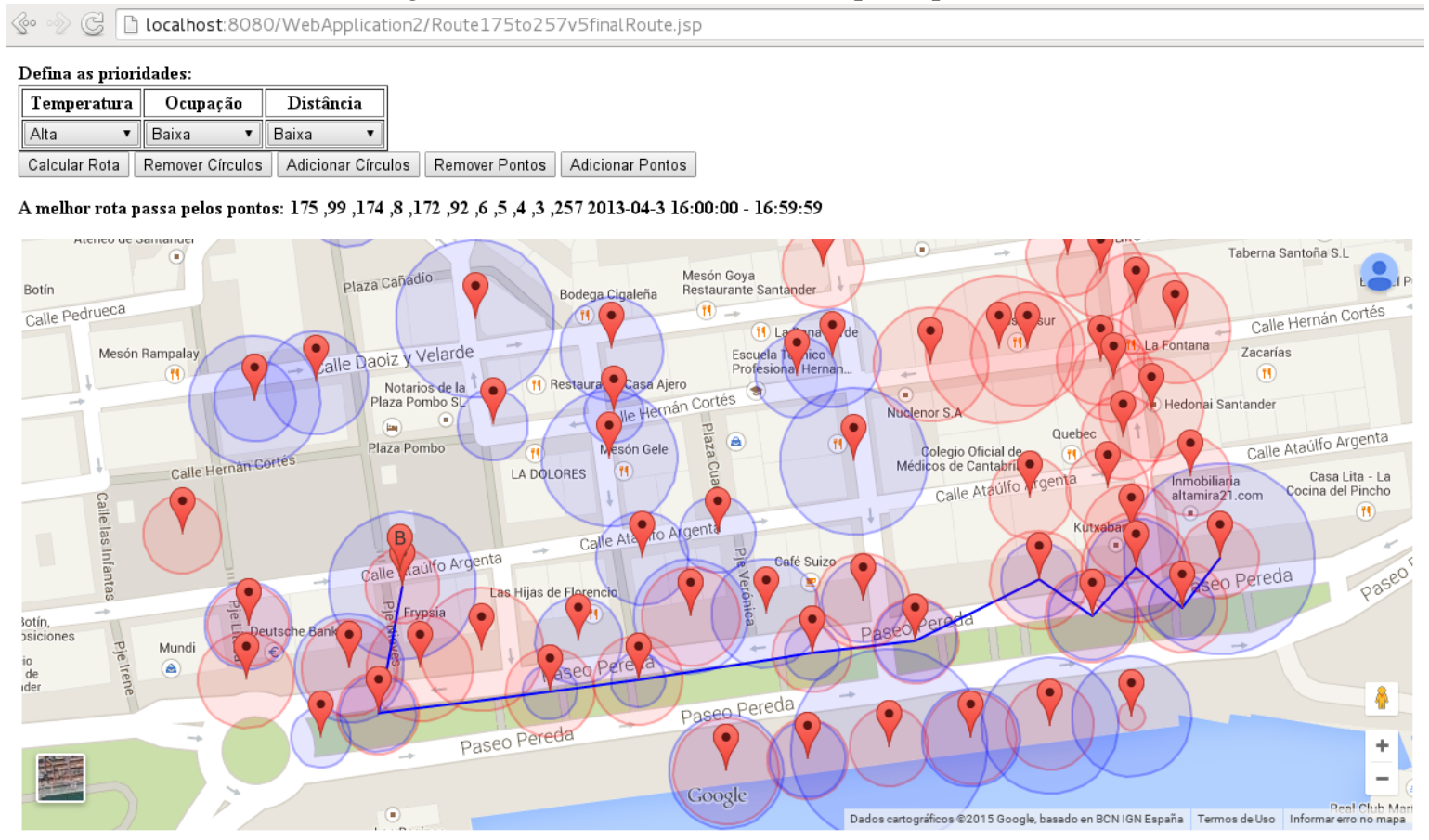

Fonte: Elaborada pelo autor.

\subsubsection{Conclusões quanto ao cenário experimental da cidade inteligente}

Pode-se observar que o aplicativo sugerido junto ao cenário do Smart Santander utiliza a nova arquitetura de IoT e módulos do LinkSmart Middleware desenvolvidos e propostos na pesquisa, mais especificamente a detecção de outlier utilizando a tecnologia de BigData, estimação de valores na camada de middleware e a utilização de técnica de criação de sensores virtuais, nesse caso ao se criar métricas para a criação de rotas usando dados de sensores e middleware de IoT.

Com esse estudo de caso comprova-se a utilidade dos módulos desenvolvidos, de modo a simplificar o desenvolvimento de aplicações para IoT. Nesse caso, especificamente, se poupam o tráfego de rede e otimizam processamentos, pois no dado cenário, o processamento para a detecção de outliers e estimação de valores é realizado uma única vez pelo middleware, sem a necessidade de um novo processamento na camada de aplicação. 


\section{CONCLUSÕES E TRABALHOS FUTUROS}

Este capítulo tem por objetivo resumir as conclusões, os resultados da pesquisa e apresentar sugestões para pesquisas futuras.

Este capítulo está organizado da seguinte maneira, a Seção 5.1 traz as conclusões da pesquisa; a Seção 5.2 traz os resultados de pesquisa e publicações; e, por fim, a Seção 5.3 descreve os trabalhos futuros propostos para esta pesquisa.

\subsection{CONCLUSÕES}

O tratamento e o processamento dos dados gerados com o modelo de IoT é um aspecto crucial e que foi abordado como tema principal desta pesquisa. Observou-se a necessidade de mecanismos eficientes para o processamento e que eles não ocorram somente na camada de aplicação e a necessidade de se ter um modelo de referência para guiar o desenvolvimento de aplicações para IoT e de um Middleware que implemente esse modelo.

Dentro desse contexto, foi proposta a utilização do modelo de referência desenvolvido pelo IoT-A e a utilização do LinkSmart Middleware como plataforma para o desenvolvimento de aplicações e a introdução dos mecanismos de análise e reconhecimento de padrões nas camadas física e de Middleware neste novo modelo de IoT.

Todos os objetivos de pesquisa elencados no Capítulo 1 foram alcançados com as implementações desenvolvidas, bem como seus respectivos experimentos.

Os experimentos demonstraram que o modelo IoT-A, juntamente com o LinkSmart Middleware atendem aos requisitos para o desenvolvimento de aplicações no contexto de IoT.

A nova arquitetura proposta permite o desenvolvimento de aplicações de IoT e provê serviços para o reconhecimento de padrões nas camadas física e de middleware, integrada à tecnologia de Big Data para processamento distribuído.

Cabe destacar que inicialmente o desenvolvimento com a plataforma de Big Data não era um requisito para a implementação da solução, porém, ao se verificar que a implementação utilizando o framework weka, que implementa algoritmos de reconhecimento de padrões, não obteve resultados satisfatórios quanto aos tempos de execução optou-se por inserir essa solução como uma característica importante para arquiteturas de IoT.

A arquitetura desenvolvida integra serviços de detecção de outliers e estimação de valores na camada física e não impõe a implementação dos algoritmos. Os serviços de detecção de outliers, estimação de valores e clustering estão presentes na camada de middleware. Essa arquitetura foi integrada à plataforma de Big Data Hadoop e as implementações algorítimcas usam o framework Mahout. 
Outro aspecto relevante da arquitetura é que sua estrutura orientada a objetos permite a fácil integração de outras implementações algorítimcas ou de plataformas de Big Data, desde que sejam satisfeitos e implementados os contratos das interfaces criadas.

Observa-se que os serviços desenvolvidos possuem um desacoplamento e independência com o LinkSmart Middleware, sendo assim, poderão ser utilizados em conjunto com outros middlewares de IoT.

Cabe ressaltar a importância da comunicação cross-layer aqui proposta, que permite a ativação de desativação dos serviços nas camadas física e de middleware, pela classe ou software com a função de coordenação para a parametrização dos algoritmos e controle dos serviços. A comunicação cross-layer é uma característica importante para arquitetura de IoT.

\subsection{DIVULGAÇÃO DA PESQUISA}

As contribuições deste trabalho foram publicadas em veículos internacionais e são:

1. O uso do LinkSmart Middleware como plataforma para IoT foi apresentado na conferência SmartSystech, em Julho de 2013, disponível na IEEE Xplore digital library, com o artigo A Novel Smart Home Application Using an Internet of Things Middleware (SOUZA; AMAZONAS, 2013), no qual, foi proposta uma aplicação de casa inteligente utilizando o LinkSmart Middleware como plataforma de IoT.

2. A principal contribuição desta pesquisa foi publicada no Journal of Machine to Machine Communications - River Publishers, em Maio de 2015, no artigo Novel IoT Architecture with Pattern Recognition Mechanism and Big Data (SOUZA; AMAZONAS, 2015), no qual se destaca a utilização do modelo de referência IoT-A, do LinkSmart Middleware, é introduzida por completa a nova plataforma de IoT, com os serviços de reconhecimento de padrões nas camadas física e de middleware, integrada à plataforma de Big Data, bem como sua estrutura orientada a objetos que permite futuras implementações e, por fim, a experimentação da arquitetura e do serviço de clustering.

3. A implementação do algoritmo de detecção de outlier descrita nesta tese é uma contribuição original apresentada na conferência 6th International Conference on Ambient Systems, Networks and Technologies (ANT-2015), presente no Procedia Computer Science, volume 52, com o artigo An Outlier Detect Algorithm using Big Data Processing and Internet of Things Architecture (SOUZA; AMAZONAS, 2015), que descreve a abordagem e implementação do algoritmo usando a tecnologia de Big Data e algoritmo de clustering em sua implementação e, por fim, sua experimentação integrada à arquitetura de IoT. 
4. A comunicação cross layer proposta e implementada nesta pesquisa foi publicada na conferência EMERGING 2015, The Seventh International Conference on Emerging Networks and Systems Intelligence, em Julho de 2015, presente na Think Mind digital library, com o artigo A New Internet of Things Architecture with Cross-Layer Communication, que descreve a comunicação cross layer integrada à nova arquitetura de IoT, ao LinkSmart Middleware e a tecnologia de Big Data, bem como a comprovação experimental desta arquitetura e comunicação (SOUZA; AMAZONAS, 2015).

A Tabela 5 resume todas as contribuições originais da pesquisa publicadas em eventos ou revistas internacionais.

Tabela 5 - Tabela com o resumo das publicações.

\begin{tabular}{|c|c|c|c|c|}
\hline No. & Título & Publicação & Ano & Formato \\
\hline 1 & $\begin{array}{c}\text { A Novel Smart Home } \\
\text { Application Using an } \\
\text { Internet of Things Middleware }\end{array}$ & $\begin{array}{l}\text { SmartSystech } \\
\text { Conference } \\
\text { IEEE Xplore }\end{array}$ & 2013 & Proceedings \\
\hline 2 & $\begin{array}{l}\text { Novel IoT Architecture } \\
\text { with Pattern Recognition } \\
\text { Mechanism and Big Data }\end{array}$ & $\begin{array}{c}\text { Journal of Machine to } \\
\text { Machine Communications } \\
\text { River Publishers }\end{array}$ & 2015 & Journal \\
\hline 3 & $\begin{array}{c}\text { An Outlier Detect } \\
\text { Algorithm using } \\
\text { Big Data Processing and } \\
\text { Internet of Things Architecture }\end{array}$ & $\begin{array}{l}\text { ANT Conference } 2015 \\
\text { Procedia on Computer } \\
\text { Science }\end{array}$ & 2015 & Proceedings \\
\hline 4 & $\begin{array}{l}\text { A New Internet of Things } \\
\text { Architecture with } \\
\text { Cross-Layer Communication }\end{array}$ & $\begin{array}{c}\text { IARIA Conference } \\
\text { Think Mind digital library }\end{array}$ & 2015 & Proceedings \\
\hline
\end{tabular}

Fonte: Elaborada pelo autor.

\subsection{TRABALHOS FUTUROS}

Como trabalhos futuros sugere-se o desenvolvimento e experimentação da plataforma aqui proposta com aplicações do mundo real com dados em tempo real. Cabe destacar o uso da plataforma aqui descrita em um contexto real com redes de telecomunicações reais e com uma escala de clientes e aplicações de modo a verificar o comportamento da plataforma e do LinkSmart Middleware com um grande número de instâncias integradas com clusters para processamento distribuído em Big Data.

Atestar a aplicabilidade das implementações algorítimcas em diversos contextos de IoT, de modo a elucidar se os algoritmos aqui utilizados conseguem modelar as inúmeras aplicações existentes nos diversos outros contextos. 
Propor outros serviços com reconhecimento de padrões e inteligência artificial no LinkSmart Middleware ou em outros frameworks para IoT.

Atestar a aplicabilidade de técnicas de extração de características, ou do inglês feature extraction, para a criação de sensores virtuais integrada à arquitetura de IoT aqui proposta, de modo a reduzir o número de dimensões a que se pretende analisar com um maior ganho de informação.

Sugere-se explorar a modularidade da plataforma de IoT aqui descrita, de modo a experimentar outras plataformas para Big Data, explorar a funcionalidade de notações semânticas existentes no LinkSmart Middleware e propor o uso do serviço de clustering para a modelagem automática dessas notações semânticas.

Analisar a aplicabilidade dos serviços de reconhecimento de padrões à segurança no contexto de IoT e integrar ao módulo de segurança do LinkSmart middleware, seja no contexto de segurança da informação e serviços ou à segurança patrimonial e pessoal ou no âmbito de cidades inteligentes, de modo que as aplicações possam conhecer os contextos e comportamentos pessoais e infiram ataques ou mudanças bruscas de comportamento individual ou em massa.

Sugere-se acoplar os serviços desenvolvidos nessa arquitetura a outros middlewares de IoT e plataformas de computação em nuvem.

Além dos trabalhos propostos, segure-se o desenvolvimento de um conjunto de aplicações com base nos dados obtidos do projeto Smart Santander, se propõe ou se estendem as seguintes aplicações futuras a curto e médio prazo:

- Aplicações para dispositivos móveis e pervasivas, com interação através de áudio, monitores de vídeo e tablets embutidos nos diversos ambientes, que ilustrem e contextualizem a temperatura dos ambientes específicos e em comparação com medições anteriores.

- Aplicações para dispositivos móveis ou pervasivas para a predição de temperatura nos diversos ambientes, mesmo que não possuam sensores.

- Aplicações para dispositivos móveis ou pervasivas que ilustrem o tráfego da determinada região na qual o usuário se encontra e que possa predizer o tráfego para determinados horários, com base em contextualização e em medições históricas e comportamentais.

- Aplicações que possam predizer a temperatura com base nos dados de tráfego da cidade.

No futuro, ao se agregar dados como luminosidade, nível de $\mathrm{CO}_{2}$, contextos dos ambientes e lugares públicos, informações sobre as rotas e destinos dos veículos, a inserção de atuado- 
res em janelas, cortinas, sistemas de aquecimento e de ar condicionado em locais públicos fechados, poderão ser propostas aplicações como:

- Aplicações para dispositivos móveis ou pervasivas que contextualizem o usuário sobre o seu comportamento e impacto no ambiente, que essas aplicações possam atuar nos ambientes públicos, através do controle e atuação nos sistemas de ar condicionado, luzes e abertura e fechamento de cortinas ou janelas, irrigação, buscando aumentar a eficiência energética no dado ambiente.

- Aplicações para dispositivos móveis ou pervasivas que possam atuar de maneira social no tráfego e locomoção na cidade, tendo em vista as possíveis rotas e destinos dos veículos privados e públicos e da população como um todo. Essas aplicações poderão atuar nos sistemas de controle de vagas nos estacionamentos e vagas públicas, atuar nas aplicações de GPS, de modo a minimizar impactos nas rotas e tráfego na cidade.

- Aplicações pervasivas ou móveis que possam predizer as características do tráfego na cidade antecipadamente usando os dados de destinos dos usuários.

- Aplicações móveis e pervasivas para segurança privada, de modo que a aplicação conheça o comportamento e rotas e destinos com veículos públicos ou privados do usuário e detecte, caso ocorram, alterações inesperadas de comportamento.

- Aplicações pervasivas nas ruas e avenidas que possam detectar o comportamento de deslocamento da população em eventos urbanos, seja com veículos privados ou públicos e possam alterar as sinalizações, sentidos das vias, semáforos, dentre outros atuadores, dado o comportamento histórico ou inesperado nas ruas e avenidas. Que essas aplicações possam interagir em tempo real com as aplicações de GPS e de deslocamento utilizadas pela população.

- Aplicações que possam alterar ou criar novos destinos e rotas para o transporte público, dado o comportamento histórico ou imediato da cidade. Que essas aplicações possam interagir em tempo real com as aplicações móveis de deslocamento utilizadas pela população.

- Aplicações móveis e pervasivas para a sugestão de atrações, eventos, lugares, cultura, etc. para o usuário, de modo que a aplicação reconheça o comportamento e padrão do usuário e mais se adapte ao seu gosto. 


\section{Referências}

AFFILIATES, O. C. and/or its. Mysql: the world's most popular open source database. June 2014. Online http://www.mysql.com/; accessado em 03-Julho-2014.

AGGARWAL, C.; ASHISH, N.; SHETH, A. The internet of things: a survey from the data-centric perspective. In: Managing and Mining Sensor Data. Managing and Mining Sensor Data. [S.1.]: Springer US, 2013. p. 383-428.

AL-QUTAYRI, M. A. Smart Home Systems. 1. ed. [S.1.]: In-Teh, 2010.

ALBANO, M. et al. Towards secure middleware for embedded peer-to-peer systems: objectives and requirements. 2007. DOI: 10.1.1.90.5982. In RSPSI 07: Workshop on Requirements and Solutions for Pervasive Software Infrastructures, 2007, pp. 1 â6.

AMAZONAS, J. R. d. A. Network virtualization and cloud computing: iot enabling thecnologies. Casagras2 Academic Seminar, September 2011. Online http://www.casagras2.com.br/downloads/day2/2-Jose_Roberto_de_Almeida_Amazonas-

Network_Virtualization_and_Cloud_Computing_IoT_enabling_echnologies.pdf; accessado em 28-Abril-2013.

BAHGA, A.; MADISETTI, V. Internet of Things: A Hands-On Approach. [S.1.]: Vijay Madisetti, 2014.

BAKKER, P.; ERTMAN, B. Building Modular Cloud Apps with OSGi. [S.1.]: O Reilly Media, 2013.

BANDYOPADHYAY, S. et al. Role of middleware for internet of things: a study. International Journal of Computer Science Engineering Survey, p. 94 - 105, 2011.

BANDYOPADHYAY, S. et al. A survey of middleware for internet of things. In: Recent Trends in Wireless and Mobile Networks. Recent Trends in Wireless and Mobile Networks. [S.1.]: Springer Berlin Heidelberg, 2011. (Communications in Computer and Information Science, v. 162), p. 288-296.

BIN, S.; YUAN, L.; XIAOYI, W. Research on data mining models for the internet of things. 2010 International Conference on Image Analysis and Signal Processing, Ieee, p. 127$132,2010$.

BOHN, H.; BOBEK, A.; GOLATOWSKI, F. Sirena - service infrastructure for realtime embedded networked devices: a service oriented framework for different domains. Networking, International Conference on Systems and International Conference on Mobile Communications and Learning Technologies, 2006. ICN/ICONS/MCL 2006. International Conference on. p. 43-43, April 2006. DOI: $10.1109 /$ ICNICONSMCL.2006.196. 
BOTTS, M. et al. Ogc sensor web enablement: overview and high level architecture. Open Geospatial Consortium, Inc. Withepaper, OGC 07-165, 2007.

CANNATA, A.; GEROSA, M.; TAISCH, M. Socrades: a framework for developing intelligent systems in manufacturing. Industrial Engineering and Engineering Management, 2008. IEEM 2008. IEEE International Conference on. p. 1904-1908, Dec 2008. DOI: 10.1109/IEEM.2008.4738203.

CAPORUSCIO, M.; RAVERDY, P.-G.; ISSARNY, V. Ubisoap: a service-oriented middleware for ubiquitous networking. Services Computing, IEEE Transactions on, v. 5, n. 1, p. 86-98, Jan 2012. DOI: 10.1109/TSC.2010.60.

CASAGRAS, E. F. P. Casagras final report: rfid and the inclusive model for the internet of things. 2009.

CHAI, T.; DRAXLER, R. R. Root mean square error (rmse) or mean absolute error (mae)? arguments against avoiding rmse in the literature. Geoscientific Model Development, v. 7, n. 3, p. 1247-1250, 2014. DOI: 10.5194/gmd-7-1247-2014.

CHARTIER, P. Regulations and standards. Casagras2 Academic Seminar, Casagras2, September 2011. Online http://www.casagras2.com.br/downloads/day2/3-Paul_ChartierRegulations_and_Standards.pdf; accessado em 28-Abril-2013.

CLARK, D. e. a. Making the world (of communications) as different place. End-to-End Research Group, IRTF, ACM SIGCOMM Computer Communication Review, p. 9196, 2005.

COMER, D. E. Computer Networks and Internets. [S.1.]: Pearson, 6th Edition, 2015.

COOPER, J. Challenges for database management in the internet of things. IETE Technical Review., v. 26:320-9, 2009.

DOUGHERTY, G. Pattern Recognition and Classification: An Introduction. 2013. ed. [S.1.]: Springer, 2012.

DUBOIS, P. MySQL Cookbook: Solutions for Database Developers and Administrators. [S.1.]: O’Reilly Media, August 2014.

ETZION, O.; NIBLETT, P. Event Processing in Action. 1st. ed. Greenwich, CT, USA: Manning Publications Co., 2010.

FACILITY, S. Smart santander - future internet research and experimentation. 2013. Online http://www.smartsantander.eu/index.php/testbeds/item/132-santander-summary; accessado em 17-Julho-2014. 
FAN, T.; CHEN, Y. A scheme of data management in the internet of things. Proceedings of IC-NIDC2010, 2010.

FüLöP, L. J. et al. Predictive complex event processing: a conceptual framework for combining complex event processing and predictive analytics. Proceedings of the Fifth Balkan Conference in Informatics. p. 26-31, 2012. DOI: 10.1145/2371316.2371323.

GAMMA, E. et al. Padrões de Projetos: Soluções Reutilizáveis. [S.1.]: BOOKMAN COMPANHIA ED, 2006.

GIACOMELLI, P. Apache Mahout Cookbook. [S.1.]: Packt Publishing, 2013.

GLUHAK, A. et al. Towards an arquitecture for a real world internet. Towards the Future Internet, p. 313-324, 2009.

GRANELLI, F. et al. Middleware building blocks for architecting rfid systems, in mobile lightweight wireless systems, ser. lecture notes of the institute for computer sciences, social informatics and telecommunications engineering. Eds. Springer Berlin Heidelberg, 2009, vol. 13, pp. 325â336, 2009. DOI: http://dx.doi.org/10.1007/978-3-642-03819-8 31. Online http://ec.europa.eu/information-society/activities/foi/events/fippp/docs/mikhailsimonov.pdf; accessado em 11-Agosto-2013.

GREENGARD, S. The Internet of Things (The MIT Press Essential Knowledge series). [S.1.]: The MIT Press (March 20, 2015), 2015.

HAN, J.; KAMBER, M.; PEI, J. Data mining: concepts and techniques, third edition (the morgan kaufmann series in data management systems). Morgan Kaufmann, July 2011.

HUANG, Y.; LI, G. Descriptive models for internet of things. International Conference on Intelligent Control and Information Processing, August 2010.

HURLBURT, G.; VOAS, J.; MILLER, K. The internet of things: a reality check. IT Professional, v. 14, n. 3, p. 56-59, 2012. DOI: 10.1109/MITP.2012.60.

INC., G. Google maps javascript api v3. 2014. Online https://developers.google.com/maps/documentation/javascript/reference?hl=pt-br; accessado em 09-Março-2015.

ITU. ITU: internet reports 2005: the Internet of Things. 2005. Online http://www.itu.int/internetofthings; accessado em 28-Outubro-2014.

ITU. ITU: Internet of Things 2009: executive summary. 2009. Online http://www.itu.int/osg/spu/publications/internt of things; accessado em 28-Outubro-2014. 
ITU-T. Overview of the internet of things. SERIES Y: Global Information Infrastructure, Internet Protocol Aspects and Next Generation Networks - Frameworks and functional architecture models, ITU-T REc.Y.2060, 2012.

JAMES, A.; COOPER, J. Challenges for database management in the internet of things. v. 26 , n. 5 , p. 320-329, 2009. DOI: $10.4103 / 0256-4602.55275$.

JAMES, A. et al. Research directions in database architectures for internet of things: a communication of the first international workshop on database architectures for the internet of things (dait 2009). p. 225-233, 2009.

JARA, A. J.; GENOUD, D.; BOCCHI, Y. Big data for smart cities with knime a real experience in the smartsantander testbed. Software: Practice and Experience, p. n/a-n/a, 2014. DOI: $10.1002 /$ spe.2274.

JAYASINGHE, D.; AZEEZ, A. Apache Axis2 Web Services. [S.1.]: Packt Publishing; 2 edition, 2011.

JEFFERY, K. The Internet of Things: The Death of a Traditional Database? IETE Technical Review, v. 26, n. 5, p. 313-319, 2009. DOI: 10.4103/0256-4602.55272.

JOACHIM, W.; WALEWSKI, S. Internet of things architecture iot-a. Deliverable D1.4 Converged architectural reference model for the IoT v2.0, 2012.

KATASONOV, A. et al. Smart semantic middleware for the internet of things. 2008. "in ICINCO-ICSOâ08, 2008, pp. 169â178; Online: DisponÃvel em: http://www.mit.jyu.fi/ai/papers/ICINCO-2008.pdf; accessado em 11-Agosto-2013".

KITSUREGAWA, M. 'Socio sense' and 'cyber infrastructure' for information explosion era: projects in japan. Lecture Notes in Computer Science, v. 4443, 2008.

KJAER, K. E. A survey of context-aware middleware. Hydra Project, 2005.

KRČO, S. et al. Smartsantander-a smart city experimental platform. 2012.

KRNIC, J.; KRCO, S. Impact of wsn applicatoins generated traffic on wcdma access networks. Proc. of the IEEE PIMRC'08, Cannes, France, 2008.

LANG, J. P. Linksmart 2.2 documentation. 2015. Online https://www.linksmart.eu/redmine/projects/linksmart-opensource/wiki; accessado em 11-Maio-2015.

LARSON, R.; FARBER, B. Estatística aplicada. 4. ed. São Paulo: Pearson Prentice Hall, 2010. 
LEI, D. et al. Automatic k-means clustering algorithm for outlier detection. In: Information Engineering and Applications. Information Engineering and Applications. [S.1.]: Springer London, 2012. (Lecture Notes in Electrical Engineering, v. 154), p. 363-372.

LEI, D. et al. Automatic k-means clustering algorithm for outlier detection. In: Information Engineering and Applications. Information Engineering and Applications. [S.1.]: Springer London, 2012. (Lecture Notes in Electrical Engineering, v. 154), p. 363-372.

LYYTINEN, K.; YOO, Y. Issues and challenges in ubiquitous computing. COMMUNICATIONSOF THE ACM, Vol. 45, No. 12. p.63-65., 2002.

MACQUEEN, J. Some methods for classification and analysis of multivariate observations. In 5-th Berkeley Symposium on Mathematical Statistics and Probability. p. 281-297, 1967.

MATTERN, F.; ZURICH, E. Ubiquitous computing: scenarios for an informatized world, communication and the media economy of the future. Springer-Verlag, pp. 145-163, 2005.

MAYER-SCHONB, V.; CUKIER, K. Big Data: A Revolution That Will Transform How We Live, Work, and Think. 2014. ed. [S.l.]: Eamon Dolan/Mariner Books, March 2014.

MCCALLUM, A.; NIGAM, K.; UNGAR, L. H. Efficient clustering of high-dimensional data sets with application to reference matching. Proceedings of the Sixth ACM SIGKDD International Conference on Knowledge Discovery and Data Mining. p. 169-178, 2000. DOI: $10.1145 / 347090.347123$.

MIT. The auto-id savant specification 1.0. 2011. Online http://www.epcglobalinc.org; accessado em 28-Outubro-2014.

NATHAN, N.; WARREN, J. Big Data: Principles and best practices of scalable realtime data systems. 1. ed. [S.1.]: Manning Publications, May 2015.

NATI, M. et al. Smartcampus: a user-centric testbed for internet of things experimentation. Wireless Personal Multimedia Communications (WPMC), 2013 16th International Symposium on. p. 1-6, June 2013.

NAVIDI, W. Statistics for Engineers and Scientists. 4. ed. [S.1.]: McGraw-Hill Education, January 2014.

NAYAK, S. et al. An integrated clustering framework using optimized k-means with firefly and canopies. Computational Intelligence in Data Mining - Volume 2. p. 333-343, 2015. DOI: 10.1007 . 
PAMULA, R.; DEKA, J.; NANDI, S. An outlier detection method based on clustering. Emerging Applications of Information Technology (EAIT), 2011 Second International Conference on. p. 253-256, Feb 2011. DOI: 10.1109/EAIT.2011.25.

PEREIRA, J.; EISENHAUER, M. Hydra - networked embedded system middleware for heterogeneous physical devices in a distributed architecture final report. 2011.

PULIAFITO, A. et al. Making the internet of things a reality: the wherex solution. The Internet of Things. p. 99-108, 2010.

ROUSSOS, G. Sensor and actuators netoworks: from smart dust to the human internet. Casagras2 Academic Seminar, Casagras2, September 2011. Online http://www.casagras2.com.br/downloads/day1/5-George_Roussos-Sensor_and_Actuator_Networks_within_IoT.pdf; accessado em 28-Abril-2013.

SALEHI, A. Design and implementation of an efficient data stream processing system. 2010. PhD. dissertation, Ecole Polytechnique Federale de Lausanne (EPFL); Online: http://biblion.epfl.ch/EPFL/theses/2010/4611/EPFL TH4611.pdf, Acessado em 25-Agosto2013.

SALTZER, J.; REED, D.; CLARK, D. End-to-end arguments in system design. 2nd International Conference on Dist Systems, Paris France, 1981.

SANTANDER, S. Smart santander - future internet research and experimentation. 2014. Online http://www.smartsantander.eu; accessado em 17-Julho-2014.

SARNOVSKY, M. et al. First demonstrator of hydra middleware architecture for building automation. Hydra Project, June 2008.

SATYANARAYANAN, M. Pervasive computing: vision and challenges. IEEE Personal Communications, 2001.

SIMONOV, M. Ismb middleware for iot (rfid). 2010. Online http://ec.europa.eu/information-society/activities/foi/events/fippp/docs/mikhailsimonov.pdf; accessado em 11-Agosto-2013.

SKARMETA, A. IEEE AINA 2013 keynote talk II: the impact of internet of things in big data approach and future internet. Advanced Information Networking and Applications (AINA), 2013 IEEE 27th International Conference on. p. xlvii-xlvii, 2013. DOI: 10.1109/AINA.2013.160.

SMITH, I. The Internet of Things 2012: New Horizons. [S.1.]: CASAGRAS2, 2012. 
SOUZA, A. M.; AMAZONAS, J. R. A novel smart home application using an internet of things middleware. Smart Objects, Systems and Technologies (SmartSysTech), Proceedings of 2013 European Conference on. p. 1-7, 2013.

SOUZA, A. M.; AMAZONAS, J. R. A new internet of things architecture with cross-layer communication. p. 1 - 6, 2015. EMERGING 2015, The Seventh International Conference on Emerging Networks and Systems Intelligence, IARIA Conference.

SOUZA, A. M.; AMAZONAS, J. R. A novel iot architecture with pattern recognition mechanism and big data. Journal of Machine to Machine Communications, v. 1, n. 4, p. 245272, 2015. DOI: http://doi: 10.13052/jmmc2246-137X.134, River Publishers.

SOUZA, A. M.; AMAZONAS, J. R. An outlier detect algorithm using big data processing and internet of things architecture. Procedia Computer Science, v. 52, n. 0, p. 1010 1015, 2015. DOI: http://dx.doi.org/10.1016/j.procs.2015.05.095. The 6th International Conference on Ambient Systems, Networks and Technologies (ANT-2015), the 5th International Conference on Sustainable Energy Information Technology (SEIT-2015).

TERZIYAN, V.; KAYKOVA, O.; ZHOVTOBRYUKH, D. Ubiroad: semantic middleware for context-aware smart road environments. 2010. In Internet and Web Applications and Services (ICIW), 2010 Fifth International Conference on, may 2010, pp. 295-302.

THEODORIDIS, S.; KOUTROUMBAS, K. Pattern Recognition, Fourth Edition. 4th. ed. [S.1.]: Academic Press, 2008.

TRIOLA, M. F. Essentials of Statistics. 5. ed. [S.1.]: Pearson, January 2014.

UBIDOTS, C. About ubidots. 2014. Online http://ubidots.com/about-ubidots.html; accessado em 08-Abril-2015.

UBIDOTS, C. Ubidots overview. 2014. Online http://ubidots.com/docs/getstarted/overview.html; accessado em 08-Abril-2015.

WANG, Y.; CAO, K.; ZHANG, X. Complex event processing over distributed probabilistic event streams. Computers and Mathematics with Applications, 2013. DOI: http://dx.doi.org/10.1016/j.camwa.2013.06.032.

WEISER, M. The computer for the 21 st century. SIGMOBILE Mob. Comput. Commun. Rev., New York, NY, USA, ACM, v. 3, n. 3, p. 3-11, jul 1999. 9 p. DOI: $10.1145 / 329124.329126$.

WHITE, T. Hadoop: The Definitive Guide. 4. ed. [S.1.]: O’Reilly Media, Inc., 2015.

ZAKI, M. J.; MEIRA, W. J. Data Mining and Analysis: Fundamental Concepts and Algorithms. 1. ed. [S.1.]: Cambridge University Press, 2014. 
ZUMEL, N.; MOUNT, J.; PORZAK, J. Practical Data Science with R. 1. ed. [S.1.]: Manning, April 2014. 